\title{
Heterotypic Docking Compatibility of Human Connexin 37 with Other Vascular Connexins
}

Nicholas Kim, The University of Western Ontario

Supervisor: Bai, Donglin, The University of Western Ontario

A thesis submitted in partial fulfillment of the requirements for the Master of Science degree in Physiology and Pharmacology

(C) Nicholas Kim 2018

Follow this and additional works at: https://ir.lib.uwo.ca/etd

Part of the Cellular and Molecular Physiology Commons

\section{Recommended Citation}

Kim, Nicholas, "Heterotypic Docking Compatibility of Human Connexin 37 with Other Vascular Connexins" (2018). Electronic Thesis and Dissertation Repository. 5480.

https://ir.lib.uwo.ca/etd/5480

This Dissertation/Thesis is brought to you for free and open access by Scholarship@Western. It has been accepted for inclusion in Electronic Thesis and Dissertation Repository by an authorized administrator of Scholarship@Western. For more information, please contact wlswadmin@uwo.ca. 


\section{Abstract}

Gap junction (GJ) channels provide direct intercellular communication. A GJ channel consists of two docked hemichannels and each hemichannel is a hexamer of six connexins. Human vascular connexins ( $\mathrm{Cx} 37, \mathrm{Cx} 40, \mathrm{Cx} 43$, and $\mathrm{Cx} 45)$ can form various types of gap junction channels to synchronize vasodilation/constriction to control local circulation. Most of our knowledge on heterotypic GJs of these vascular connexins comes from studies on rodent connexins. However it is not clear if these human connexins can also form heterotypic GJs. The present study used an in vitro expression system to investigate the coupling status and GJ properties of human heterotypic Cx37/Cx40, Cx37/Cx43, and Cx37/Cx45 GJs. Our results showed that Cx37/Cx43 and Cx37/Cx45 GJs, but not Cx37/Cx40 GJs, were functional and with unique rectifying channel properties. The docking between $\mathrm{Cx} 37$ and $\mathrm{Cx} 40$ could be rescued by designed $\mathrm{Cx} 40$ variants. The unique heterotypic $\mathrm{Cx} 37 / \mathrm{Cx} 43$ and $\mathrm{Cx} 37 / \mathrm{Cx} 45$ GJ properties may help us understand the intercellular communication between vascular cells.

\section{Keywords}

Gap junction, connexin37, $\mathrm{V}_{\mathrm{j}}$-gating, vasculature, myoendothelial junction, patch clamp, endothelium 


\section{Co-Authorship Statement}

Chapter 2 will be submitted as a manuscript for publication. Electrophysiological data was collected by Nicholas Kiwon Kim. Honghong Chen generated untagged expression vectors for Cx37, Cx40, Cx43, Cx45 and all Cx40 mutant cDNAs.

\section{Acknowledgements}

After several months in the Bai lab, I would like to acknowledge fellow colleagues, friends and mentors who helped me in my journey. I would like to thank Benny, Mary Grace, and Mahmoud. In my first year, you all helped me develop my skills in patch clamp technique as well as teach me many life skills to handle graduate studies. Artur, it was a lot of fun having you visit our lab for an entire year. I learned from you that a great deal of effort is always needed to fulfill my passions and goals. Your drive and positive attitude to learn as well as your ability to drink coffee is inspirational and addicting. I thank you for extending my knowledge about patch clamp technique and teaching me about your culture. Do not worry, Brazil is definitely on my travel bucket list. Kelvin and Ushra, you two made my second year quite interesting and it was a pleasure mentoring both of you. You did really well. To the past and present students, although the time I got to know you was brief, I wish you luck in your future endeavors. Hong and Dr. Bai, I would like to express my gratitude for showing a lot of patience and support in developing my research skills. I gained valuable knowledge and still realize that learning or research never ends. 


\section{Table of Contents}

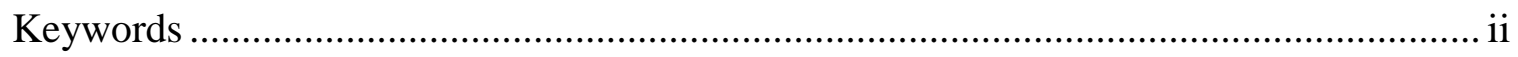

Co-Authorship Statement..................................................................................... ii

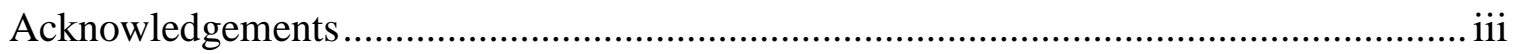

List of Figures and Tables................................................................................... vi

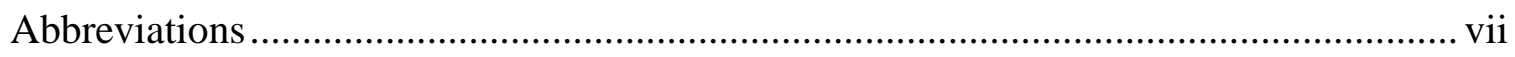

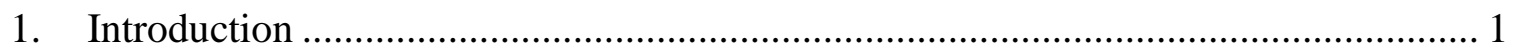

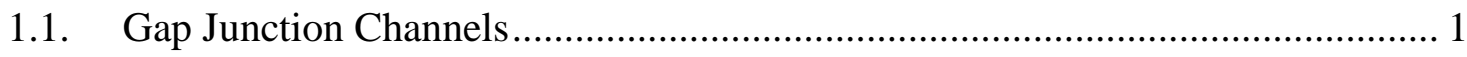

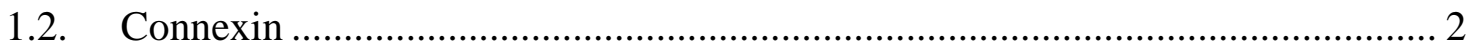

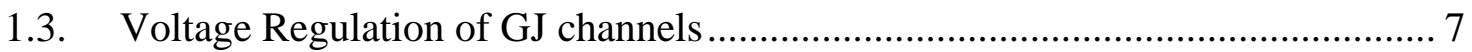

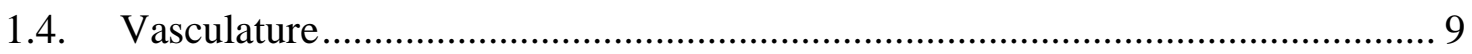

1.4.1. Myoendothelial Junction...................................................................... 9

1.4.2. Localization and Knockout Studies of Vascular Connexins....................... 12

1.5. Rationale and Hypothesis ............................................................................ 13

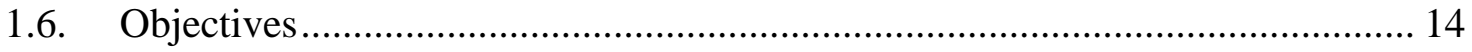

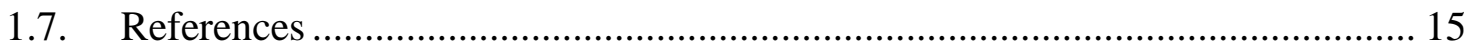

2. Human $\mathrm{Cx} 37$ does not form heterotypic gap junction channels with $\mathrm{Cx} 40 \ldots \ldots \ldots \ldots . . .23$

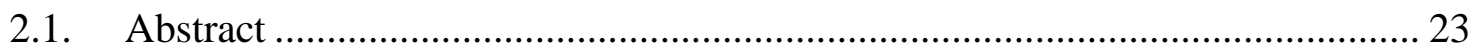

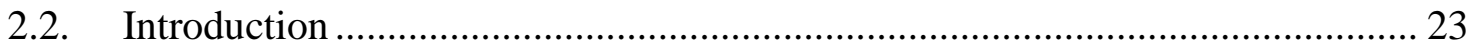

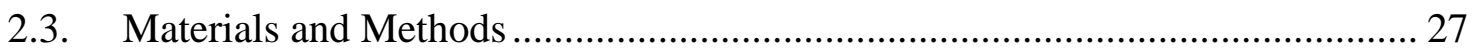

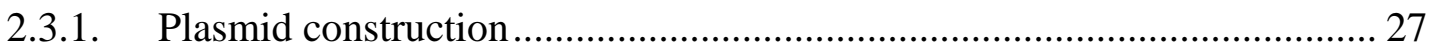

2.3.2. Cell culture and transient transfections ..................................................... 27

2.3.3. Electrophysiological recording ………................................................. 28

2.3.4. Transjunctional voltage dependent gating ................................................ 29

2.3.5. Statistical Analysis............................................................................... 29

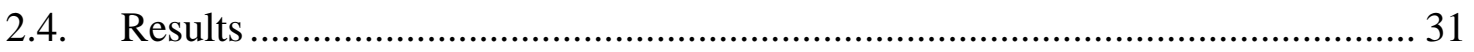

2.4.1 Human Cx37, Cx40, Cx43, and Cx45 formed functional homotypic gap

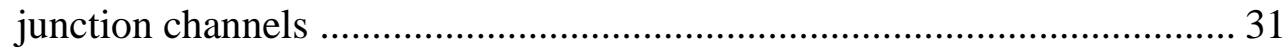

2.4.2 Cx37 formed functional heterotypic GJs with $\mathrm{Cx} 43$ or $\mathrm{Cx} 45$ but not with

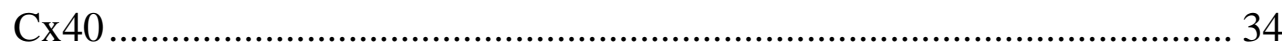




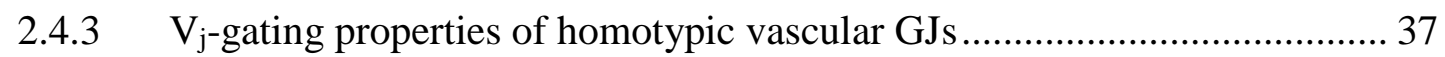

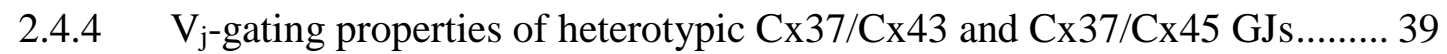

2.4.5 Characterization of $\mathrm{V}_{\mathrm{j}}$-gating of heterotypic Cx37/Cx45 GJs with prolonged

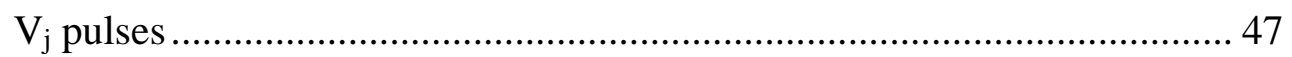

2.4.6 Establish gap junction coupling of $\mathrm{Cx} 37 / \mathrm{Cx} 40$ by designed docking variants

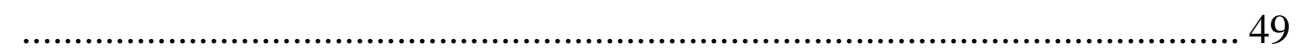

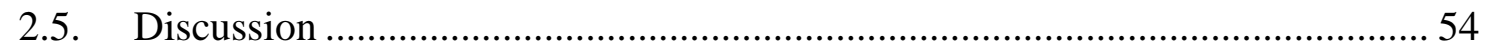

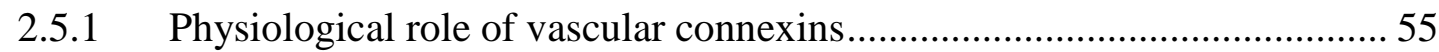

2.5.2 A group of docking compatible connexins ............................................ 56

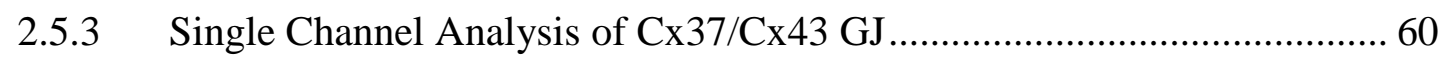

2.5.4 Cx40 hemichannel does not dock with Cx37 hemichannel .......................60

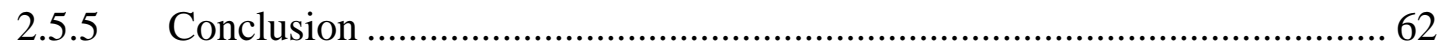

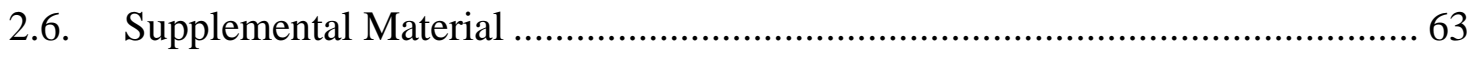

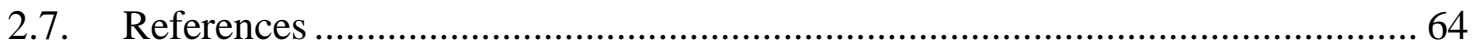

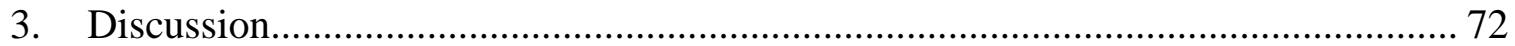

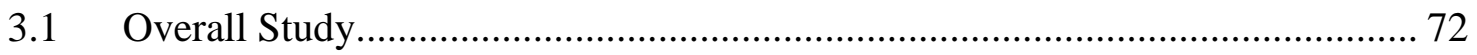

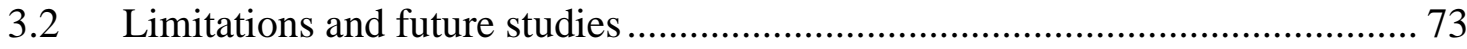

3.3 Physiological role of vascular connexins from mice KOs ............................. 75

3.4 Characterization of heterotypic GJs with Cx37 f....................................... 76

3.5 Cx40 hemichannel does not dock with Cx37 hemichannel ............................ 79

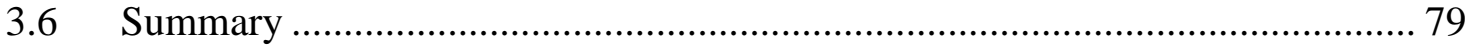

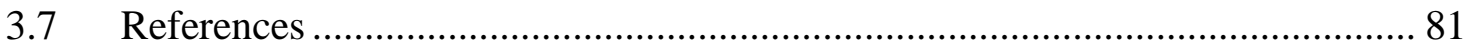

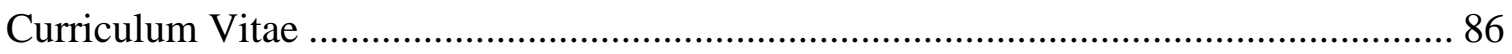




\section{List of Figures and Tables}

Figure 1-1. Gap junction channel composition, structural topology of a single connexin, and dendrogram of 21 human connexins. 6

Figure 1-2. Cell type specific expression of $\mathrm{Cx} 37, \mathrm{Cx} 40, \mathrm{Cx} 43$, and $\mathrm{Cx} 45$ in the vasculature.

Figure 2-1. Coupling percentage and conductance of human homotypic vascular gap junction (GJ) channels 33

Figure 2-2. Coupling percentage and $\mathrm{G}_{\mathrm{j}}$ of human heterotypic $\mathrm{Cx} 37 / \mathrm{Cx} 40, \mathrm{Cx} 37 / \mathrm{Cx} 43$, and

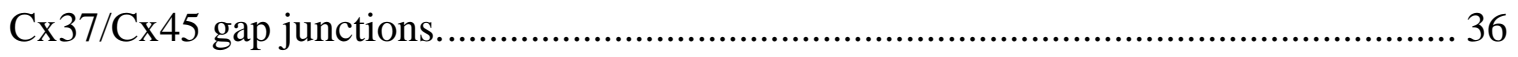

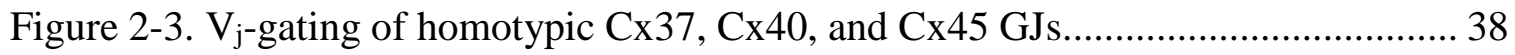

Figure 2-4. $\mathrm{V}_{\mathrm{j}}$-gating of heterotypic Cx37/Cx43 and Cx37/Cx45 GJs........................... 40 Figure 2-5. Heterotypic Cx37/Cx43 and Cx37/Cx45 GJs showed similar and different

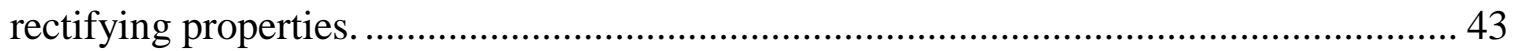

Figure 2-6. Unitary channel properties of heterotypic Cx37/Cx43 GJ......................... 46 Figure 2-7. Long voltage pulse protocol revealed the threshold of heterotypic Cx37/Cx45

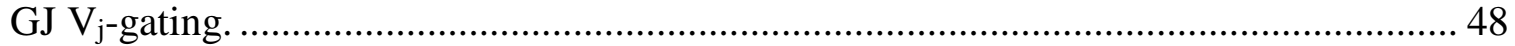

Figure 2-8. Coupling percentage and $\mathrm{G}_{\mathrm{j}}$ of heterotypic GJs of $\mathrm{Cx} 37$ with $\mathrm{Cx} 40$ mutants. 50

Figure 2-9. $\mathrm{V}_{\mathrm{j}}$-gating of heterotypic Cx37/D55N and Cx37/P193Q GJs. ...................... 51

Table 2-1. Boltzmann Fitting parameters for homotypic and heterotypic GJs 52

Supplemental Figure 2-1. Fluorescence microscopy images superimposed with DIC of transfected N2A cells. 63 


\section{Abbreviations}

ATP

CL

CT

Cx37

Cx40

Cx43

Cx45

DMEM

DsRed

EGTA

E1

E2

ECS

GFP

GJ

$\mathbf{G}_{\mathbf{j}}$

$\mathbf{G}_{\mathbf{j}, \mathbf{s s}} \quad$ Normalized steady state transjunctional conductance

Adenosine triphosphate

Cytoplasmic loop of a connexin

Carboxyl-terminus of a connexin

Connexin37

Connexin40

Connexin43

Connexin45

Dulbecco's modified Eagle's medium

Discosoma sp. red fluorescent protein

The first extracellular loop of a connexin

The second extracellular loop of a connexin

Extracellular solution

Green fluorescent protein

Gap junction

Transjunctional conductance
Ethylene glycol-bis( $\beta$-aminoethyl ether)-N,N,N',N'-tetraacetic acid 


\begin{tabular}{|c|c|}
\hline HB & Hydrogen bond \\
\hline HEPES & 4-(2-hydroxyethyl)-1-piperazineethanesulfonic acid \\
\hline ICS & Intracellular solution \\
\hline $\mathbf{I}_{\mathbf{j}}$ & Transjunctional current \\
\hline $\mathbf{i}_{\mathbf{j}}$ & Unitary junctional current \\
\hline kDa & KiloDalton \\
\hline M1 - 4 & Transmembrane domain $1-4$ of a connexin \\
\hline MEGJ & Myoendothelial gap junction \\
\hline $\mathbf{m V}$ & Millivolts \\
\hline N2A & Mouse neuroblastoma cells \\
\hline $\mathbf{n S}$ & Nanosiemens \\
\hline NT & Amino terminus \\
\hline IRES & Internal ribosome entry site \\
\hline pS & Picosiemens \\
\hline SEM & Standard error of the mean \\
\hline $\mathbf{V}_{\mathbf{j}}$ & Transjunctional voltage \\
\hline WT & Wild Type \\
\hline$\gamma_{\mathbf{j}}$ & Gap junction unitary channel conductance \\
\hline
\end{tabular}




\section{Introduction}

\subsection{Gap Junction Channels}

Gap junction (GJ) channels mediate cell-to-cell communication by providing low resistance passages for ions (e.g. $\mathrm{K}^{+}$), metabolites (e.g. ATP), and small signaling molecules (e.g. cyclic AMP) less than 1 kiloDalton (kDa) in size (Goldberg et al., 1999; Goodenough and Paul, 2009; Kumar and Gilula, 1996). GJ channels are ubiquitously identified throughout tissues and organs of the body, contributing to the maintenance of electrical and metabolic homeostasis of adjacent cells. Their functions become specific to their tissue environment and the individual connexin components. In avascular organs such as the lens of the eyes, GJs maintain homeostasis between cells by mediating the exchange of nutrients and waste product (White et al., 1994). In contrast, GJ channels allow action potential propagation in excitable cells such as cardiomyocytes and electrical synapses of neurons to ensure high conduction velocity of the electrical stimuli throughout the heart and in a neuronal circuit respectively (Barr et al., 1965; Davis et al., 1995).

A GJ channel can be formed as a result of two hemichannels on nearby cells in close proximity with one another (Bai, 2016; Kumar and Gilula, 1996). Each hemichannel (or connexon) is a hexamer of six connexin proteins that dock in a head-to-head manner (Bai, 2016; Saez et al., 2003) (Figure 1-1A). As each cell can express more than one type of connexin isoform, this can lead to the formation of different hemichannels and GJ channels (Sohl, 2004). Homomeric homotypic GJs have both hemichannels comprised of the same connexin subunits. In contrast, the two hemichannels in homomeric heterotypic GJs are different in composition when compared with each other, but contain the same 
connexin subunits within each hemichannel. Lastly, heteromeric heterotypic GJs have at least two different types of connexins forming at least one of the two hemichannels (Goodenough and Paul, 2009) (Figure 1-1B). Normally GJ channels cluster with each other to form aggregates known as GJ plaques; however, morphological and freeze-fracture studies have shown individual GJ channels can also be found at the cell-to-cell interface (de Wit et al., 2009; Johnson et al., 1974; Laird, 1996; Sandow and Hill, 2000). Furthermore, mutations in the coding region of connexin genes are associated with several inherited human diseases including congenital hearing loss, lens cataracts, demyelinating X-linked Charcot-Marie-Tooth disease, and oculodentodigital dysplasia (Bergoffen et al., 1993; Laird, 2006; Liu et al., 1997; Shiels et al., 1998).

\subsection{Connexin}

Connexins are denoted by the species of origin as well as the predicted molecular weight (e.g. mCx37 is the mouse variant of $\mathrm{Cx} 37$ and would have a molecular weight of $37 \mathrm{kDA})$. Nearly all characterized connexin members begin the oligomerization process at the endoplasmic reticulum. They are then trafficked to the plasma membrane through the secretory pathway of the Golgi network (Laird, 1996). However, Cx43 appeared to utilize different intracellular compartments to oligomerize (Laird, 1996; Maza et al., 2003). Upon reaching the plasma membrane, these hemichannels can function as undocked hemichannels, or dock with another hemichannel of a nearby cell to form a GJ channel (Laird, 1996).

Twenty-one connexin genes are identified in the human genome, whereas 20 connexin genes have been found in the mouse genome (Saez et al., 2003; Sohl, 2004). Through detailed analysis in the amino acid sequences of all 21 human connexin genes, a 
phylogenetic tree was generated to further classify these connexins into 5 groups (e.g. $\alpha, \beta$, $\gamma, \delta, \varepsilon)$ (Figure 1-1C). These groups became part of their genetic nomenclature (Bai, 2016; Kumar and Gilula, 1996). As extensively discussed in the review (Bai et al., 2018), there are a few differences to note between mouse and human connexins apart from their predicted function to form intercellular channels. First, for some connexins genes, no homologues were identified between the two species such as mCx33 and hCx25. Second, some connexins that share the same name and molecular weight could have up to $29 \%$ difference (i.e. $\mathrm{Cx} 46)$ in their amino acid sequences. Third, mouse and human connexins show similar expression patterns in tissues; however, differences were observed regarding with their docking compatibilities (Bruzzone et al., 1993; Elfgang et al., 1995; Jassim et al., 2016; Ye et al., 2017).

Although there are different isoforms, connexin family members all share similar topological features such as a cytosolic amino terminus and a carboxyl terminus (NT and CT respectively). In addition, there are four alpha helical transmembrane domains (M1-4), two extracellular domains (E1 and E2), and one cytoplasmic loop (CL) (right panel of Figure 1-1A) (Kumar and Gilula, 1996; Milks et al., 1988). With the big contribution from Maeda and fellow colleagues, a crystalized structure of human Cx26 with a resolution of $3.5 \AA$ was resolved in 2009. This helped improve the understanding on GJ structure and highlighted the domains involved in docking (Maeda et al., 2009). In both extracellular domains (E1 and E2), there are three cysteine residues per domain that can form disulfide bridges connecting E1 and E2 within the same connexin (Bai, 2016; Laird, 1996). Interestingly these two domains were found to be highly conserved within the connexin family, especially the three cysteine residues (Bai, 2016; Sohl, 2004). Previous mutation 
studies involving the removal of these cysteine residues resulted in non-functional GJ channels; strengthening their crucial role in GJ formation (Dahl et al., 1992; Good et al., 2012). Although the connexins of each hemichannel appear to dock in a one-to-one ratio, a closer inspection revealed that the connexins are staggered in the docking interface (Figure 1-1A,B). In the E1 docking interface, two hydrogen bonds (HBs) were formed with an opposing connexin subunit and another two HBs interacted with another opposing connexin. On the other hand, the E2-E2 docking interface is restricted between two connexins held together by six HBs (Bai et al., 2018). A total of $60 \mathrm{HB}$ are formed when two connexons dock with each other; forming a GJ channel (Bai et al., 2018). 


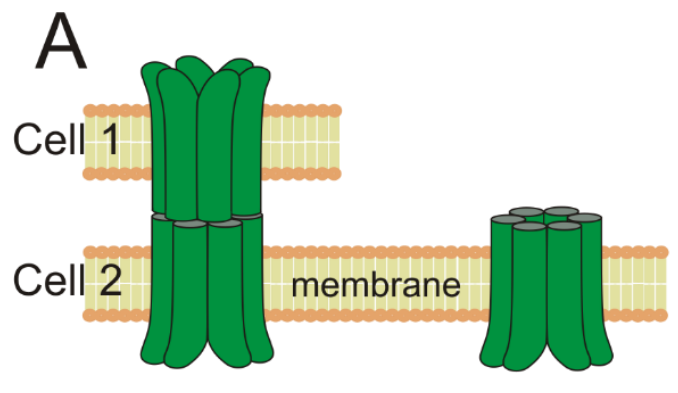

Gap Junction

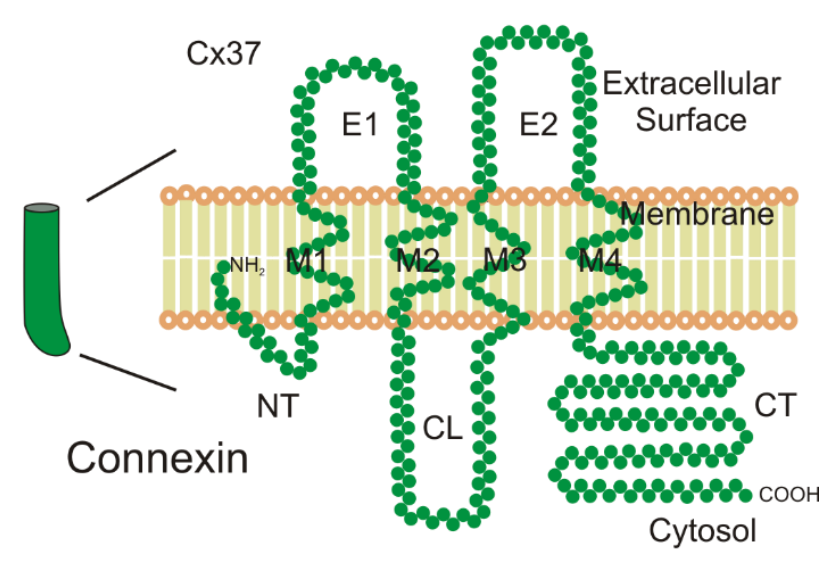

B

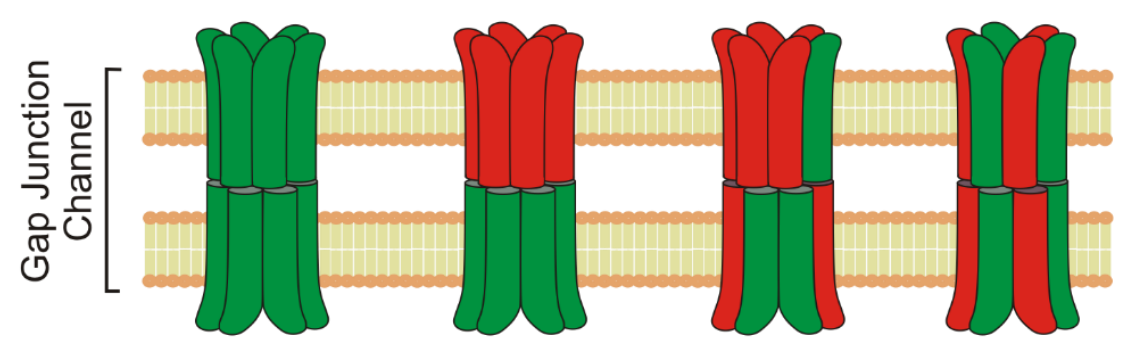

Hemichannel Homomeric Homomeric

GJ Channel Homotypic Heterotypic

Heteromeric

Heterotypic
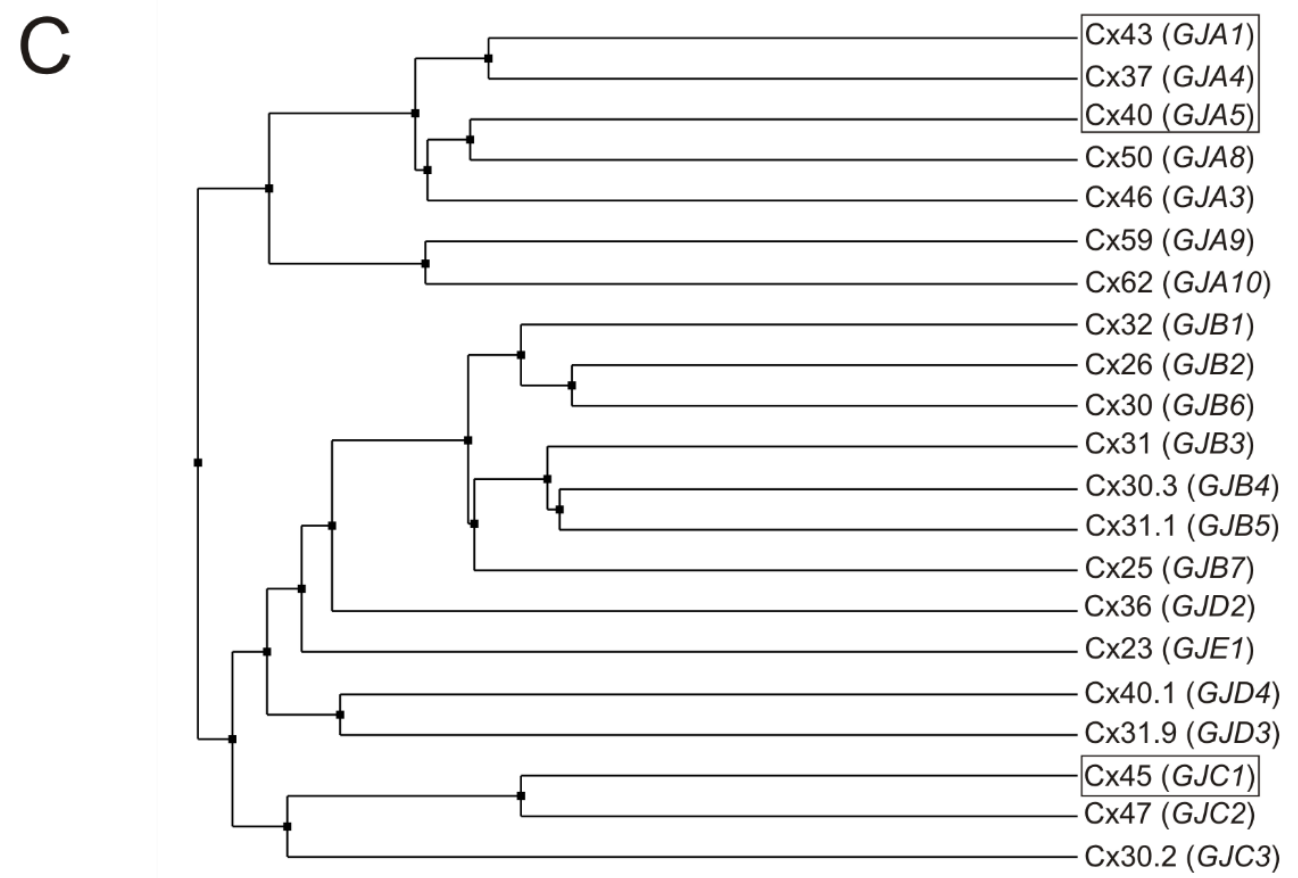

Figure 1-1 
Figure 1-1. Gap junction channel composition, structural topology of a single connexin, and dendrogram of 21 human connexins.

(A) GJ channels consist of two connexons (or hemichannels) docked with each other between two neighbouring cells. Each connexon is a hexameric oligomer of connexins. Connexin37 (Cx37), like other connexins, contain four alpha helical transmembrane domains (M1-4), two extracellular loops (E1 and E2), a cytoplasmic loop (CL), a cytosolic amino terminus (NT), and a carboxyl terminus (CT) (Milks et al., 1988). (B) The classification of GJs is dependent on the docked hemichannel composition. (C) Average distance generated using BLOSUM62 from ClustalWS alignment. Connexins pertaining to the vasculature are indicated with square outlines. Different connexins groups are indicated by the alphabetical letters within the gene name (e.g.; A, B, C, D, E correspond to $\alpha, \beta, \gamma, \delta, \varepsilon$ respectively). Panels A and B were modified from (Bai et al., 2018). 


\subsection{Voltage Regulation of GJ channels}

Gap junction permeability and conductance can be regulated by many factors including transjunctional voltage and membrane voltage (Gonzalez et al., 2007). Similar to voltage-gated ion channels, GJs exhibit a sensitivity to voltage, which alters the conductance of the channel through a process known as voltage-dependent deactivation or gating (Bukauskas and Verselis, 2004; Gonzalez et al., 2007). Voltage-dependent deactivation can be divided into two types: membrane potential $\left(\mathrm{V}_{\mathrm{m}}\right)$ and transjunctional potential $\left(\mathrm{V}_{\mathrm{j}}\right)$. The former refers to the voltage difference between the intracellular and extracellular space of the cell. On the other hand, the latter refers to the voltage difference between the interior of two adjacent cells linked by GJ channels (Gonzalez et al., 2007). The $V_{m}$ of two cells can vary but the $V_{j}$ will not be influenced as long as the change in both $\mathrm{V}_{\mathrm{m}} \mathrm{s}$ are identical (Gonzalez et al., 2007). However when the change in $\mathrm{V}_{\mathrm{m}}$ of the two cells are different, a transjunctional voltage gradient is created; resulting in a $V_{j}$.

Electrophysiological studies through dual whole-cell patch clamp in in vitro expression systems such as Xenopus oocytes, Hela cells, or mouse neuroblastoma (N2A) cells are often used to observe the aforementioned $\mathrm{V}_{\mathrm{j}}$-gating properties of different GJs channels. In preparation for electrophysiological recording, GJ-deficient cell lines such as N2A cells would be transfected with a connexin of interest. Typically, changes in $\mathrm{V}_{\mathrm{j}}$ are administered artificially, and the corresponding transjunctional current $\left(\mathrm{I}_{\mathrm{j}}\right)$ responses are recorded (Jassim et al., 2016; Noureldin et al., 2018; Ye et al., 2017). Activity of multiple GJ channels, reflected by the $\mathrm{I}_{\mathrm{j}}$ recordings, is used to create a normalized steady state-topeak conductance ratio $\left(G_{j, s s}\right)$ plotted against the respective $V_{j} s$. The $G_{j, s s}-V_{j}$ plot of most GJs can be well fitted with a two-state Boltzmann equation (Spray et al., 1981). This fitting 
provides a unique set of Boltzmann parameters which reflect the $\mathrm{V}_{\mathrm{j}}$-gating properties displayed by different GJs.

A common characteristic of $\mathrm{GJ}$ s is $\mathrm{V}_{\mathrm{j}}$-dependent gating $\left(\mathrm{V}_{\mathrm{j}}\right.$-gating). Depending on the connexin type, other properties observed include the $\mathrm{V}_{\mathrm{j}}$-gating polarity and kinetics such as the change in the transjunctional conductance $\left(\mathrm{G}_{\mathrm{j}}\right)$ over time (Bennett and Verselis,

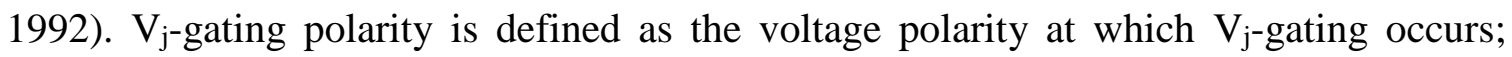
closing the hemichannel (Chen-Izu et al., 2001). For example; homotypic Cx45 GJs possess a negative $\mathrm{V}_{\mathrm{j}}$-gating polarity as $\mathrm{V}_{\mathrm{j}}$-gating closes the hemichannel at $-\mathrm{V}_{\mathrm{j}} \mathrm{s}$ (ChenIzu et al., 2001). Furthermore it was suggested that each hemichannel in a GJ contains two $\mathrm{V}_{\mathrm{j}}$-sensitive sensors and two gates connected symmetrically in series, which controls the closure of the GJ channels. As the two gates are connected in series, closing of one gate will affect the voltage distribution of the whole GJ channel which is named the contingent gating theory (Bukauskas and Verselis, 2004; Harris et al., 1981). The theory proposed that the state of one hemichannel is dependent on the state of the other hemichannel; hence acting in a contingent manner (Harris et al., 1981). At the single channel level, multiple conductance states have been observed: a fully open state, one or more subconducting (or residual) states, and a closed state (Bukauskas and Weingart, 1994; Veenstra et al., 1994). Interestingly, single channel GJs appeared to display two distinct $\mathrm{V}_{\mathrm{j}}$-gating mechanisms

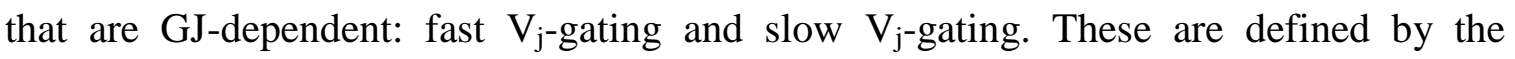
transitions between different conducting states over time (Bukauskas and Weingart, 1994). Fast $\mathrm{V}_{\mathrm{j}}$-gating (typical transition time of $<1-2 \mathrm{~ms}$ ) is the transition between the main open state and subconducting state meanwhile slow $\mathrm{V}_{\mathrm{j}}$-gating (typical transition time of $\sim 15$ to 
$60 \mathrm{~ms}$ ) is the transition between an open or subconducting state to a fully closed state (Bukauskas and Verselis, 2004; Bukauskas and Weingart, 1994).

\subsection{Vasculature}

Within both human and mouse vasculature, GJ channels have been found between endothelial cells (ECs) and vascular smooth muscle cells (VSMCs) (Figure 1-2) (de Wit et al., 2009). ECs function in syncytium during vasodilation as electrical signal conductions are facilitated by GJ channels (Bagher and Segal, 2011). Similarly VSMCs coupled by GJs are able to synchronize fluctuations in intracellular calcium concentrations which can lead towards spontaneous diameter changes in arteries (Haddock and Hill, 2005). A previous study reported further signal propagation in ECs, as injected current barely attenuated compared to the steep decrease seen in VSMCs (Yamamoto et al., 2001). This suggested that ECs help mediate signal propagation over long distances. The presence of GJs amongst ECs is well established via electron microscopy as they are easily found in large abundance with large GJ plaques (Ko et al., 1999; Yeh et al., 1998). On the other hand, GJs are not as effortlessly detected in VSMCs due to the limited number of GJs and smaller plaque sizes (Beny and Connat, 1992).

\subsubsection{Myoendothelial Junction}

Although the internal elastic lamina separates ECs and VSMCs, there are fenestrations detected in small arteries (Campbell and Roach, 1981). It is at these sites where ECs and VSMCs can make contact with each other known as myoendothelial junctions, with small vascular beds showing greater numbers of these junctions (Figure 1-2) (de Wit et al., 2009; Sandow and Hill, 2000). The origin of these projections varies between different vessel types, but the majority appears to come from the endothelial side (Sandow 
et al., 2003). Within most MEJs, GJ plaques are smaller in size (<100 nm) with as little as only one GJ channel compared to the larger plaques and several channels found between ECs. (Little et al., 1995; Sandow and Hill, 2000). These observations would explain the difficulty of detecting GJ channels in the MEJs. 


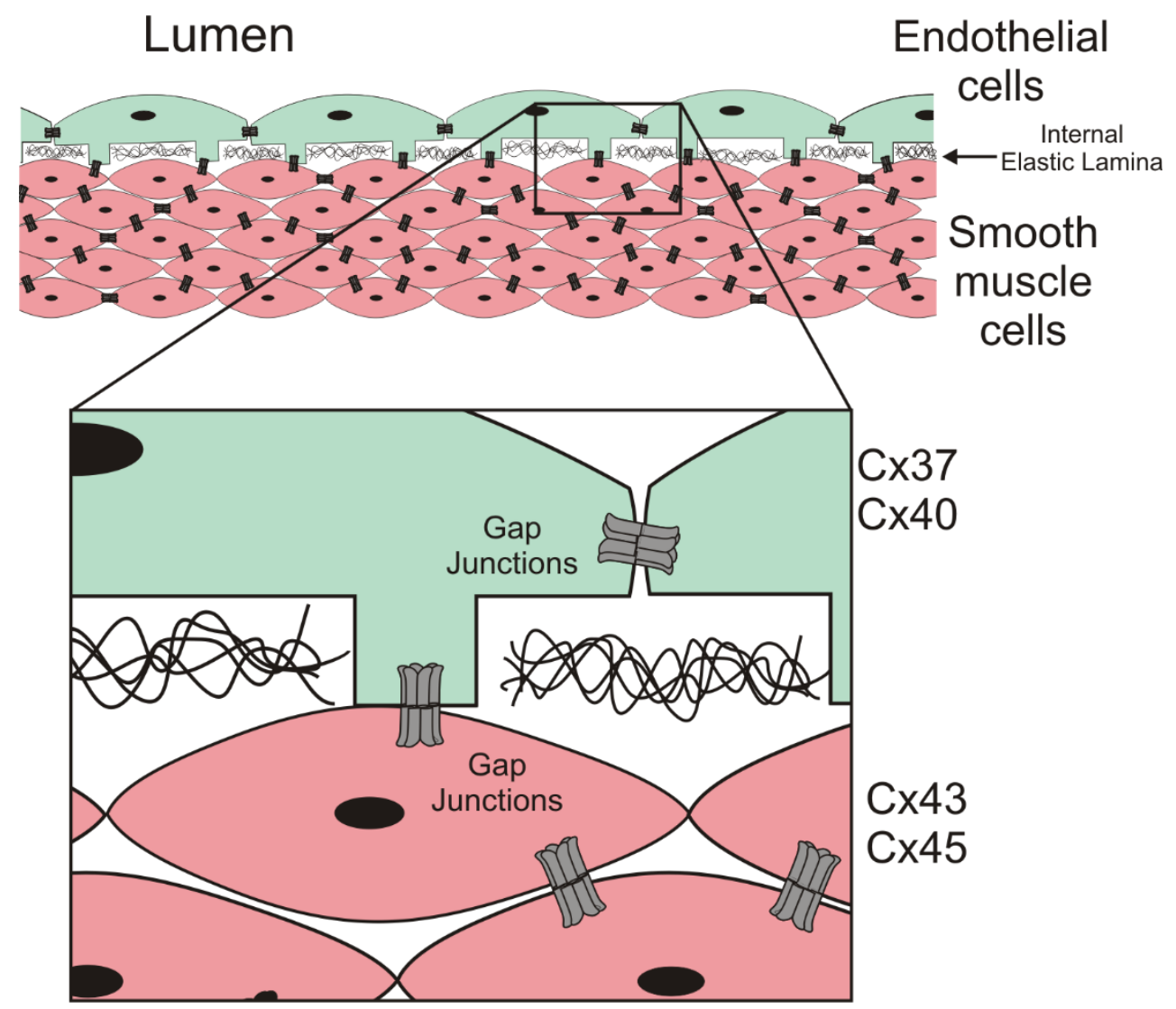

Figure 1-2. Cell type specific expression of $\mathrm{Cx} 37, \mathrm{Cx} 40, \mathrm{Cx} 43$, and $\mathrm{Cx} 45$ in the vasculature.

Abundant expression of Cx37 and Cx40 (Gabriels and Paul, 1998; van Kempen and Jongsma, 1999) are located in the endothelium, whereas Cx43 and Cx45 are abundantly expressed in smooth muscle cells (Bruzzone et al., 1993; Little et al., 1995; Pogoda et al., 2014; Severs et al., 2001). The expression pattern of these connexins in the vasculature predicted formation of several types of gap junctions (GJs), including homomeric homotypic, homomeric heterotypic, and heteromeric heterotypic GJs 


\subsubsection{Localization and Knockout Studies of Vascular Connexins}

The four connexin isoforms that are often discussed in the vasculature are Cx37, Cx40, Cx43, and Cx45. The first three are $\alpha$-connexins, but the last belongs in the $\gamma$ group (Bai, 2016; Willecke et al., 2002). The expressions of these connexins are not uniform, and can vary between species and blood vessel size. Many studies have agreed on the abundant expression of Cx37 and Cx40 in ECs, whereas Cx43 and Cx45 are abundantly expressed in VSMCs (Figure 1-2) (Begandt et al., 2017; Bruzzone et al., 1993; Gabriels and Paul, 1998; Hill et al., 2002; Little et al., 1995; Pogoda et al., 2014; Severs et al., 2001; van Kempen and Jongsma, 1999; van Kempen et al., 1995). However it is important to note that these connexins are not confined to the specific cell type, as $\mathrm{Cx} 37$ has also been detected in the tunica media of the caudal and basilar arteries (Hill et al., 2002; Rummery et al., 2002). Likewise Cx40 and Cx43 may be expressed in both cell types (Gabriels and Paul, 1998; Little et al., 1995; van Kempen and Jongsma, 1999).

Knock-out $(\mathrm{KO})$ studies in mice have shown that the removal of connexin genes can result in severe malformations in the vasculature (Sohl, 2004). Cx45 KO mice exhibited impaired vascular development and organization of blood vessels, which eventually led to death early in the embryonic stage (E9.5 to E10.5) (Kruger et al., 2000). For $\mathrm{Cx} 43 \mathrm{KO}$ mice, several genes associated with differentiation and function of vascular cells were modified and altered the cell signaling pathways regulating vasculogenesis and angiogenesis (Clauss et al., 2006; Walker et al., 2005). Moreover, embryos died at birth due to blockage of the right ventricular outflow tract (Reaume et al., 1995). On the other hand, mice were viable from the individual Cx40 or Cx37 KOs (Figueroa and Duling, 2009;

Kirchhoff et al., 1998; Simon et al., 1997). Cx40 deficient mice embryos displayed small 
defects along the cardiac septum and predisposition towards arrhythmias (Figueroa and Duling, 2009; Kirchhoff et al., 1998). Interestingly, no vascular abnormalities including heart dysfunction were observed with Cx37 deficient mice except that females were reported to be infertile (Simon et al., 1997). However with Cx37 and Cx40 double KO, mice pups died around birth due to severe vascular abnormalities with pronounced dilatations (Simon and McWhorter, 2003). These studies highlight an important role of these connexins in vasculature development and function.

\subsection{Rationale and Hypothesis}

There are four connexin isoforms expressed in the vasculature: Cx37, Cx40, Cx43, and $\mathrm{Cx} 45$. It was noted that they belong in the same group of docking-compatible connexins (Bai et al., 2018; Elfgang et al., 1995). A previous study done by Elfgang and colleagues revealed that $\mathrm{mCx} 37$ is able to form homomeric heterotypic GJ channels with other mouse connexins including $\mathrm{mCx} 40, \mathrm{mCx} 43$, and $\mathrm{mCx} 45$. This was demonstrated through the transfer of Lucifer yellow dye in transfected HeLa cells (Elfgang et al., 1995). However, the heterotypic GJ channel properties of $\mathrm{hCx} 37$ have not been investigated. The importance of the present study is to determine if the heterotypic GJ channel formation of hCx37 is different as previous studies on the other three human vascular connexins demonstrated different heterotypic docking behaviours compared to mouse counterparts (Jassim et al., 2016; Ye et al., 2017). The difference in the amino acid sequence identity between mouse and human vascular connexins can be as high as 17\% (Sohl, 2004). This difference in amino acid sequence identity may potentially induce selectivity in the heterotypic interaction and limit different GJ formation (Bruzzone et al., 1993; Jassim et 
al., 2016; Ye et al., 2017). It is hypothesized that human Cx37 is able to form homomeric heterotypic GJs with other human vascular connexins, including Cx40, Cx43, or Cx45.

\subsection{Objectives}

i. To determine if hCx37 is able to form functional homomeric heterotypic GJs with human $\mathrm{Cx} 40, \mathrm{Cx} 43$, or $\mathrm{Cx} 45$ in $\mathrm{N} 2 \mathrm{~A}$ cells, each of these connexins were transfected with an untagged fluorescent protein (e.g. Cx37-IRES-GFP, Cx40IRES-DsRed, Cx43-IRES-DsRed, or Cx45-IRES-DsRed). Using dual whole-cell patch clamp, transjunctional voltages $\left(\mathrm{V}_{\mathrm{j}} \mathrm{s}\right)$ will be administered to cell pairs with positive expression of GFP (or Ds-Red). Next, a transjunctional current ( $\left.\mathrm{I}_{\mathrm{j}}\right)$ will be measured at each respective $\mathrm{V}_{\mathrm{j}} \mathrm{s}$. The coupling percentage and coupling conductance $\left(\mathrm{G}_{\mathrm{j}}\right)$ will be analyzed on homotypic and heterotypic cell pairs.

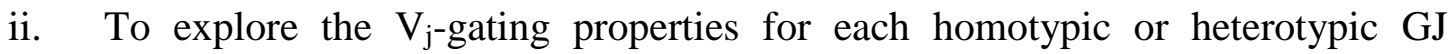
channels. The normalized steady state conductance $\left(\mathrm{G}_{\mathrm{j}, \mathrm{ss}}\right)$ will be plotted as a function of the respective $\mathrm{V}_{\mathrm{j}}$ and fitted with a Boltzmann equation for each $\mathrm{V}_{\mathrm{j}}$ polarity. From this, the extent of the conductance change will be observed via the Boltzmann parameters. 


\subsection{References}

Bagher, P., and S.S. Segal. 2011. Regulation of blood flow in the microcirculation: role of conducted vasodilation. Acta Physiol (Oxf). 202:271-284.

Bai, D. 2016. Structural analysis of key gap junction domains_-Lessons from genome data and disease-linked mutants. Seminars in Cell \& Developmental Biology. 50:74-82.

Bai, D., B. Yue, and H. Aoyama. 2018. Crucial motifs and residues in the extracellular loops influence the formation and specificity of connexin docking. Biochim Biophys Acta. 1860:9-21.

Barr, L., M.M. Dewey, and W. Berger. 1965. Propagation of Action Potentials and the Structure of the Nexus in Cardiac Muscle. J Gen Physiol. 48:797-823.

Barrio, L.C., J. Capel, J.A. Jarillo, C. Castro, and A. Revilla. 1997. Species-specific voltage-gating properties of connexin-45 junctions expressed in Xenopus oocytes. Biophys J. 73:757-769.

Barrio, L.C., T. Suchyna, T. Bargiello, L.X. Xu, R.S. Roginski, M.V. Bennett, and B.J. Nicholson. 1991. Gap junctions formed by connexins 26 and 32 alone and in combination are differently affected by applied voltage. Proc Natl Acad Sci U S A. 88:8410-8414.

Begandt, D., M.E. Good, A.S. Keller, L.J. DeLalio, C. Rowley, B.E. Isakson, and X.F. Figueroa. 2017. Pannexin channel and connexin hemichannel expression in vascular function and inflammation. BMC Cell Biology. 18.

Bennett, M.V., and V.K. Verselis. 1992. Biophysics of gap junctions. Semin Cell Biol. 3:29-47.

Beny, J.L., and J.L. Connat. 1992. An electron-microscopic study of smooth muscle cell dye coupling in the pig coronary arteries. Role of gap junctions. Circ Res. 70:4955.

Bergoffen, J., S.S. Scherer, S. Wang, M.O. Scott, L.J. Bone, D.L. Paul, K. Chen, M.W. Lensch, P.F. Chance, and K.H. Fischbeck. 1993. Connexin mutations in X-linked Charcot-Marie-Tooth disease. Science. 262:2039-2042. 
Brink, P.R., K. Cronin, K. Banach, E. Peterson, E.M. Westphale, K.H. Seul, S.V. Ramanan, and E.C. Beyer. 1997. Evidence for heteromeric gap junction channels formed from rat connexin43 and human connexin37. Am J Physiol. 273:C1386-1396.

Bruzzone, R., J.A. Haefliger, R.L. Gimlich, and D.L. Paul. 1993. Connexin40, a component of gap junctions in vascular endothelium, is restricted in its ability to interact with other connexins. Mol. Biol. Cell. 4:7-20.

Bruzzone, R., T.W. White, and D.L. Paul. 1994. Expression of chimeric connexins reveals new properties of the formation and gating behavior of gap junction channels. $J$ Cell Sci. 107 ( Pt 4):955-967.

Bukauskas, F.F., and V.K. Verselis. 2004. Gap junction channel gating. Biochim Biophys Acta. 1662:42-60.

Bukauskas, F.F., and R. Weingart. 1994. Voltage-dependent gating of single gap junction channels in an insect cell line. Biophys J. 67:613-625.

Campbell, G.J., and M.R. Roach. 1981. Fenestrations in the internal elastic lamina at bifurcations of human cerebral arteries. Stroke. 12:489-496.

Chen-Izu, Y., A.P. Moreno, and R.A. Spangler. 2001. Opposing gates model for voltage gating of gap junction channels. Am J Physiol Cell Physiol. 281:C1604-1613.

Clauss, S.B., D.L. Walker, M.L. Kirby, D. Schimel, and C.W. Lo. 2006. Patterning of coronary arteries in wildtype and connexin43 knockout mice. Dev Dyn. 235:27862794.

Dahl, G., R. Werner, E. Levine, and C. Rabadan-Diehl. 1992. Mutational analysis of gap junction formation. Biophys J. 62:172-180.

Davis, L.M., M.E. Rodefeld, K. Green, E.C. Beyer, and J.E. Saffitz. 1995. Gap junction protein phenotypes of the human heart and conduction system. J Cardiovasc Electrophysiol. 6:813-822.

de Wit, C., M. Boettcher, and V.J. Schmidt. 2009. Signaling across myoendothelial gap junctions - fact or fiction? Cell Communication \& Adhesion. 15:231-245.

Elenes, S., A.D. Martinez, M. Delmar, E.C. Beyer, and A.P. Moreno. 2001. Heterotypic docking of $\mathrm{Cx} 43$ and $\mathrm{Cx} 45$ connexons blocks fast voltage gating of $\mathrm{Cx} 43$. Biophys J. 81:1406-1418. 
Elfgang, C., R. Eckert, H. Lichtenberg-Frate, A. Butterweck, O. Traub, R.A. Klein, D.F. Hulser, and K. Willecke. 1995. Specific permeability and selective formation of gap junction channels in connexin-transfected HeLa cells. J. Cell Biol. 129:805817.

Emerson, G.G., and S.S. Segal. 2000. Electrical coupling between endothelial cells and smooth muscle cells in hamster feed arteries: role in vasomotor control. Circ Res. $87: 474-479$.

Figueroa, X.F., and B.R. Duling. 2009. Gap junctions in the control of vascular function. Antioxid Redox Signal. 11:251-266.

Fishman, G.I., A.P. Moreno, D.C. Spray, and L.A. Leinwand. 1991. Functional analysis of human cardiac gap junction channel mutants. Proc Natl Acad Sci U S A. 88:35253529.

Gabriels, J.E., and D.L. Paul. 1998. Connexin43 is highly localized to sites of disturbed flow in rat aortic endothelium but connexin37 and connexin40 are more uniformly distributed. Circ Res. 83:636-643.

Goldberg, G.S., P.D. Lampe, and B.J. Nicholson. 1999. Selective transfer of endogenous metabolites through gap junctions composed of different connexins. Nat Cell Biol. 1:457-459.

Gonzalez, D., J.M. Gomez-Hernandez, and L.C. Barrio. 2007. Molecular basis of voltage dependence of connexin channels: an integrative appraisal. Prog Biophys Mol Biol. 94:66-106.

Good, M.E., J.F. Ek-Vitorin, and J.M. Burt. 2012. Extracellular loop cysteine mutant of cx37 fails to suppress proliferation of rat insulinoma cells. J Membr Biol. 245:369380.

Goodenough, D.A., and D.L. Paul. 2009. Gap Junctions. Cold Spring Harbor Perspectives in Biology. 1:a002576-a002576.

Haddock, R.E., and C.E. Hill. 2005. Rhythmicity in arterial smooth muscle. J Physiol. $566: 645-656$.

Harris, A.L., D.C. Spray, and M.V. Bennett. 1981. Kinetic properties of a voltagedependent junctional conductance. J Gen Physiol. 77:95-117. 
Hennemann, H., T. Suchyna, H. Lichtenberg-Frate, S. Jungbluth, E. Dahl, J. Schwarz, B.J. Nicholson, and K. Willecke. 1992. Molecular cloning and functional expression of mouse connexin40, a second gap junction gene preferentially expressed in lung. $J$ Cell Biol. 117:1299-1310.

Hill, C.E., N. Rummery, H. Hickey, and S.L. Sandow. 2002. Heterogeneity in the distribution of vascular gap junctions and connexins: implications for function. Clin Exp Pharmacol Physiol. 29:620-625.

Jassim, A., H. Aoyama, W.G. Ye, H. Chen, and D. Bai. 2016. Engineered Cx40 variants increased docking and function of heterotypic Cx40/Cx43 gap junction channels. $J$ Mol Cell Cardiol. 90:11-20.

Johnson, R., M. Hammer, J. Sheridan, and J.P. Revel. 1974. Gap junction formation between reaggregated Novikoff hepatoma cells. Proc Natl Acad Sci U SA. $71: 4536-4540$.

Kirchhoff, S., E. Nelles, A. Hagendorff, O. Kruger, O. Traub, and K. Willecke. 1998. Reduced cardiac conduction velocity and predisposition to arrhythmias in connexin40-deficient mice. Curr Biol. 8:299-302.

Ko, Y.S., H.I. Yeh, S. Rothery, E. Dupont, S.R. Coppen, and N.J. Severs. 1999. Connexin make-up of endothelial gap junctions in the rat pulmonary artery as revealed by immunoconfocal microscopy and triple-label immunogold electron microscopy. $J$ Histochem Cytochem. 47:683-692.

Kruger, O., A. Plum, J.S. Kim, E. Winterhager, S. Maxeiner, G. Hallas, S. Kirchhoff, O. Traub, W.H. Lamers, and K. Willecke. 2000. Defective vascular development in connexin 45-deficient mice. Development. 127:4179-4193.

Kumar, N.M., and N.B. Gilula. 1996. The gap junction communication channel. Cell. 84:381-388.

Laird, D.W. 1996. The life cycle of a connexin: gap junction formation, removal, and degradation. J Bioenerg Biomembr. 28:311-318.

Laird, D.W. 2006. Life cycle of connexins in health and disease. Biochem J. 394:527-543.

Little, T.L., E.C. Beyer, and B.R. Duling. 1995. Connexin 43 and connexin 40 gap junctional proteins are present in arteriolar smooth muscle and endothelium in vivo. Am J Physiol. 268:H729-739. 
Liu, X.Z., J. Walsh, P. Mburu, J. Kendrick-Jones, M.J. Cope, K.P. Steel, and S.D. Brown. 1997. Mutations in the myosin VIIA gene cause non-syndromic recessive deafness. Nat Genet. 16:188-190.

Maeda, S., S. Nakagawa, M. Suga, E. Yamashita, A. Oshima, Y. Fujiyoshi, and T. Tsukihara. 2009. Structure of the connexin 26 gap junction channel at $3.5 \mathrm{~A}$ resolution. Nature. 458:597-602.

Maza, J., M. Mateescu, J. Das Sarma, and M. Koval. 2003. Differential oligomerization of endoplasmic reticulum-retained connexin43/connexin32 chimeras. Cell Commun Adhes. 10:319-322.

Milks, L.C., N.M. Kumar, R. Houghten, N. Unwin, and N.B. Gilula. 1988. Topology of the 32-kd liver gap* junction protein determined by site-directed antibody localizations. EMBO J. 7:2967-2975.

Noureldin, M., H. Chen, and D. Bai. 2018. Functional Characterization of Novel Atrial Fibrillation-Linked GJA5 (Cx40) Mutants. Int J Mol Sci. 19.

Pogoda, K., M. Füller, U. Pohl, and P. Kameritsch. 2014. NO, via its target Cx37, modulates calcium signal propagation selectively at myoendothelial gap junctions. Cell Communication and Signaling. 12:33.

Rackauskas, M., M.M. Kreuzberg, M. Pranevicius, K. Willecke, V.K. Verselis, and F.F. Bukauskas. 2007. Gating properties of heterotypic gap junction channels formed of connexins 40, 43, and 45. Biophys J. 92:1952-1965.

Reaume, A.G., P.A. de Sousa, S. Kulkarni, B.L. Langille, D. Zhu, T.C. Davies, S.C. Juneja, G.M. Kidder, and J. Rossant. 1995. Cardiac malformation in neonatal mice lacking connexin43. Science. 267:1831-1834.

Reed, K.E., E.M. Westphale, D.M. Larson, H.Z. Wang, R.D. Veenstra, and E.C. Beyer. 1993. Molecular cloning and functional expression of human connexin37, an endothelial cell gap junction protein. J Clin Invest. 91:997-1004.

Rummery, N.M., H. Hickey, G. McGurk, and C.E. Hill. 2002. Connexin37 is the major connexin expressed in the media of caudal artery. Arterioscler Thromb Vasc Biol. 22:1427-1432. 
Saez, J.C., V.M. Berthoud, M.C. Branes, A.D. Martinez, and E.C. Beyer. 2003. Plasma membrane channels formed by connexins: their regulation and functions. Physiol. Rev. 83:1359-1400.

Sandow, S.L., and C.E. Hill. 2000. Incidence of myoendothelial gap junctions in the proximal and distal mesenteric arteries of the rat is suggestive of a role in endothelium-derived hyperpolarizing factor-mediated responses. Circ Res. 86:341346.

Sandow, S.L., R. Looft-Wilson, B. Doran, T.H. Grayson, S.S. Segal, and C.E. Hill. 2003. Expression of homocellular and heterocellular gap junctions in hamster arterioles and feed arteries. Cardiovasc Res. 60:643-653.

Severs, N.J., S. Rothery, E. Dupont, S.R. Coppen, H.I. Yeh, Y.S. Ko, T. Matsushita, R. Kaba, and D. Halliday. 2001. Immunocytochemical analysis of connexin expression in the healthy and diseased cardiovascular system. Microsc Res Tech. 52:301-322.

Shiels, A., D. Mackay, A. Ionides, V. Berry, A. Moore, and S. Bhattacharya. 1998. A missense mutation in the human connexin50 gene (GJA8) underlies autosomal dominant "zonular pulverulent" cataract, on chromosome 1q. Am J Hum Genet. 62:526-532.

Simon, A.M., D.A. Goodenough, E. Li, and D.L. Paul. 1997. Female infertility in mice lacking connexin 37. Nature. 385:525-529.

Simon, A.M., and A.R. McWhorter. 2003. Decreased intercellular dye-transfer and downregulation of non-ablated connexins in aortic endothelium deficient in connexin37 or connexin40. J Cell Sci. 116:2223-2236.

Sohl, G. 2004. Gap junctions and the connexin protein family. Cardiovascular Research. 62:228-232.

Spray, D.C., A.L. Harris, and M.V. Bennett. 1981. Equilibrium properties of a voltagedependent junctional conductance. J Gen Physiol. 77:77-93.

Valiunas, V., J. Gemel, P.R. Brink, and E.C. Beyer. 2001. Gap junction channels formed by coexpressed connexin40 and connexin43. Am J Physiol Heart Circ Physiol. 281:H1675-1689. 
van Kempen, M.J., and H.J. Jongsma. 1999. Distribution of connexin37, connexin40 and connexin43 in the aorta and coronary artery of several mammals. Histochem Cell Biol. 112:479-486.

van Kempen, M.J., I. ten Velde, A. Wessels, P.W. Oosthoek, D. Gros, H.J. Jongsma, A.F. Moorman, and W.H. Lamers. 1995. Differential connexin distribution accommodates cardiac function in different species. Microsc Res Tech. 31:420-436.

Veenstra, R.D., H.Z. Wang, E.C. Beyer, S.V. Ramanan, and P.R. Brink. 1994. Connexin37 forms high conductance gap junction channels with subconductance state activity and selective dye and ionic permeabilities. Biophys J. 66:1915-1928.

Verselis, V.K., C.S. Ginter, and T.A. Bargiello. 1994. Opposite voltage gating polarities of two closely related connexins. Nature. 368:348-351.

Walker, D.L., S.J. Vacha, M.L. Kirby, and C.W. Lo. 2005. Connexin43 deficiency causes dysregulation of coronary vasculogenesis. Dev Biol. 284:479-498.

Welsh, D.G., and S.S. Segal. 1998. Endothelial and smooth muscle cell conduction in arterioles controlling blood flow. Am J Physiol. 274:H178-186.

White, T.W., R. Bruzzone, S. Wolfram, D.L. Paul, and D.A. Goodenough. 1994. Selective interactions among the multiple connexin proteins expressed in the vertebrate lens: the second extracellular domain is a determinant of compatibility between connexins. J Cell Biol. 125:879-892.

White, T.W., D.L. Paul, D.A. Goodenough, and R. Bruzzone. 1995. Functional analysis of selective interactions among rodent connexins. Mol Biol Cell. 6:459-470.

Willecke, K., J. Eiberger, J. Degen, D. Eckardt, A. Romualdi, M. Guldenagel, U. Deutsch, and G. Sohl. 2002. Structural and functional diversity of connexin genes in the mouse and human genome. Biol Chem. 383:725-737.

Xin, L., X.Q. Gong, and D. Bai. 2010. The role of amino terminus of mouse Cx50 in determining transjunctional voltage-dependent gating and unitary conductance. Biophys J. 99:2077-2086.

Yamamoto, Y., M.F. Klemm, F.R. Edwards, and H. Suzuki. 2001. Intercellular electrical communication among smooth muscle and endothelial cells in guinea-pig mesenteric arterioles. J Physiol. 535:181-195. 
Ye, W.G., B. Yue, H. Aoyama, N.K. Kim, J.A. Cameron, H. Chen, and D. Bai. 2017. Junctional delay, frequency, and direction-dependent uncoupling of human heterotypic Cx45/Cx43 gap junction channels. J Mol Cell Cardiol. 111:17-26.

Yeh, H.I., S. Rothery, E. Dupont, S.R. Coppen, and N.J. Severs. 1998. Individual gap junction plaques contain multiple connexins in arterial endothelium. Circ Res. $83: 1248-1263$. 


\title{
2. Human $\mathrm{Cx} 37$ does not form heterotypic gap junction
}

\author{
channels with $\mathrm{Cx} 40$
}

\subsection{Abstract}

Human vascular connexins (Cx37, Cx40, Cx43, and Cx45) can form various types of gap junction channels to synchronize vasodilation/constriction to control local circulation. Most of our knowledge on heterotypic gap junctions of these vascular connexins was from studies on rodent connexins. In human vasculature, the same connexins exist, but whether these human connexins can form heterotypic GJs as those of rodents have not been fully studied. Here we used in vitro expression system to study the coupling status and GJ properties of human heterotypic Cx37/Cx40, Cx37/Cx43, and Cx37/Cx45 GJs. Our results showed that Cx37/Cx43 and Cx37/Cx45 GJs, but not Cx37/Cx40 GJs, were functional and each with unique rectifying channel properties. The failure of docking between Cx37 and Cx40 could be rescued by designed Cx40 variants. The heterotypic Cx37/Cx43 and Cx37/Cx45 GJ properties may help us in understanding the intercellular communication between vascular cells.

\subsection{Introduction}

Gap junction (GJ) channels provide direct passages for ions, metabolites, and small signalling molecules less than 1 kiloDalton (kDA) in size between two adjacent cells (Goldberg et al., 1999; Goodenough and Paul, 2009; Kumar and Gilula, 1996). GJ channels are formed from two properly docked hemichannels (or connexons), each of which is a hexamer of connexins (Bai, 2016; Saez et al., 2003). There are 21 connexin genes in the human genome (20 connexin genes in the mouse genome) encoding different connexins 
commonly showing tissue-specific expression pattern (Saez et al., 2003; Sohl, 2004). All connexins are predicted to have a similar topological structure with four transmembrane domains (M1-4), two extracellular loops (E1 and E2), a cytoplasmic loop (CL), and with both amino and carboxyl terminus (NT and CT, respectively) in the cytosol (Kumar and Gilula, 1996; Milks et al., 1988). Most connexins have been shown to be able to form functional GJs to mediate gap junctional intercellular communications between cells from the same tissue (most commonly in the form of homotypic GJs) as well as between cells from different tissues (commonly via heterotypic GJs if these cells express different set of connexins). The functional consequence of GJs is to synchronize physiological activities in a variety of tissues and organs (Bennett and Verselis, 1992; Bruzzone et al., 1993; Goodenough and Paul, 2009; Kumar and Gilula, 1996).

Within the vasculature, GJ channels are found at the cell junctions between endothelial cells (ECs), in the junctions between vascular smooth muscle cells (VSMCs), and also at the myoendothelial junctions between these two cells (de Wit et al., 2009). In large arteries, an internal elastic lamina is found to fully separate ECs from VSMCs, but in small arteries and arterioles the internal elastic lamina shows fenestrations, where endothelial cells often project out to make direct contact with VSMCs forming myoendothelial gap junctions (MEGJs) (Campbell and Roach, 1981; de Wit et al., 2009; Sandow and Hill, 2000). Four connexins, Cx37, Cx40, Cx43, and Cx45, have been identified in the vasculature with $\mathrm{Cx} 37$ and Cx40 preferentially expressed in the ECs (Gabriels and Paul, 1998; van Kempen and Jongsma, 1999) and Cx43 and Cx45 were found in the VSMCs (Bruzzone et al., 1993; Little et al., 1995; Pogoda et al., 2014; Severs et al., 2001). Lower level of expression of Cx43 in ECs and Cx37 in VSMCs were also reported 
(Gabriels and Paul, 1998; Little et al., 1995; Rummery et al., 2002; Severs et al., 2001; van Kempen and Jongsma, 1999). Cell type specific expression of different connexins in the small arteries predicted formation of homomeric homotypic, homomeric heterotypic, and heteromeric heterotypic GJs in ECs, VSMCs, and at the junctions between these cells. Previous studies on heterotypic docking compatibility of these vascular connexins were almost exclusively on rodent connexins. Limited information is available on the functional status of heterotypic GJs and their channel properties of human vascular connexins, especially on the heterotypic docking compatibility of human Cx37 with other vascular connexins ( $\mathrm{Cx} 40, \mathrm{Cx} 43$, and $\mathrm{Cx} 45)$, leaving an important knowledge gap for our understanding of human vascular GJs.

Knowledge accumulated from studies on rodent connexins revealed that Cx37, $\mathrm{Cx} 40, \mathrm{Cx} 43$, and $\mathrm{Cx} 45$ belong to the same group of docking-compatible connexins and each of them was almost fully capable of forming heterotypic GJs with each other (Bai, 2016; Brink et al., 1997; Elenes et al., 2001; Elfgang et al., 1995; Hennemann et al., 1992; Rackauskas et al., 2007). For example, mouse Cx37 was reported to be able to form homomeric heterotypic GJs channels with mouse $\mathrm{Cx} 40, \mathrm{Cx} 43$, or $\mathrm{Cx} 45$, to allow successful intercellular transfer of Lucifer Yellow in transfected HeLa cells (Elfgang et al., 1995). Correspondingly electrical coupling in transfected N2A cells or oocyte expression system indicated that $\mathrm{Cx} 37$ can form heterotypic GJ channels with $\mathrm{Cx} 40$ or $\mathrm{Cx} 43$ respectively (Brink et al., 1997; Hennemann et al., 1992). However studies on human vascular connexins revealed that $\mathrm{Cx} 40$ showed virtually no coupling when docked with $\mathrm{Cx} 43$ or Cx45, distinct from those observed in rodent connexins (Jassim et al., 2016; Ye et al., 2017). 
The ability of $\mathrm{Cx} 37$ to dock with other vascular connexins ( $\mathrm{Cx} 40, \mathrm{Cx} 43$ and $\mathrm{Cx} 45)$ has not been studied.

It is hypothesized that human Cx37 is able to form homomeric heterotypic GJs with Cx40, Cx43, or Cx45 which may play a role in GJ coupling between ECs, VSMCs or ECVSMCs. Our in vitro study showed that cells expressing human Cx37 was able to form functional heterotypic GJs with cells expressing $\mathrm{Cx} 43$ or $\mathrm{Cx} 45$, but not with cells expressing Cx40. Designed docking variants in Cx40 E1 or E2 domains successfully established heterotypic docking with Cx37. Both Cx37/Cx43 and Cx37/Cx45 GJs showed unique $\mathrm{V}_{\mathrm{j}}$-gating properties, which could be modulated by a few millivolts difference in all pairs' resting membrane potentials. Characterizing the properties of these heterotypic GJs can reveal how vascular GJs are being dynamically regulated by transjunctional voltage. 


\subsection{Materials and Methods}

\subsubsection{Plasmid construction}

Human Cx37 was generously provided by Dr. Dale Laird (University of Western Ontario) and was cloned into pIRES2-EGFP vector to have Cx37-IRES-GFP with following primers:

Forward: $\quad$ 5' GGCACTCGAGATGGGTGACTGGGGC3'

Reverse: $\quad$ 5' ACCGGATCCTTATACATACTGCTTCTTAGAAGC 3'

Human Cx40-IRES-DsRed and Cx45-IRES-DsRed were generated as previously described (Jassim et al., 2016; Ye et al., 2017). Cx40-IRES-DsRed were used as templates to generate untagged individual point mutants (D55N and P193Q) similar to those described earlier (Jassim et al., 2016). Cx43-IRES-DsRed was generated from Cx43-IRESGFP into a pIRES2-DsRed2 vector between restriction sties EcoR1 and BgllI.

2.3.2. Cell culture and transient transfections

Gap junction (GJ) deficient mouse neuroblastoma (N2A) cells (American Type Culture Collection, Manassas, VA, USA) were grown in Dulbecco's Modified Eagle's Medium (DMEM) (Life Technologies Corporation, Grand Island, NY, USA) containing $4.5 \mathrm{~g} / \mathrm{L} \mathrm{D}-(+)$-glucose, $584 \mathrm{mg} / \mathrm{L} \mathrm{L}$-glutamine, $110 \mathrm{mg} / \mathrm{L}$ sodium pyruvate, $10 \%$ fetal bovine serum (FBS), $1 \%$ penicillin, and $1 \%$ streptomycin, in an incubator with $5 \% \mathrm{CO}_{2}$ at $37^{\circ} \mathrm{C}$ (Sun et al., 2013). N2A cells were transfected with $1.0 \mu \mathrm{g}$ of a cDNA construct and $2 \mu \mathrm{L}$ of X-tremeGENE HP DNA transfection reagent (Roche Diagnostics GmbH, Indianapolis, IN, USA) in Opti-MEM + GlutaMAX-I medium for 5 hours. At the end of transfection, the medium was changed back to FBS-containing DMEM and incubated overnight. Next day transfected N2A cells were replated on glass coverslips for an hour 
prior to transfer to recording chamber. Cell pairs with both cells expressing of Cx37-IRESGFP (or Cx40, Cx43, Cx45, each of them in IRES-DsRed vector) were selected for homotypic GJ studies (Supplemental Figure 2-1). For heterotypic GJ studies, Cx37-IRESGFP transfected cells were mixed with cells transfected with Cx40-IRES-DsRed, Cx43IRES-DsRed, or Cx45-IRES-DsRed and replated on glass coverslips to allow formation of heterotypic cell pairs with one expressing GFP and the other expressing DsRed.

\subsubsection{Electrophysiological recording}

Glass coverslips containing transfected cells were transferred to a recording chamber on an inverted microscope (Leica DM IRB, Ontario, Canada) containing extracellular solution (ECS) at room temperature $\left(22-24^{\circ} \mathrm{C}\right)$. The ECS contained (in $\left.\mathrm{mM}\right)$ : $135 \mathrm{NaCl}, 2 \mathrm{CsCl}, 2 \mathrm{CaCl}_{2}, 1 \mathrm{MgCl}_{2}, 1 \mathrm{BaCl}_{2}, 10 \mathrm{HEPES}, 5 \mathrm{KCl}, 5 \mathrm{D}$-(+)-glucose, 2 Sodium pyruvate, $\mathrm{pH} 7.4$ with $1 \mathrm{M} \mathrm{NaOH}$, and osmolarity of 310-320 mOsm. Whole cell voltage clamp was performed on each of the cell pair with Axopatch 200B amplifier (Molecular Devices, Sunnyvale, CA, USA). Patch pipette was pulled with a puller (PC-10, Narishige International USA Inc., Amityville, NY, USA) and was filled with intracellular solution (ICS) containing (in mM): $130 \mathrm{CsCl}, 10$ EGTA, $0.5 \mathrm{CaCl}_{2}, 5 \mathrm{Na}_{2} \mathrm{ATP}, 10 \mathrm{HEPES}$, pH 7.2 with $1 \mathrm{M} \mathrm{CsOH}$, and osmolarity of 290-300 mOsm. Each of the cell pair was voltage clamped at $0 \mathrm{mV}$. In one cell, a series of voltage pulses was applied for 7 seconds. The other cell of the pair was constantly held at $0 \mathrm{mV}$ to record gap junctional current $\left(\mathrm{I}_{\mathrm{j}}\right)$. Currents were low-pass filtered (Bessel filter at $1 \mathrm{kHz}$ ) and recorded using pClamp9.2 in a computer at a sampling rate of $10 \mathrm{kHz}$ via an AD/DA converter (Digidata 1322A, Molecular Devices, Sunnyvale, CA, USA). 


\subsubsection{Transjunctional voltage dependent gating}

Transjunctional voltage $\left(\mathrm{V}_{\mathrm{j}}\right)$ dependent gating $\left(\mathrm{V}_{\mathrm{j}}\right.$-gating $)$ was studied in homotypic and heterotypic cell pairs. Voltage pulses of $\pm 5, \pm 20$ to $\pm 100 \mathrm{mV}$ with $20 \mathrm{mV}$ increments were delivered in one of the cell pair to establish $\mathrm{V}_{\mathrm{j}} \mathrm{s}$ and transjunctional currents $\left(\mathrm{I}_{\mathrm{j}} \mathrm{s}\right)$ were recorded in the other cell. In most cases, $\mathrm{I}_{\mathrm{j}} \mathrm{s}$ peaked at the beginning and then deactivated (especially with high $\mathrm{V}_{\mathrm{j}} \mathrm{s}, \pm 40$ to $\pm 100 \mathrm{mV}$ ) to a steady-state near the end of a 7 second $\mathrm{V}_{\mathrm{j}}$ pulse. Gap junctional conductance $\left(\mathrm{G}_{\mathrm{j}}\right)$ was calculated $\left(\mathrm{G}_{\mathrm{j}}=\mathrm{I}_{\mathrm{j}} / \mathrm{V}_{\mathrm{j}}\right)$. The steady state $\mathrm{G}_{\mathrm{j}}$ was normalized to the peak $G_{j}$ to obtain a normalized steady-state junctional conductance $\left(G_{j, s s}\right)$ for each tested $V_{j} s$. The $G_{j, s s}$ were then plotted with $V_{j} s$ to obtain a $G_{j, s s}-V_{j}$ plot, which could normally fit well with a two-state Boltzmann equation for each $\mathrm{V}_{\mathrm{j}}$ polarity (Jassim et al., 2016). Boltzmann parameters, $V_{0}, G_{\min }, G_{\max }$, A, were determined for each $G_{J} . V_{0}$ is the voltage when the conductance is reduced by half $\left[\left(\mathrm{G}_{\max }-\mathrm{G}_{\min }\right) / 2\right], \mathrm{G}_{\min }$ is the normalized voltage-insensitive residual conductance, while $G_{\max }$ represents the maximum normalized conductance, and $A$ is the slope of the curve which reflects $\mathrm{V}_{\mathrm{j}}$-gating sensitivity (Spray et al., 1981).

$$
\mathrm{G}_{\mathrm{j}, \mathrm{ss}}=\left(\frac{\left(G_{\max }-G_{\min }\right)}{1+\mathrm{e}\left(V_{j^{-}-V_{o}}\right)}\right)+G_{\text {min }}
$$

\subsubsection{Statistical Analysis}

Data are expressed as mean \pm SEM. Kruskal Wallis followed by a Dunn's post-hoc test were used to compare multiple groups of non-parametric data, as specified. One-way ANOVA was used to compare multiple groups of data with Gaussian distribution. One sample $t$-test was used to test if the normalize $\mathrm{G}_{\mathrm{j}}$,ss was different from the theoretical value of 1 for the long $\mathrm{V}_{\mathrm{j}}$ pulse (15 seconds) experiment. Statistical significance is indicated with 
the asterisks on the graphs only for biologically meaningful group comparisons $(* P<0.05$; $* * P<0.01$; or $* * * P<0.001)$. 


\subsection{Results}

2.4.1 Human $\mathrm{Cx} 37, \mathrm{Cx} 40, \mathrm{Cx} 43$, and $\mathrm{Cx} 45$ formed functional homotypic gap junction channels

N2A cells were transfected with expression vectors containing one of the vascular connexins and each with an untagged fluorescent protein (e.g. Cx37-IRES-GFP, Cx40IRES-DsRed, Cx43-IRES-DsRed, or Cx45-IRES-DsRed). Cell pairs with positive expression of GFP (or DsRed) were voltage clamped using dual whole cell patch clamp technique. Majority of cell pairs expressing Cx37 showed transjunctional currents $\left(\mathrm{I}_{\mathrm{j}} \mathrm{s}\right)$ in response to a $\mathrm{V}_{\mathrm{j}}$ pulse $(+20 \mathrm{mV}$, Figure 2-1A), indicating successful formation of $\mathrm{Cx} 37$ GJs. Coupling percentage for cell pairs expressing Cx37 was calculated for each transfection and the average coupling\% of ten transfections was plotted as a bar graph (Figure 2-1B). The average coupling conductance $\left(\mathrm{G}_{\mathrm{j}}\right)$ of $\mathrm{Cx} 37$ expressing cell pairs was obtained and plotted (Figure 2-1C). Cell pairs expressing Cx40, Cx43, or Cx45 showed similar coupling $\%$ and $\mathrm{G}_{\mathrm{j}}$ as those of $\mathrm{Cx} 37$, except the average of $\mathrm{Cx} 45 \mathrm{G}_{\mathrm{j}}$ was significantly lower than that of Cx37 (Figure 2-1C, p < 0.01). $\mathrm{I}_{\mathrm{j}} \mathrm{s}$ of $\mathrm{Cx} 37, \mathrm{Cx} 40$, or $\mathrm{Cx} 43$ were typically stable during a $20 \mathrm{mV} \mathrm{V}$ j pulse, except $\mathrm{I}_{\mathrm{j}}$ of $\mathrm{Cx} 45$, where a time-dependent deactivation was routinely observed (Figure 2-1A). The averaged $\mathrm{Cx} 45 \mathrm{G}_{\mathrm{j}}$ is the lowest and that of $\mathrm{Cx} 43$ is the highest in the tested GJs. 

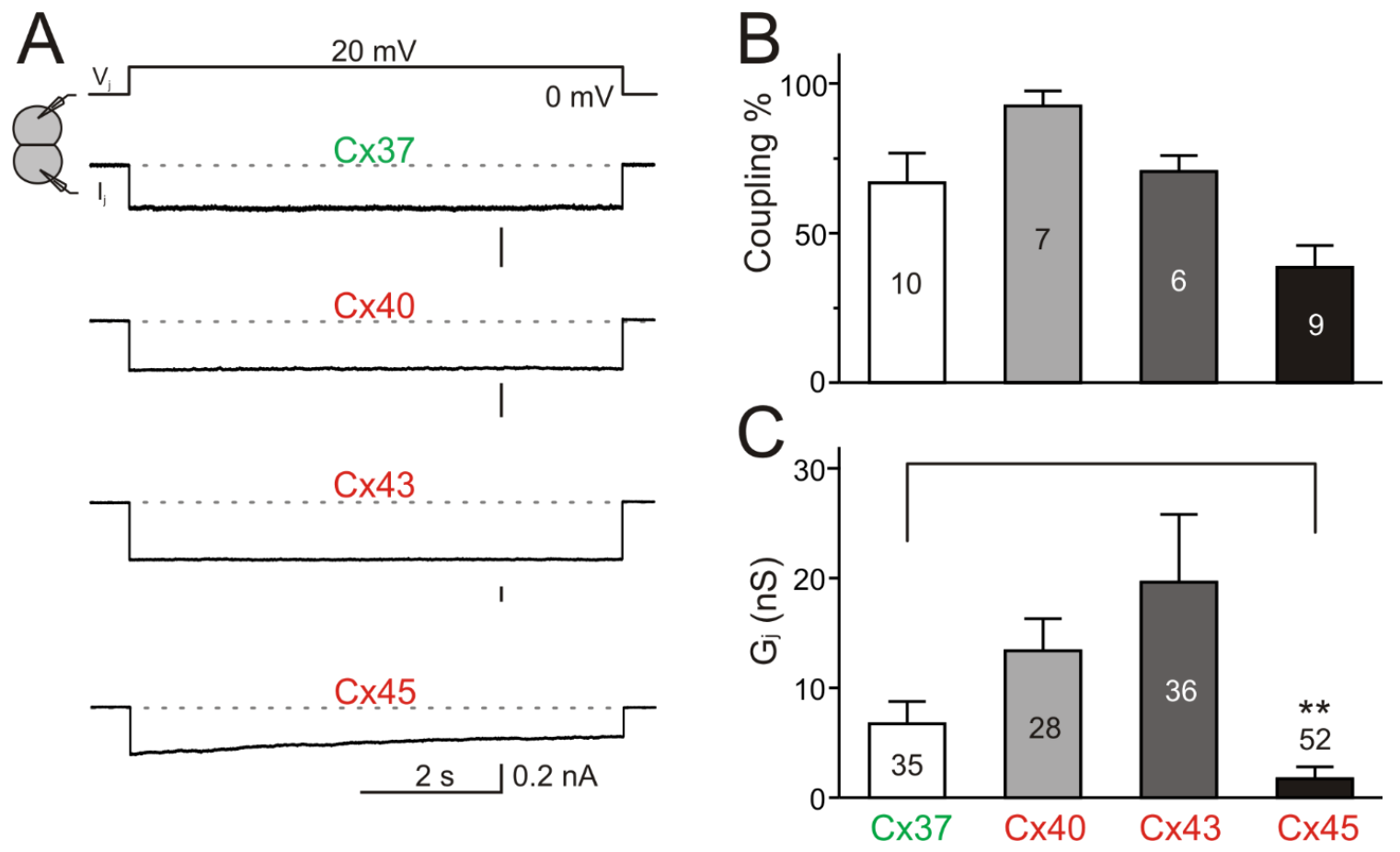

Figure 2-1 
Figure 2-1. Coupling percentage and conductance of human homotypic vascular gap junction (GJ) channels

(A) Dual whole cell patch clamp technique was used to measure transjunctional current $\left(\mathrm{I}_{\mathrm{j}}\right)$ from N2A cell pairs expressing $\mathrm{Cx} 37, \mathrm{Cx} 40, \mathrm{Cx} 43$, or $\mathrm{Cx} 45$ in response to a $+20 \mathrm{mV} \mathrm{V}$ pulse. The green $\mathrm{Cx} 37$ and red $\mathrm{Cx} 40, \mathrm{Cx} 43$, or $\mathrm{Cx} 45$ text indicate untagged reporters (GFP or DsRed) were expressed with these connexins. (B) Bar graph summarizes the average coupling percentage (coupling\%) of cell pairs expressing homotypic Cx37, Cx40, Cx43, or $\mathrm{Cx} 45$ for each transfection. Cx37 cell pairs showed similar coupling\% as that of each tested connexin. The total number of independent transfections is indicated within each bar. (C) Bar graph illustrates the average transjunctional conductance $\left(\mathrm{G}_{\mathrm{j}}\right)$ of all cell pairs expressing the connexins. The $\mathrm{G}_{\mathrm{j}}$ was calculated from initial Ijs of cell pairs showing timedependent changes. A Kruskal-Wallis test followed by Dunn's multiple comparison test showed the $\mathrm{G}_{\mathrm{j}}$ of $\mathrm{Cx} 37$ was similar to those of $\mathrm{Cx} 40$ and $\mathrm{Cx} 43$, but significantly greater than $\mathrm{Cx}_{45} \mathrm{G}_{\mathrm{j}}(\mathrm{p}<0.05)$. The total number of recorded cell pairs is indicated on each bar. 
2.4.2 Cx37 formed functional heterotypic GJs with $\mathrm{Cx} 43$ or $\mathrm{Cx} 45$ but not with $\mathrm{Cx} 40$

To test if human Cx37 can form functional heterotypic GJs with other vascular connexins, cells expressing Cx37 (with untagged GFP) were mixed with cells expressing $\mathrm{Cx} 40, \mathrm{Cx} 43$, or $\mathrm{Cx} 45$ (all with untagged DsRed). Heterotypic cell pairs (one GFP+ and the other DsRed+) were selected to test their coupling status (coupling\%) and coupling conductance $\left(\mathrm{G}_{\mathrm{j}}\right)$. Most of heterotypic $\mathrm{Cx} 37 / \mathrm{Cx} 43$ or $\mathrm{Cx} 37 / \mathrm{Cx} 45$ cell pairs formed functional GJs similar to the levels of their respective homotypic GJs (Figure 2-2B). Only $19 \pm 10 \%$ of heterotypic $\mathrm{Cx} 37 / \mathrm{Cx} 40$ cell pairs was able to form functional GJs, which was significantly lower than that of Cx40 GJ ( $p<0.01$, Figure 2-2B), but not statistically different from that of $\mathrm{Cx} 37$. The $\mathrm{G}_{\mathrm{j}}$ of the heterotypic GJs was measured and plotted with their respective homotypic GJs (Figure 2-2C). Heterotypic Cx37/Cx43 and Cx37/Cx45 GJs showed similar level of $\mathrm{G}_{\mathrm{j}}$ as those of their respective homotypic GJs. However, Cx37/Cx40 GJs displayed a significantly lower $\mathrm{G}_{\mathrm{j}}$ than homotypic $\mathrm{Cx} 37$ or $\mathrm{Cx} 40$ GJs (Figure $2-2 \mathrm{C}, \mathrm{p}<0.01$ ). Combined lower coupling $\%$ and $\mathrm{G}_{\mathrm{j}}$ of $\mathrm{Cx} 37 / \mathrm{Cx} 40 \mathrm{GJ}$ s indicate that $\mathrm{Cx} 37$ is unlikely to form heterotypic GJs with $\mathrm{Cx} 40$. 


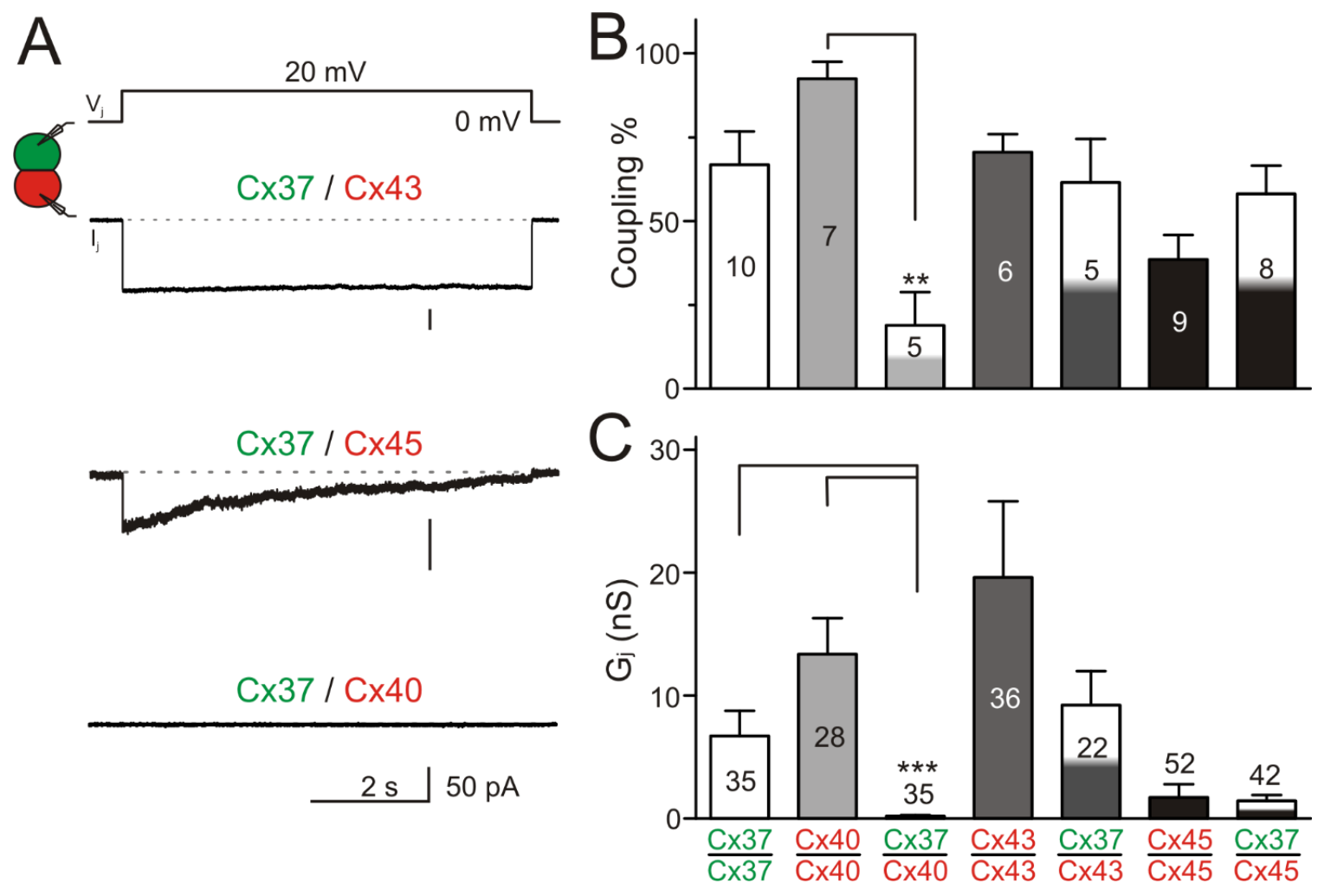

Figure 2-2 
Figure 2-2. Coupling percentage and $\mathrm{G}_{\mathrm{j}}$ of human heterotypic $\mathrm{Cx} 37 / \mathrm{Cx} 40, \mathrm{Cx} 37 / \mathrm{Cx} 43$, and $\mathrm{Cx} 37 / \mathrm{Cx} 45$ gap junctions.

(A) $\mathrm{V}_{\mathrm{j}}\left(20 \mathrm{mV}\right.$ )-induced $\mathrm{I}_{\mathrm{j}} \mathrm{s}$ recorded from $\mathrm{N} 2 \mathrm{~A}$ cell pairs expressing $\mathrm{Cx} 37$ in one and $\mathrm{Cx} 43$, Cx45, or Cx40, in the other. Functional heterotypic Cx37/Cx43, or Cx37/Cx45 GJs could be formed, but most of the $\mathrm{Cx} 37 / \mathrm{Cx} 40$ cell pairs failed to show $\mathrm{I}_{\mathrm{j}}$. (B) Bar graph summarizes the coupling\% of heterotypic Cx37/Cx40, Cx37/Cx43, or Cx37/ Cx45 GJs. A significantly lower coupling\% was observed for $\mathrm{Cx} 37 / \mathrm{Cx} 40$ cell pairs than that of homotypic $\mathrm{Cx} 40$ ( $\mathrm{p}<0.01)$, but not with homotypic Cx37. The total number of independent transfection is indicated on each bar. (C) Bar graph illustrates the coupling conductance $\left(\mathrm{G}_{\mathrm{j}}\right)$ of heterotypic cell pairs as indicated. Cx37/Cx 40 showed a significantly decreased $\mathrm{G}_{\mathrm{j}}$ compared to each of the homotypic GJs ( $\mathrm{p}<0.001)$. The total number of recorded cell pairs is indicated on each bar. Data for homotypic Cx37 and Cx40 GJs were identical as those presented in Figure 2-1 for easy comparison. 


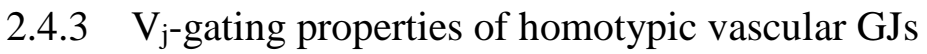

To investigate the transjunctional voltage dependent $\mathrm{I}_{\mathrm{j}}$ deactivation $\left(\mathrm{V}_{\mathrm{j}}\right.$-gating $)$ of cell pairs forming homotypic $\mathrm{Cx} 37, \mathrm{Cx} 40, \mathrm{Cx} 43$ or $\mathrm{Cx} 45 \mathrm{GJ}$ s, the $\mathrm{I}_{\mathrm{j}} \mathrm{s}$ were measured in response to a series of $\mathrm{V}_{\mathrm{j}}$ pulses (as shown in Figure 2-3A). The $\mathrm{I}_{\mathrm{j}} \mathrm{s}$ of cell pairs expressing these connexins showed symmetrical $\mathrm{V}_{\mathrm{j}}$-dependent deactivation with different $\mathrm{V}_{\mathrm{j} \text {-gating }}$ properties. For Cx37 GJs, when $\mathrm{V}_{\mathrm{j}}$ absolute value was $\leq 20 \mathrm{mV}$, $\mathrm{I}_{\mathrm{j}}$ showed no deactivation. $\mathrm{I}_{\mathrm{j}} \mathrm{s}$, in response to $\mathrm{V}_{\mathrm{j}} \mathrm{s}$ in the range of \pm 40 to $\pm 100 \mathrm{mV}$, showed strong deactivation. The normalized steady state conductance $\left(\mathrm{G}_{\mathrm{j}, \mathrm{ss}}\right)$ was plotted as a function of $\mathrm{V}_{\mathrm{j}}$ (open grey circles in Figure 2-3B), which could be well fitted by a Boltzmann equation for each $V_{j}$ polarity (smooth dashed grey lines in Figure 2-3B). $\mathrm{V}_{\mathrm{j}}$-gating of $\mathrm{Cx} 40$ (black filled circles in the middle panel of Figure 2-3B) or Cx45 (black filled circles in the bottom panel of Figure 2-3B) GJs were also studied using identical $V_{j}$ protocol. As shown in Figure 2-3B, $\mathrm{G}_{\mathrm{j}, \mathrm{ss}}-\mathrm{V}_{\mathrm{j}}$ plots could be well fitted with Boltzmann equations for both $\mathrm{Cx} 40$ and $\mathrm{Cx} 45 \mathrm{GJ}$. Comparing with the Boltzmann fitting parameters of Cx37 GJs, the Cx40 GJ showed a larger $\mathrm{V}_{0}$, with similar $\mathrm{G}_{\min }$ and $A$, while $\mathrm{Cx}_{\mathrm{x}} 45$ GJs showed lower $\mathrm{G}_{\min }$, and $\mathrm{V}_{0}$ but similar A (Table 2-1). The Cx37 GJ Boltzmann fitting curves (smooth dashed grey lines) were plotted onto the $\mathrm{G}_{\mathrm{j}, \mathrm{ss}}-\mathrm{V}_{\mathrm{j}}$ plots of $\mathrm{Cx} 40$ and $\mathrm{Cx} 45$ GJs for easy comparison (Figure 2-3B). Under the same experimental conditions, the $\mathrm{V}_{\mathrm{j}}$-gating analysis of $\mathrm{Cx} 43$ expressing cell pairs was not possible due to $\mathrm{G}_{\mathrm{j}}$ level was too high to maintain proper voltage clamp. 

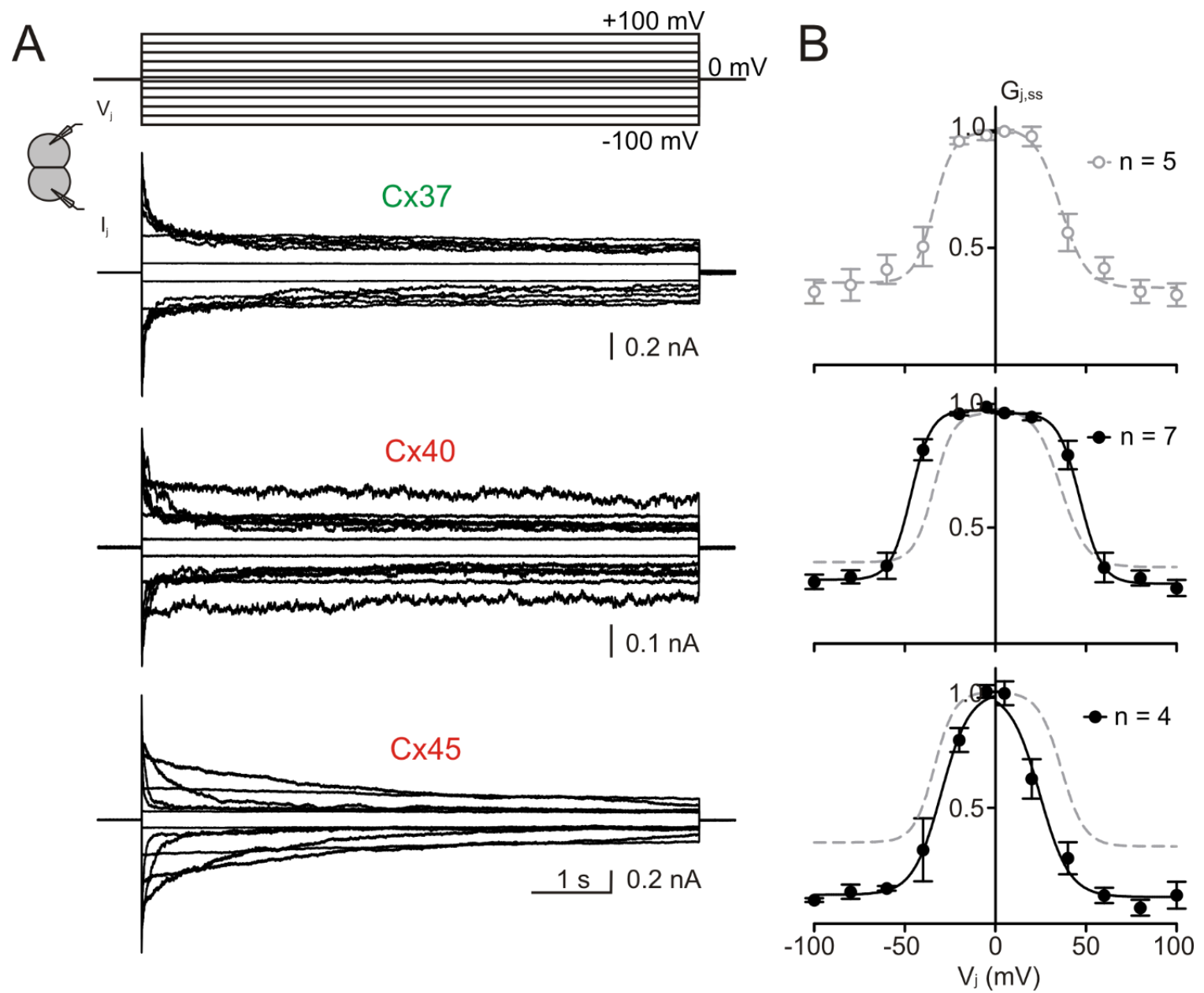

Figure 2-3. $\mathrm{V}_{\mathrm{j}}$-gating of homotypic Cx37, Cx40, and Cx45 GJs.

(A) Superimposed junctional currents $\left(\mathrm{I}_{\mathrm{j}} \mathrm{s}\right)$ were recorded from cell pairs expressing homotypic $\mathrm{Cx} 37, \mathrm{Cx} 40$, or $\mathrm{Cx} 45$ GJs in response to a series of $\mathrm{V}_{\mathrm{j}}$ pulses $( \pm 5, \pm 20$ to \pm 100 $\mathrm{mV}$ with $20 \mathrm{mV}$ increment). (B) Normalized steady state junctional conductance, $\mathrm{G}_{\mathrm{j}, \mathrm{ss}}$, (a ratio of steady state $\mathrm{G}_{\mathrm{j}}$ to the initial $\mathrm{G}_{\mathrm{j}}$ ) of $\mathrm{Cx} 37$ (open grey circles), $\mathrm{Cx} 40$, and $\mathrm{Cx} 45$ (middle and bottom panels respectively, black filled circles) were plotted as a function of $V_{j s}$. Boltzmann equations were used to fit $G_{j, s s}-V_{j}$ plots for each of these homotypic GJs. The Boltzmann fitting of Cx37 GJ (dashed grey lines were superimposed on every plot for comparison). Number of cell pairs for each plot is indicated. 


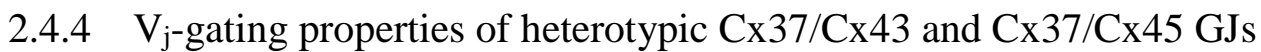

The same twelve voltage pulses were delivered to one of the heterotypic $\mathrm{Cx} 37 / \mathrm{Cx} 43$ or $\mathrm{Cx} 37 / \mathrm{Cx} 45$ cell pairs, the typical induced junctional currents $\left(\mathrm{I}_{\mathrm{j}} \mathrm{s}\right)$ showed strong $\mathrm{V}_{\mathrm{j}}$-gating when $\mathrm{Cx} 37$ cell with $+\mathrm{V}_{\mathrm{j}} \mathrm{s}$ (or when $\mathrm{Cx} 43$ or $\mathrm{Cx} 45$ with $-\mathrm{V}_{\mathrm{j}} \mathrm{s}$ ), but at the opposite $\mathrm{V}_{\mathrm{j}}$ s (i.e. $\mathrm{Cx} 37$ with $-\mathrm{V}_{\mathrm{j}} \mathrm{s}$ or $\mathrm{Cx} 43$, or $\mathrm{Cx} 45$ with $+\mathrm{V}_{\mathrm{j}} \mathrm{s}$ ), little $\mathrm{V}_{\mathrm{j}}$-gating was observed for $\mathrm{Cx} 37 / \mathrm{Cx} 43 \mathrm{GJ}$ or even reverse $\mathrm{V}_{\mathrm{j}}$-gating for $\mathrm{Cx} 37 / \mathrm{Cx} 45$ GJ (Figure 2-4A). The $\mathrm{V}_{\mathrm{j}}$

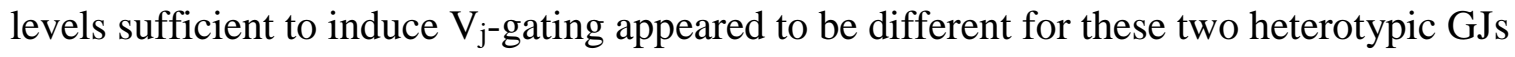
with $\mathrm{Cx} 37 / \mathrm{Cx} 43 \mathrm{GJ}$ in the range of +40 to $+100 \mathrm{mV}$ (on Cx37 or -40 to $-100 \mathrm{mV}$ on $\mathrm{Cx} 43$ ) and $\mathrm{Cx} 37 / \mathrm{Cx} 45 \mathrm{GJ}$ in the range of +20 to $+100 \mathrm{mV}$ (on $\mathrm{Cx} 37$ or -20 to $-100 \mathrm{mV}$ on $\mathrm{Cx} 45$ ). $\mathrm{G}_{\mathrm{j}, \mathrm{ss}}-\mathrm{V}_{\mathrm{j}}$ plots were generated for $\mathrm{Cx} 37 / \mathrm{Cx} 43$ and $\mathrm{Cx} 37 / \mathrm{Cx} 45$ GJs and in both cases the data were fitted well with Boltzmann equations when $\mathrm{Cx} 37$ with $+\mathrm{V}_{\mathrm{j}}$ (or when $\mathrm{Cx} 43$ or Cx45 with $-V_{j}$ ) (Figure 2-4B), but not the opposite $V_{j}$. The Boltzmann fitting parameters are listed in Table 2-1. The $\mathrm{V}_{0}$ of Cx37/Cx43 GJ was significantly higher than that of Cx37 GJ and the $\mathrm{G}_{\min }$ and $\mathrm{V}_{0}$ of $\mathrm{Cx} 37 / \mathrm{Cx} 45 \mathrm{GJ}$ were significantly lower than those of $\mathrm{Cx} 37 \mathrm{GJ}$, but none of the Boltzmann fitting parameters were different from those of Cx45 GJ (Table 2-1). 

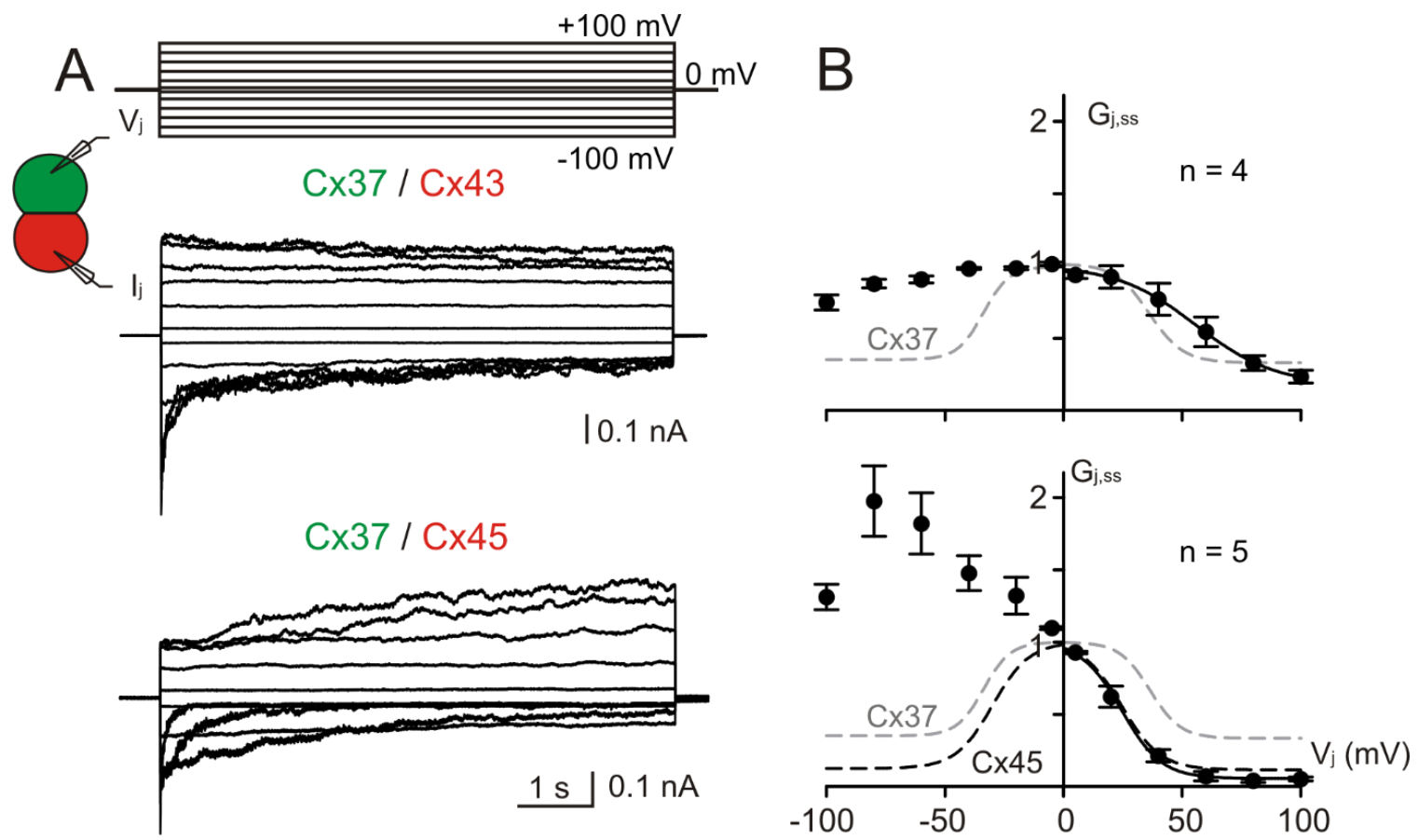

Figure 2-4. $\mathrm{V}_{\mathrm{j}}$-gating of heterotypic $\mathrm{Cx} 37 / \mathrm{Cx} 43$ and $\mathrm{Cx} 37 / \mathrm{Cx} 45$ GJs.

(A) Superimposed $\mathrm{I}_{\mathrm{j}} \mathrm{s}$ from heterotypic $\mathrm{Cx} 37 / \mathrm{Cx} 43$ or $\mathrm{Cx} 37 / \mathrm{Cx} 45$ cell pairs in response to a series of $\mathrm{V}_{\mathrm{j}}$ pulses as indicated. (B) Normalized steady state junctional conductance, $\mathrm{G}_{\mathrm{j}, \mathrm{ss}}$, of $\mathrm{Cx} 37 / \mathrm{Cx} 43$ or $\mathrm{Cx} 37 / \mathrm{Cx} 45$ were plotted with tested $\mathrm{V}_{\mathrm{j}}$. The data of $\mathrm{G}_{\mathrm{j}, \mathrm{ss}}-\mathrm{V}_{\mathrm{j}}$ plot when Cx37 cell with $+\mathrm{V}_{\mathrm{j}}$ (or when $\mathrm{Cx} 43$ or $\mathrm{Cx} 45$ with $-\mathrm{V}_{\mathrm{j}}$ ) could be well fitted with a Boltzmann equation for each of $\mathrm{Cx} 37 / \mathrm{Cx} 43$ or $\mathrm{Cx} 37 / \mathrm{Cx} 45$ GJs. Boltzmann fitting curves of $\mathrm{V}_{\mathrm{j}^{-}}$gating of homotypic Cx37 (smooth grey dashed lines) or Cx45 (smooth black dashed lines) GJ were superimposed on the plots for easy comparison (smooth black lines). 
The $\mathrm{I}_{\mathrm{j}} \mathrm{s}$ of these two heterotypic GJs displayed some interesting features. For example, the amplitude of the initial inward (defined by the $\mathrm{Cx} 43$ or $\mathrm{Cx} 45$ cell) junctional currents, $I_{j, \text { ini }}$, induced by a $V_{j}$ appeared to be larger than the corresponding outward $I_{j, \text { ini }}$ for both heterotypic GJs (Figure 2-5B). However, the amplitude of the end of inward junctional currents, $\mathrm{I}_{\mathrm{j}, \text { end }}$, were much lower than the corresponding outward $\mathrm{I}_{\mathrm{j}, \text { end }}$ (Figure 2-5B). To quantitatively describe this, we calculated the ratio of junctional conductance $\mathrm{G}_{\mathrm{j}}(-) / \mathrm{G}_{\mathrm{j}}(+)$ for both the $\mathrm{I}_{\mathrm{j}, \mathrm{ini}}$ and $\mathrm{I}_{\mathrm{j}, \text { end }}$ and plotted with the absolute $\mathrm{V}_{\mathrm{j}} \mathrm{s}$ (Figure 2-5C). It is very interesting to observe that the ratio $\mathrm{G}_{\mathrm{j}}(-) / \mathrm{G}_{\mathrm{j}}(+)$ for $\mathrm{Cx} 37 / \mathrm{Cx} 43$ GJs were $\mathrm{V}_{\mathrm{j}}$ dependent $(\mathrm{P}<0.01$ for the initial [open triangles] and $\mathrm{P}=0.01$ for the end [grey triangles]). But the ratio $\mathrm{G}_{\mathrm{j}}(-) / \mathrm{G}_{\mathrm{j}}(+)$ for $\mathrm{Cx} 37 / \mathrm{Cx} 45$ GJs failed to show any $\mathrm{V}_{\mathrm{j}}$ dependence for both the initial and end of the $\mathrm{I}_{\mathrm{j}} \mathrm{s}(\mathrm{P}>0.05$ for both cases). 


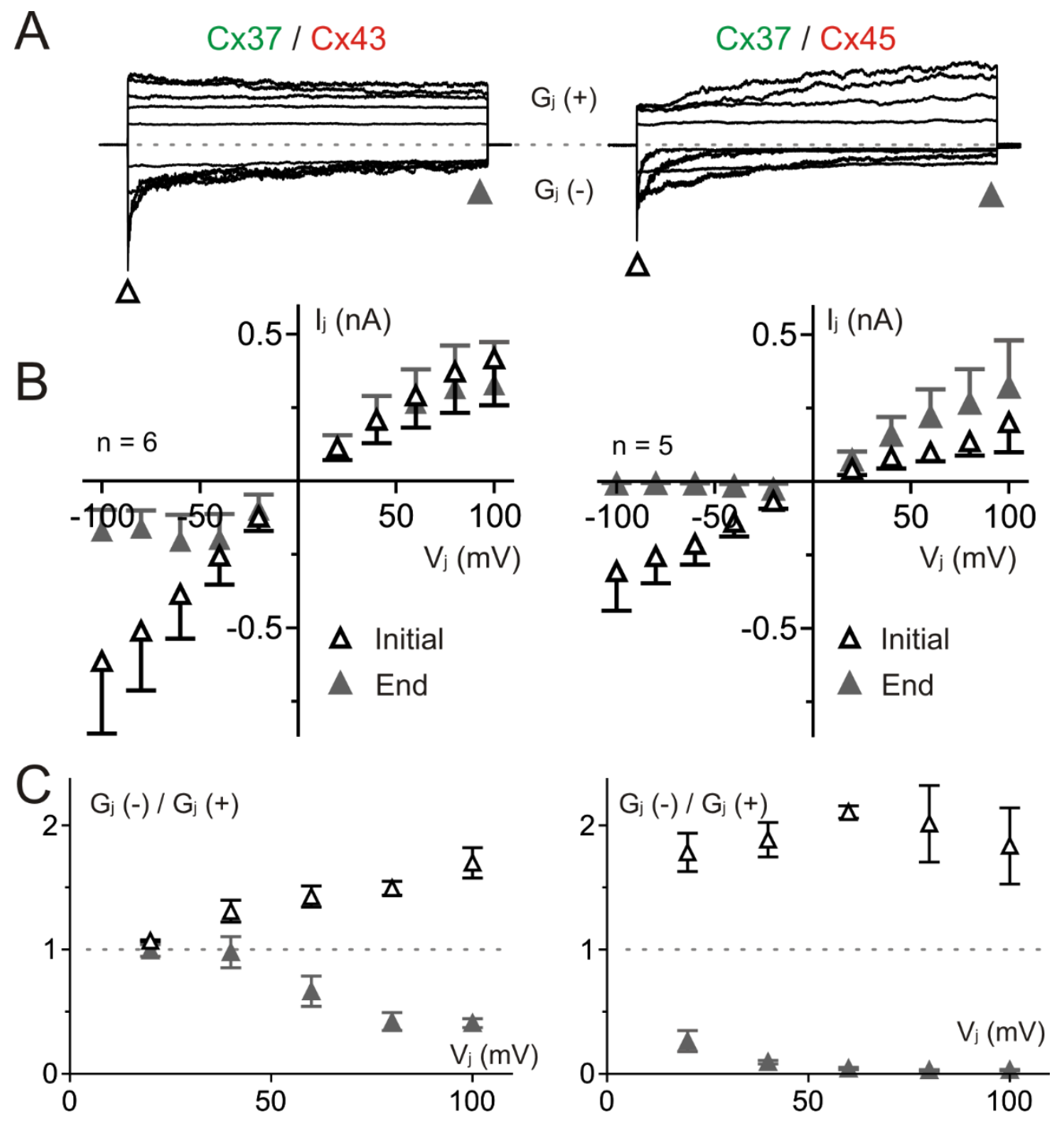

Figure 2-5 
Figure 2-5. Heterotypic Cx37/Cx43 and Cx37/Cx45 GJs showed similar and different rectifying properties.

(A) Same $\mathrm{I}_{\mathrm{j}} \mathrm{s}$ as shown in Figure 2-4A are shown here to illustrate measurement at the initial (open triangle) and the end (grey filled triangle) of each $\mathrm{I}_{\mathrm{j}}$ and the definition of conductance $G_{j}(+)$ when $C x 43$ or $C x 45$ with $+V_{j}$ s and the conductance $G_{j}(-)$ when $C x 43$ or $\mathrm{Cx} 45$ with $-\mathrm{V}_{\mathrm{j}} \mathrm{s}$. (B) $\mathrm{I}_{\mathrm{j}}-\mathrm{V}_{\mathrm{j}}$ plots were constructed for $\mathrm{Cx} 37 / \mathrm{Cx} 43$ and $\mathrm{Cx} 37 / \mathrm{Cx} 45 \mathrm{GJs}$ for both the initial (black open triangles) and end (filled grey triangles) of the $\mathrm{I}_{\mathrm{j}}$ response. (C) The ratios of $\mathrm{G}_{\mathrm{j}}(-) / \mathrm{G}_{\mathrm{j}}(+)$ for the initial (black open triangles) and end (filled grey triangles) were plotted with $\mathrm{V}_{\mathrm{j}} \mathrm{s}$. The ratio was constant for $\mathrm{Cx} 37 / \mathrm{Cx} 45$ GJs at different $\mathrm{V}_{\mathrm{j}} \mathrm{s}$, but was not the case for $\mathrm{Cx} 37 / \mathrm{Cx} 43 \mathrm{GJ}$, which showed an increase with $\mathrm{V}_{\mathrm{j}}$ for the initial conductance ratio, but a decrease for the end conductance ratio. 
One of the $\mathrm{Cx} 37 / \mathrm{Cx} 43$ cell pairs showed one functional GJ channel to allow us to study single channel currents $\left(\mathrm{i}_{\mathrm{j}} \mathrm{s}\right)$ at different $\mathrm{V}_{\mathrm{j}} \mathrm{s}$. All point histograms and Gaussian fits were used to measure the amplitudes of $i_{j} s$ for the main conducting state (the main open state). Various levels of subconductance states were also observed (Figure 2-6A, B). The plot of $i_{j}-V_{j}$ did not follow a simple linear regression with both $V_{j}$ polarities and showed inward rectification similar to that of macroscopic $\mathrm{I}_{\mathrm{j}}-\mathrm{V}_{\mathrm{j}}$ plot for Cx37/Cx43 GJs (Figure 2-6C). Rectification was observed as there was a change in $\mathrm{I}_{\mathrm{j}}$ with increasing $\mathrm{V}_{\mathrm{j}} \mathrm{s}$ due to a change in channel conductance or resistance. The gap junctional unitary conductance $\left(\gamma_{\mathrm{j}}\right)$ of the main open state showed some interesting features. First, when $\mathrm{Cx} 43$ with $-\mathrm{V}_{\mathrm{j}}$ (or Cx37 with $\left.+V_{j}\right)$ the $\gamma_{j}(-)$ is larger than the $\gamma_{j}$ of opposite $V_{j}$ polarity, $\gamma_{j}(+)$. Second, both $\gamma_{j}(-)$ and $\gamma_{j}(+)$ were not constant at different $V_{j}$ levels. The $\gamma_{j}(-)$ increased with the increase of $V_{j}$ values, while the $\gamma_{j}(+)$ decreased with the increase of $V_{j}$ values. Third, the ratio of $\gamma_{\mathrm{j}}(-) / \gamma_{\mathrm{j}}(+)$ appeared to increase with $\mathrm{V}_{\mathrm{j}}$ values in a linear fashion (Figure 2-6C), again similar to what observed for the macroscopic $G_{j}(-) / G_{j}(+)$ ratio changes with $V_{j}$. More experiments are needed to have proper statistical analysis to confirm these interesting properties of $\mathrm{Cx} 37 / \mathrm{Cx} 43 \mathrm{GJ}$ channels. 


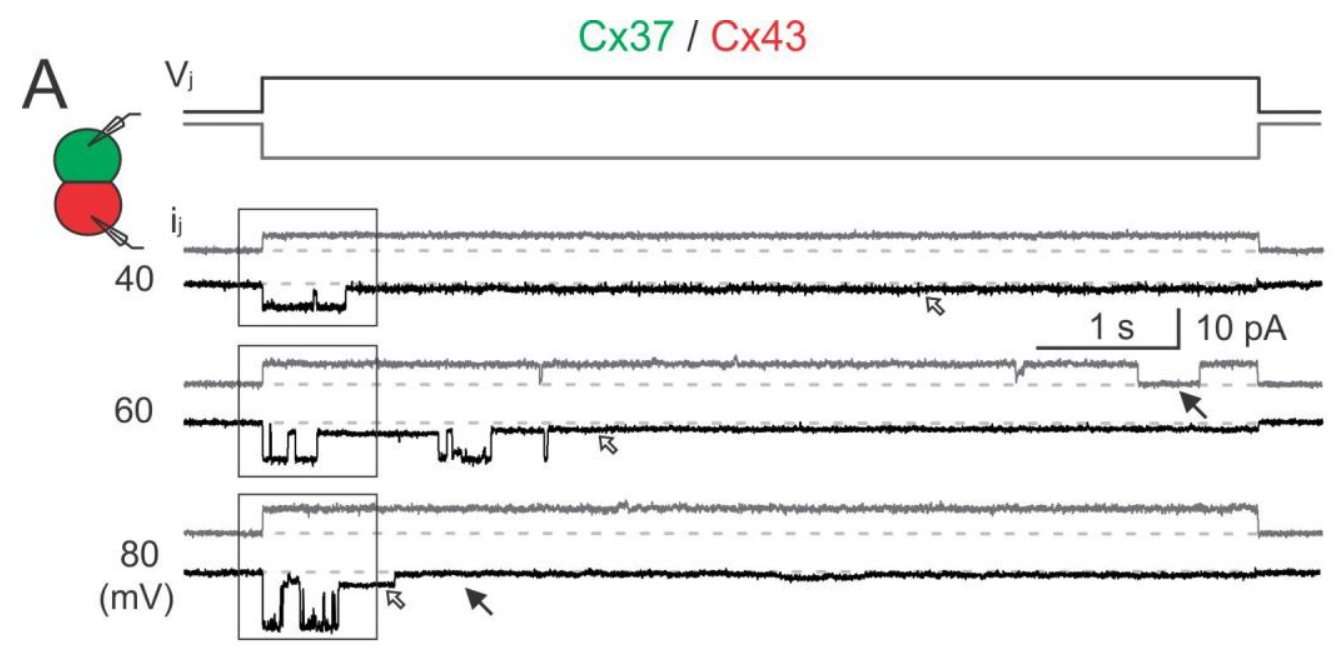

B

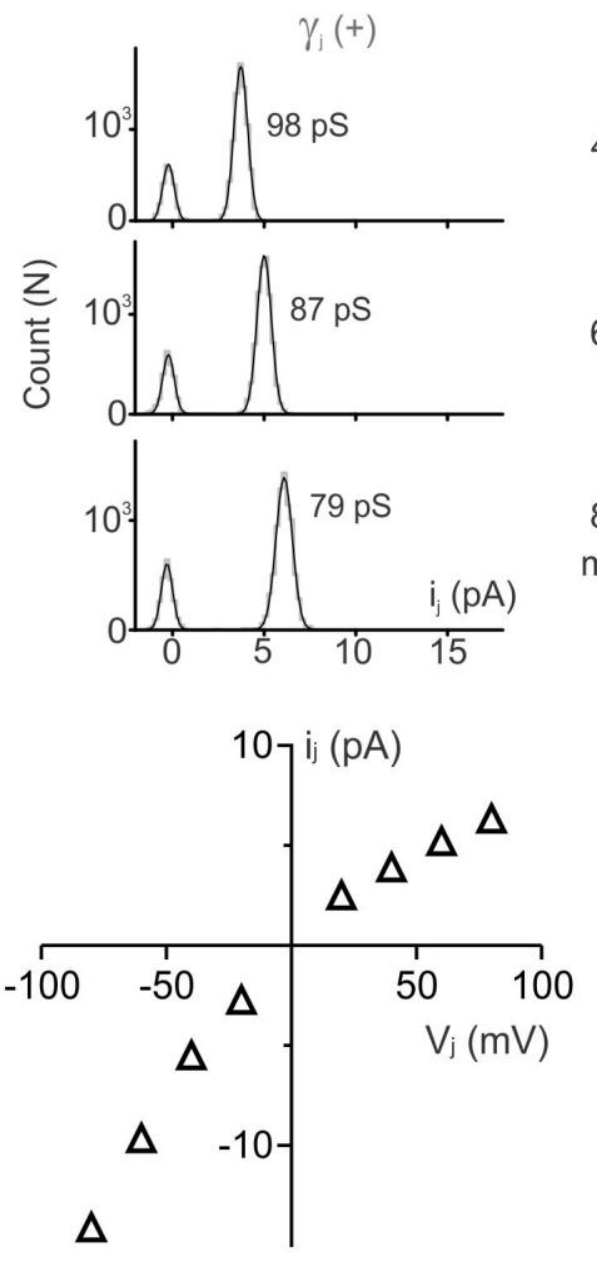

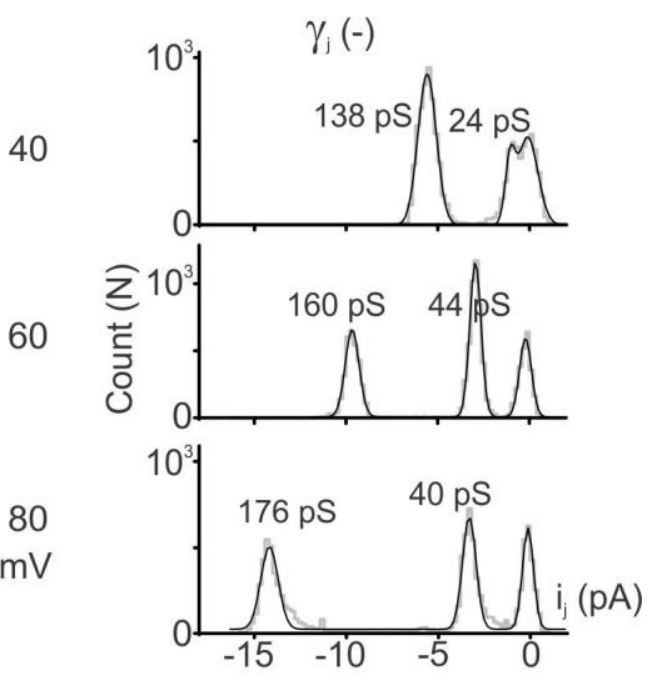

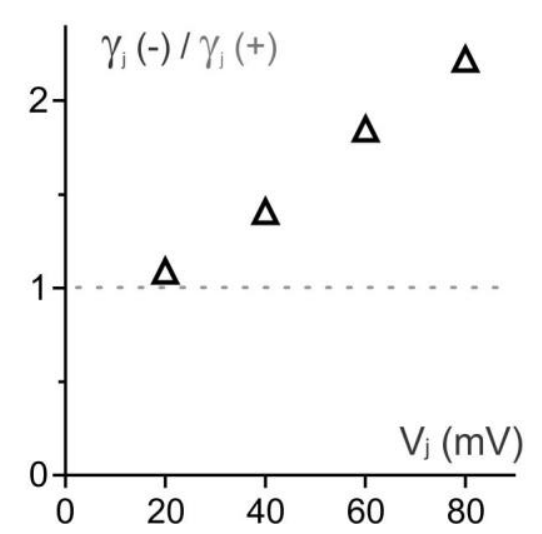

Figure 2-6 
Figure 2-6. Unitary channel properties of heterotypic Cx37/Cx43 GJ.

(A) Single channel currents $\left(\mathrm{i}_{\mathrm{j}} \mathrm{s}\right)$ were recorded from a heterotypic $\mathrm{Cx} 37 / \mathrm{Cx} 43$ cell pair at the indicated $\mathrm{V}_{\mathrm{j}} \mathrm{s}$. (B) All point histograms were generated at the boxed areas shown in panel A. Gaussian fits were used to determine the $i_{j}$ amplitudes of main open state and the subconductance states. (C) $\mathrm{i}_{\mathrm{j}}-\mathrm{V}_{\mathrm{j}}$ relationship of this heterotypic Cx37/Cx43 GJ was constructed and showed inward rectification. Right panel is the ratio of $\gamma_{j}(-) / \gamma_{j}(+)-V_{j}$ relationship for this GJ. It appeared that the ratio is increased with $\mathrm{V}_{\mathrm{j}}$ in a linear fashion. 
2.4.5 Characterization of $\mathrm{V}_{\mathrm{j}}$-gating of heterotypic $\mathrm{Cx} 37 / \mathrm{Cx} 45$ GJs with prolonged $\mathrm{V}_{\mathrm{j}}$ pulses

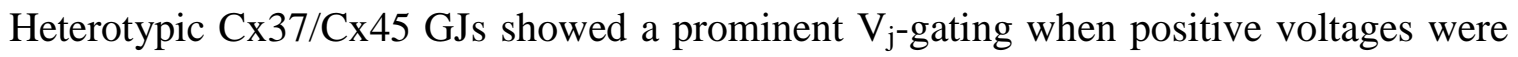
administered to the $\mathrm{Cx} 37$ cell (or $\mathrm{Cx} 45$ cell with $-\mathrm{V}_{\mathrm{j}}$ ) and an apparent reverse $\mathrm{V}_{\mathrm{j}}$-gating on the opposite $\mathrm{V}_{\mathrm{j}}$ polarity. To further evaluate the minimum level of $\mathrm{V}_{\mathrm{j}} \mathrm{s}$ showing $\mathrm{V}_{\mathrm{j}}$-gating or reverse $\mathrm{V}_{\mathrm{j}}$-gating, we recorded $\mathrm{I}_{\mathrm{j}} \mathrm{s}$ in response to much longer $\mathrm{V}_{\mathrm{j}}$ pulses (duration $=15$ seconds) and longer inter pulse intervals (15 seconds) to allow recovery of deactivated GJs (Figure 2-7A). We focused on very low $\mathrm{V}_{\mathrm{j}}$ levels from \pm 2 to $\pm 20 \mathrm{mV}$. As shown in Figure 2-7B, the threshold $V_{j}$ for the normalized steady state conductance $\left(\mathrm{G}_{\mathrm{j}, \mathrm{ss}}\right)$ significantly below one (or displaying $\mathrm{V}_{\mathrm{j}}$-gating) was $-5 \mathrm{mV}$ (on $\mathrm{Cx} 45$ cell) and the threshold $\mathrm{V}_{\mathrm{j}}$ for $\mathrm{G}_{\mathrm{j}, \mathrm{ss}}$ higher than one (or the reverse $\mathrm{V}_{\mathrm{j}}$-gating) was $+10 \mathrm{mV}$ (on $\mathrm{Cx} 45$ cell). We believe that these values are under estimated as we only used a 15 seconds voltage pulse, which appeared to be not sufficiently long to reach a full steady state. As previously described in Figure 2-5B, the $\mathrm{I}_{\mathrm{j}} \mathrm{s}$ of heterotypic $\mathrm{Cx} 37 / \mathrm{Cx} 45$ displayed similar rectifications at lower $\mathrm{V}_{\mathrm{j}} \mathrm{s}$ (analysis not included in the figure). The ratio of the junctional conductance $\mathrm{G}_{\mathrm{j}}(-) / \mathrm{G}_{\mathrm{j}}(+)$ for both the $\mathrm{I}_{\mathrm{j}, \text { ini }}$ and $\mathrm{I}_{\mathrm{j}, \text { end }}$ were plotted with the absolute $\mathrm{V}_{\mathrm{j}}$ s. However at lower $\mathrm{V}_{\mathrm{j}} \mathrm{s}$, the ratio $\mathrm{G}_{\mathrm{j}}(-) / \mathrm{G}_{\mathrm{j}}(+)$ of $\mathrm{Cx} 37 / \mathrm{Cx} 45$ increased with increasing $\mathrm{V}_{\mathrm{j}} \mathrm{s}(\mathrm{P}<0.01$ for the initial and $\mathrm{P}<$ 0.05 for the end) (analysis not included in the figure). 


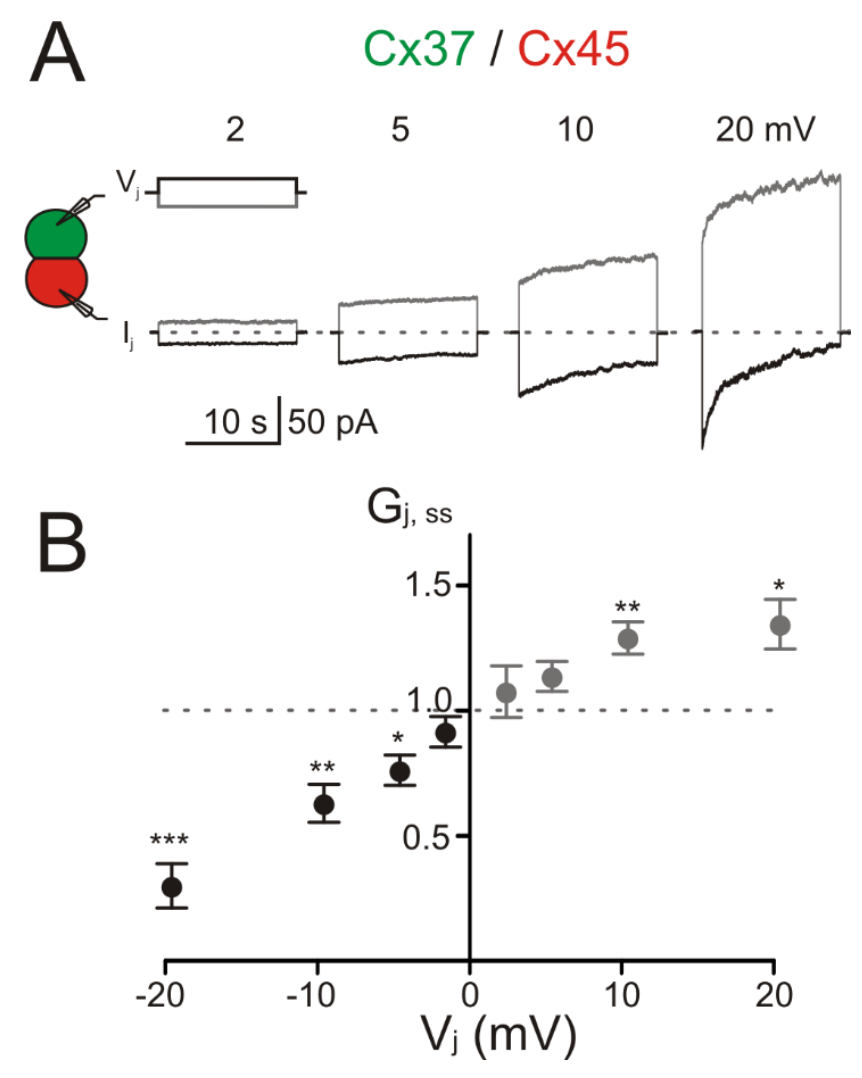

Figure 2-7. Long voltage pulse protocol revealed the threshold of heterotypic $\mathrm{Cx} 37 / \mathrm{Cx} 45$ GJ $V_{j}$-gating.

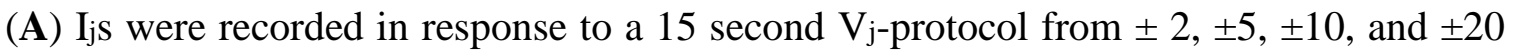
$\mathrm{mV}$ (as indicated above) for heterotypic $\mathrm{Cx} 37 / \mathrm{Cx} 45$ cell pairs. The grey colored $\mathrm{I}_{\mathrm{j}} \mathrm{s}$ correspond to $-\mathrm{V}_{\mathrm{j}}$ on $\mathrm{Cx} 37$ cell or $+\mathrm{V}_{\mathrm{j}}$ on $\mathrm{Cx} 45$ cell. While black colored $\mathrm{I}_{\mathrm{j}} \mathrm{s}$ correspond to $+\mathrm{V}_{\mathrm{j}}$ on $\mathrm{Cx} 37$ cell or $-\mathrm{V}_{\mathrm{j}}$ on $\mathrm{Cx} 45$ cell. (B) Normalized $\mathrm{G}_{\mathrm{j}, \mathrm{ss}}$ of $\mathrm{Cx} 37 / \mathrm{Cx} 45 \mathrm{GJ}$ were plotted to the respective $V_{j s}$ (defined by $C x 45$ cells). A significant reduction of $G_{j, s s}$ during a $V_{j}$ pulse was observed at $-5 \mathrm{mV}(\mathrm{p}<0.05)$, increased $\mathrm{V}_{\mathrm{j}} \mathrm{s}(-10$ and $-20 \mathrm{mV})$ showed more reduction of $\mathrm{G}_{\mathrm{j}, \mathrm{ss}}\left(\mathrm{p}<0.01\right.$ for both $\left.\mathrm{V}_{\mathrm{j}} \mathrm{s}\right)$. On the other hand, reverse gating was observed as early as $+10 \mathrm{mV}$ leading to a significant increase in $\mathrm{G}_{\mathrm{j}, \mathrm{ss}}(\mathrm{p}<0.01)$. $\mathrm{G}_{\mathrm{j}, \mathrm{ss}}$ average values were compared to one (the grey dotted line) using a one-sample t-test. 


\subsubsection{Establish gap junction coupling of $\mathrm{Cx} 37 / \mathrm{Cx} 40$ by designed docking variants}

Sequence alignment and homology modeling of Cx40 GJs revealed several key residues at the docking interface (for example, D55 on the E1 and P193 on the E2 domain) could restrict its ability to dock with other connexins. Designed Cx40 variants, D55N or P193Q, have been shown to successfully rescue the ability of Cx40 to dock with Cx43 and Cx45 (Jassim et al., 2016; Ye et al., 2017). To test if these residues in Cx40 are also responsible for its failure in forming functional heterotypic Cx37/Cx40 GJs, heterotypic Cx37/Cx40 D55N (or Cx37/Cx40 P193Q) cell pairs were selected for dual patch clamp analysis. As shown in Figure 2-8, majority of heterotypic Cx37/D55N or Cx37/P193Q cell pairs formed functional GJs. The coupling percentages of both Cx37/D55N and Cx37/P193Q were similar to those of homotypic Cx37 or Cx40, but were significantly higher than that of $\mathrm{Cx} 37 / \mathrm{Cx} 40$ cell pair $(\mathrm{p}<0.05$, Figure $2-8 \mathrm{~B})$. Similarly, the $\mathrm{G}_{\mathrm{j}}$ of heterotypic Cx37/D55N (or Cx37/P193Q) GJs was significantly higher than that of $\mathrm{Cx} 37 / \mathrm{Cx} 40$ and was similar to those of homotypic Cx37 or Cx40 GJs (Figure 2-8C). Significantly increased coupling\% and $\mathrm{G}_{\mathrm{j}}$ of Cx37/D55N or Cx37/P193Q than those of Cx37/Cx40 demonstrated that these Cx40 variants were fully capable of docking with Cx37 to form functional heterotypic GJs. The $\mathrm{V}_{\mathrm{j}}$-gating of Cx37/D55N or Cx37/P193Q GJs was largely symmetrical similar to those of homotypic Cx37 and Cx40 GJs (Figure 2-9A). $G_{j, s s}-V_{j}$ plots were constructed and the data were fitted well with Boltzmann equations for both $\mathrm{V}_{\mathrm{j}}$ polarities (Figure 2-9B). The Boltzmann fitting parameters (Table 2-1) were similar to those of Cx37 or Cx40 GJs with only one consistent change for both variants, a lower $\mathrm{V}_{0}$ values than those of $\mathrm{Cx} 40 \mathrm{GJ}$ when $\mathrm{Cx} 37$ cell with $-\mathrm{V}_{\mathrm{j}}$ ( or $\mathrm{Cx} 40$ variants with $\left.+\mathrm{V}_{\mathrm{j}} \mathrm{s}\right)$. 


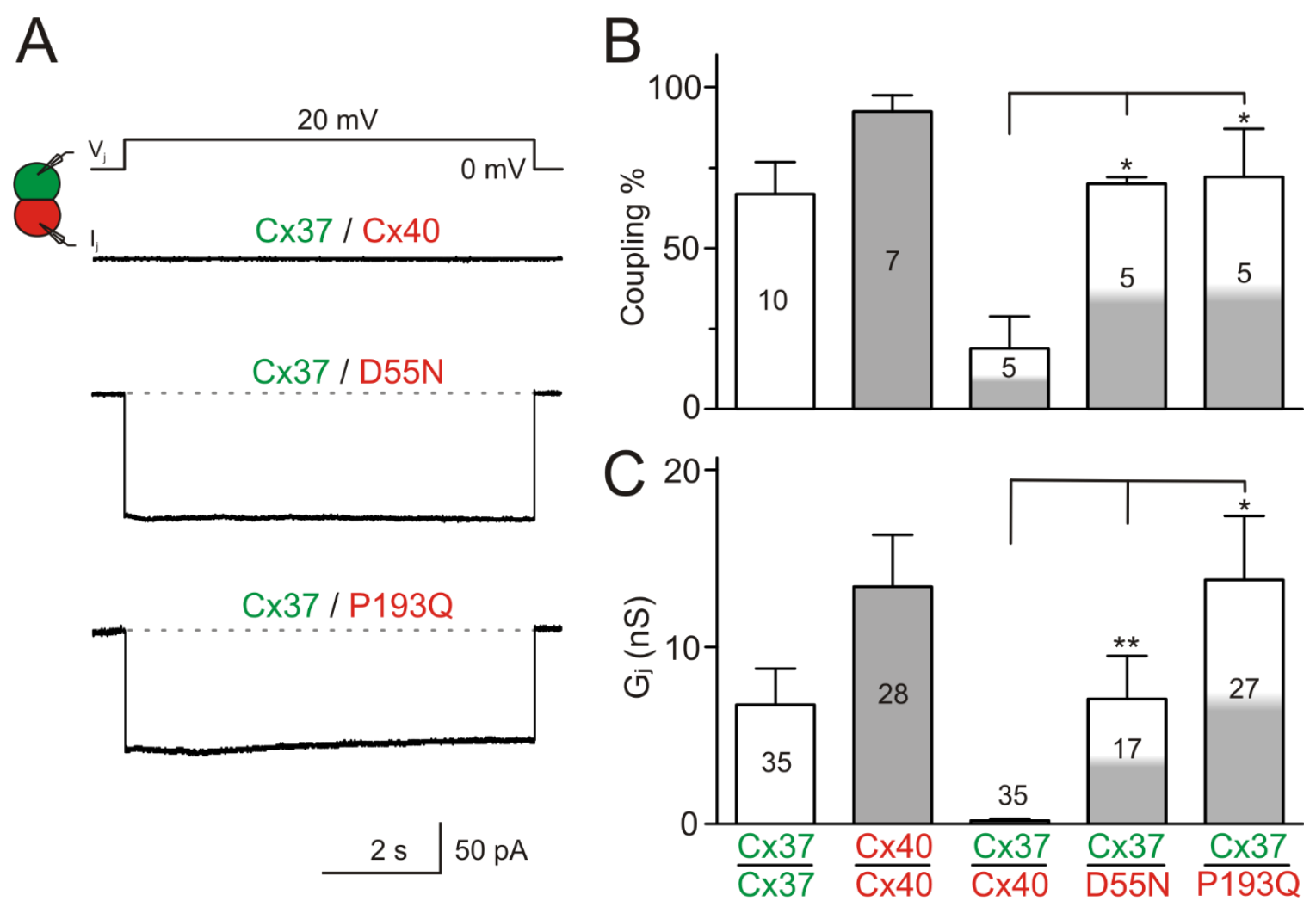

Figure 2-8. Coupling percentage and $\mathrm{G}_{\mathrm{j}}$ of heterotypic $\mathrm{GJ}$ s of $\mathrm{Cx} 37$ with $\mathrm{Cx} 40$ mutants.

(A) Representative $\mathrm{I}_{\mathrm{j}} \mathrm{s}$ were recorded from heterotypic Cx37/Cx40 D55N (Cx37/D55N) or Cx37/P193Q cell pairs in response to $+20 \mathrm{mV} \mathrm{V}$ pulse. (B) Bar graph summarizes the coupling\% of heterotypic Cx37/Cx40, Cx37/D55N, and Cx37/P193Q GJs. Both Cx37/D55N and Cx37/P193Q showed a significant increase in the coupling\% compared to that of $\mathrm{Cx} 37 / \mathrm{Cx} 40(\mathrm{p}<0.05)$. The total number of independent transfections is indicated. (C) Bar graph illustrates the averaged $\mathrm{G}_{\mathrm{j}}$ of different cell pairs as indicated. A significant increase in $\mathrm{G}_{\mathrm{j}}$ was observed for both $\mathrm{Cx} 37 / \mathrm{D} 55 \mathrm{~N}$ and $\mathrm{Cx} 37 / \mathrm{P} 193 \mathrm{Q}$ cell pairs compared to that of $\mathrm{Cx} 37 / \mathrm{Cx} 40(\mathrm{p}<0.01)$. The total number of recorded cell pairs is indicated. Data for homotypic Cx37 and Cx40 GJs were identical as those presented in Figure 2-1 for easy comparison. 


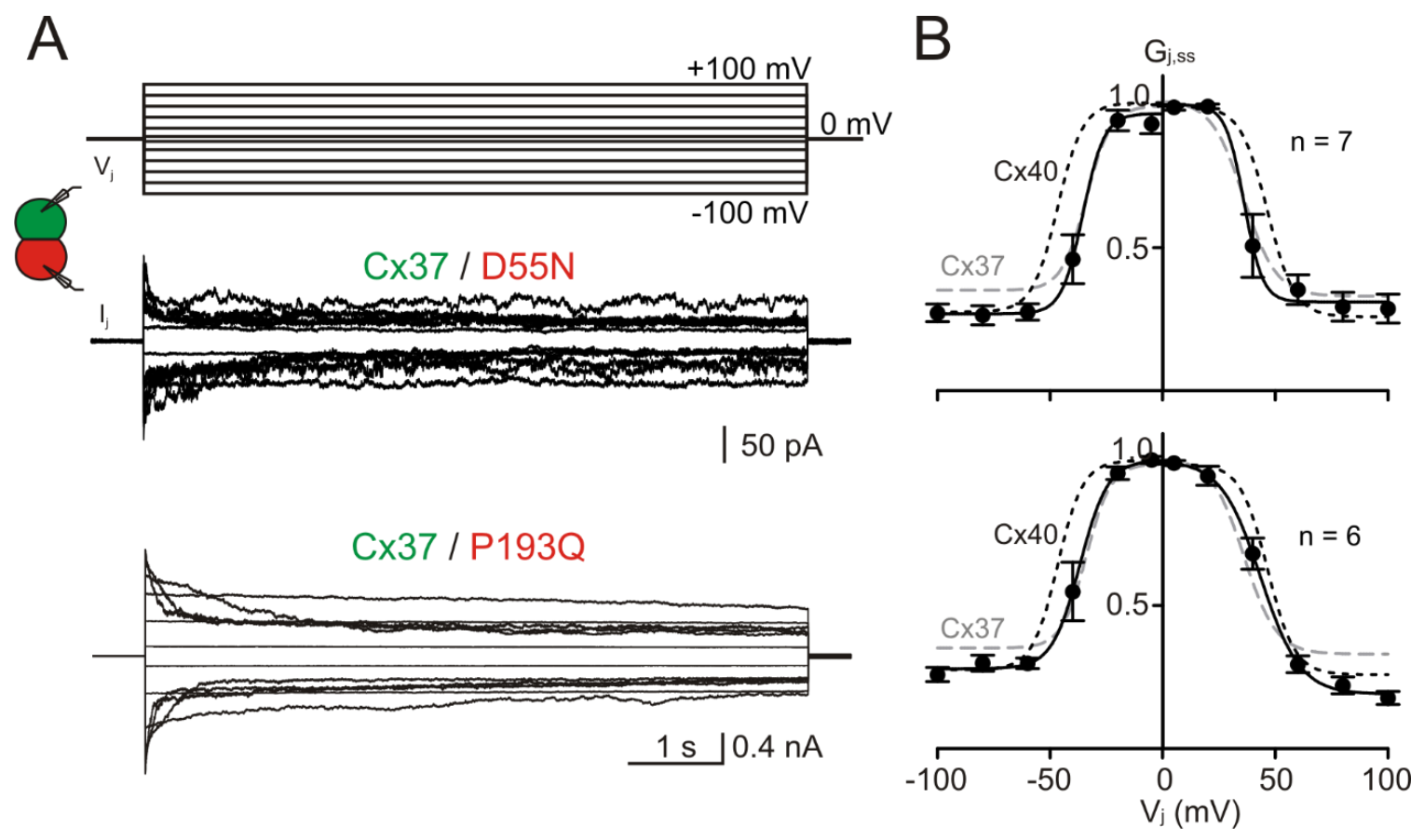

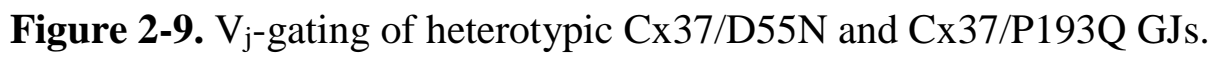

(A) Superimposed Ijs were recorded from heterotypic Cx37/D55N or Cx37/P193Q GJs in response to a series of $\mathrm{V}_{\mathrm{j}}$ pulses as indicated. (B) Normalized $\mathrm{G}_{\mathrm{j}, \mathrm{ss}}$ of heterotypic Cx37/D55N or Cx37/P193Q (black filled circles) were plotted to different $\mathrm{V}_{\mathrm{js}} . \mathrm{G}_{\mathrm{j}, \mathrm{ss}}-\mathrm{V}_{\mathrm{j}}$ plots were fitted well with Boltzmann equations for each $\mathrm{V}_{\mathrm{j}}$ polarity (smooth black lines). Boltzmann fitting curves for Cx37 GJ (smooth grey dashed lines) and Cx40 GJ (smooth black dashed lines) were superimposed for easy comparison. 
Table 2-1. Boltzmann Fitting parameters for homotypic and heterotypic GJs

\begin{tabular}{|c|c|c|c|c|}
\hline & $\begin{array}{c}\mathbf{V}_{\mathbf{j}} \\
\text { Polarity }^{\dagger}\end{array}$ & $\mathbf{G}_{\min }$ & $\mathbf{V}_{\mathbf{0}}$ & $A$ \\
\hline \multirow{2}{*}{$\begin{array}{l}\text { Cx37 } \\
(\mathrm{n}=5)\end{array}$} & + & $0.33 \pm 0.03$ & $36.1 \pm 2.6$ & $0.14 \pm 0.05$ \\
\hline & - & $0.35 \pm 0.03$ & $33.9 \pm 3.2$ & $0.18 \pm 0.08$ \\
\hline \multirow{2}{*}{$\begin{array}{l}\mathrm{Cx} 40 \\
(\mathrm{n}=7)\end{array}$} & + & $0.26 \pm 0.03$ & $46.7 \pm 1.9^{*}$ & $0.17 \pm 0.04$ \\
\hline & - & $0.28 \pm 0.02$ & $46.6 \pm 1.7^{* *}$ & $0.18 \pm 0.04$ \\
\hline \multirow{2}{*}{$\begin{array}{l}\text { Cx45 } \\
(\mathrm{n}=4)\end{array}$} & + & $0.12 \pm 0.03 * * *$ & $24.6 \pm 2.2^{*}$ & $0.12 \pm 0.03$ \\
\hline & - & $0.13 \pm 0.03 * * *$ & $29.9 \pm 2.2$ & $0.13 \pm 0.02$ \\
\hline $\begin{array}{c}\text { Cx37 / Cx43 } \\
(\mathrm{n}=4)\end{array}$ & + & $0.18 \pm 0.13$ & $55.8 \pm 7.3^{*}$ & $0.06 \pm 0.03$ \\
\hline $\begin{array}{c}\mathrm{Cx} 37 / \mathrm{Cx} 45 \\
(\mathrm{n}=5)\end{array}$ & + & $\begin{array}{c}0.06 \pm 0.02^{* * * *} \\
(\mathrm{w} / \mathrm{Cx} 37)\end{array}$ & $\begin{array}{c}24.5 \pm 1.3^{* * *} \\
(\mathrm{w} / \mathrm{Cx} 37)\end{array}$ & $0.12 \pm 0.01$ \\
\hline \multirow{2}{*}{$\begin{array}{c}\text { Cx37 / Cx40 D55N } \\
(\mathrm{n}=7)\end{array}$} & + & $0.31 \pm 0.03$ & $36.3 \pm 4.3$ & $0.24 \pm 0.26$ \\
\hline & - & $0.27 \pm 0.02$ & $\begin{array}{l}35.4 \pm 2.7^{*} \\
(\mathrm{w} / \mathrm{Cx} 40)\end{array}$ & $0.21 \pm 0.11$ \\
\hline \multirow{2}{*}{$\begin{array}{c}\text { Cx37 / Cx40 P193Q } \\
(\mathrm{n}=5)\end{array}$} & + & $\begin{array}{l}0.19 \pm 0.02 * \\
(w / C \times 37)\end{array}$ & $43.6 \pm 1.5$ & $0.11 \pm 0.02$ \\
\hline & - & $0.28 \pm 0.03$ & $\begin{array}{l}36.7 \pm 2.0^{* *} \\
(\mathrm{w} / \mathrm{Cx} 40)\end{array}$ & $0.16 \pm 0.06$ \\
\hline
\end{tabular}


Data are presented as mean $\pm \mathrm{SEM}$ and $\mathrm{V}_{0}$ are absolute values. One-way ANOVA followed by Tukey post-hoc test was used to compare Boltzmann fitting parameters of the homotypic and heterotypic GJs against the respective controls with the same $\mathrm{V}_{\mathrm{j}}$ polarity. Student $t$-test was used to compare Boltzmann fitting parameters of Cx37/Cx43 GJ with those of Cx37. The number of asterisks indicate the statistical difference level $(* \mathrm{p}<0.05, * * \mathrm{p}<0.01$, $* * * \mathrm{p}<0.001)$

${ }^{\dagger} \mathrm{V}_{\mathrm{j}}$ polarity of heterotypic GJs is defined by the relative voltage level of Cx37-expressing cell. 


\subsection{Discussion}

The present study is the first to investigate the functional status and channel properties of human Cx37 with Cx40, Cx43, or Cx45 heterotypic GJs. The results showed that the coupling status and $\mathrm{G}_{\mathrm{j}}$ of both heterotypic $\mathrm{Cx} 37 / \mathrm{Cx} 43$ and $\mathrm{Cx} 37 / \mathrm{Cx} 45 \mathrm{GJ}$ s were comparable to the respective homotypic controls. However significant lower coupling\% and low $\mathrm{G}_{\mathrm{j}}$ were observed for heterotypic $\mathrm{Cx} 37 / \mathrm{Cx} 40$ cell pairs. Based on these observations, Cx37 was able to form heterotypic GJ channels with $\mathrm{Cx} 43$ and $\mathrm{Cx} 45$ but not with $\mathrm{Cx} 40$. Characteristics including asymmetric $\mathrm{V}_{\mathrm{j}}$-gating and $\mathrm{I}_{\mathrm{j}}$ rectifications were observed with both Cx37/Cx43 and Cx37/Cx45. Cx37/Cx43 GJs displayed $\mathrm{V}_{\mathrm{j}}$-dependent deactivation with both $\mathrm{V}_{\mathrm{j}}$ polarities. On the other hand, Cx37/Cx45 GJs exhibited strong deactivation with $-\mathrm{V}_{\mathrm{j}} \mathrm{s}$ administered to the $\mathrm{Cx} 45$ cell and reverse gating with $+\mathrm{V}_{\mathrm{j}} \mathrm{s}$. Interestingly, the $\mathrm{I}_{\mathrm{j}}-\mathrm{V}_{\mathrm{j}}$ plot of $\mathrm{Cx} 37 / \mathrm{Cx} 43 \mathrm{GJ}$ showed continuous voltage dependent $\mathrm{I}_{\mathrm{j}}$ rectification however $\mathrm{I}_{\mathrm{j}}-\mathrm{V}_{\mathrm{j}}$ plot rectification of $\mathrm{Cx} 37 / \mathrm{Cx} 45 \mathrm{GJ}$ was only at $\mathrm{V}_{\mathrm{j}}=0 \mathrm{mV}$ was not. Current rectification was observed within the preliminary single channel currents of $\mathrm{Cx} 37 / \mathrm{Cx} 43$ as the ratio of $\gamma_{\mathrm{j}}(-) / \gamma_{\mathrm{j}}(+)$ appeared to increase with $\mathrm{V}_{\mathrm{j}}$ values in a linear fashion. But more experiments with proper statistical analysis are required to confirm this. A longer $\mathrm{V}_{\mathrm{j}}$ pulse protocol was designed for $\mathrm{Cx} 37 / \mathrm{Cx} 45$ to closely examine the $\mathrm{V}_{\mathrm{j}}$-dependent deactivation at lower voltages (Figure 2-7). The reduction in $\mathrm{G}_{\mathrm{j}, \mathrm{ss}}$ occurred when a $\mathrm{V}_{\mathrm{j}}$ pulse of $-5 \mathrm{mV}$ was applied to the $\mathrm{Cx} 45$ cell whereas an increase was observed at $+10 \mathrm{mV}$. Finally to change the low probability of coupling $\%$ and $\mathrm{G}_{\mathrm{j}}$, two previously engineered $\mathrm{Cx} 40$ variants, D55N and P193Q, were able to form functional heterotypic GJs with Cx37.

The relevance of the present study is to help understand the different types of GJs that can potentially form with human connexin 37 as each cell type is capable of expressing 
more than one connexin. The present study demonstrated that functional channels can respond differently to subtle voltage changes and exert unique channel properties. Overall this would reflect the different GJ channels throughout the vasculature between ECs, VSMCs, and even at the myoendothelial junction. Although the signaling cascade to maintain vasomotor tone may originate either from the EC or VSMC side, GJs are important within the vasculature to help facilitate low resistance passage in signal conductions both electrically and metabolically.

\subsubsection{Physiological role of vascular connexins}

The maintenance of vasomotor tone is crucial in the vasculature in order to accommodate various blood flow and pressure. Through GJs, electrical signals are propagated through interconnected cells, either homocellularly or heterocellularly, to coordinate spontaneous diameter changes in blood vessels (Haddock and Hill, 2005). Mouse models with vascular connexin gene KOs assisted researchers in understanding the important role these genes possess in the structural integrity and function of blood vessels. Kruger and colleagues observed several developmental traits were impaired in $\mathrm{Cx} 45 \mathrm{KO}$ mice including the transformation of mature vessels, formation of vascular trees in the yolk sac, and smooth muscle layer development around major arteries (Kruger et al., 2000). As apoptosis was observed in virtually all tissues, death was imminent in the early embryonic stages (E9.5 to E10.5) (Kruger et al., 2000). For Cx43 KO mice, they died at birth due to the obstruction of the right ventricular outflow tract (Reaume et al., 1995). Moreover even the loss a single allele demonstrated defects in the patterning of coronary arteries (Clauss et al., 2006). The $\mathrm{KO}$ of the $\mathrm{Cx} 43$ gene appeared to alter the cell signaling pathways regulating vasculogenesis and angiogenesis as several genes associated with differentiation and 
function of vascular cells were modified (Walker et al., 2005). On the other hand, mice were viable from the individual $\mathrm{Cx} 40$ or $\mathrm{Cx} 37 \mathrm{KOs}$ and considered as non-lethal. $\mathrm{Cx} 40$ KO mice embryos displayed small defects along the cardiac septum and predisposition towards arrhythmias (Figueroa and Duling, 2009; Kirchhoff et al., 1998). Interestingly, no vascular abnormalities including heart dysfunction were observed with $\mathrm{Cx} 37$ deficient mice except that females were reported to be infertile (Simon et al., 1997). Interestingly a double $\mathrm{KO}$ of $\mathrm{Cx} 37$ and $\mathrm{Cx} 40$ was discovered to be lethal as mice died around birth because of several vascular abnormalities with susceptibility to vasodilatations (Simon and McWhorter, 2003).

\subsubsection{A group of docking compatible connexins}

As each cell type in the vasculature can express more than one connexin isoform, co-expression can also lead to the potential formation of heterotypic GJ channels including heteromeric heterotypic (Sohl, 2004). Homomeric heterotypic GJs were focused in the present study as it was easier to control the connexin expression and docking of hemichannels. According to studies on docking-compatible connexins with $\mathrm{Cx} 37$, the heterotypic GJs are Cx37/Cx40, Cx37/Cx43, and Cx37/Cx45 which can potentially form intercellular connections between ECs and EC-VSMCs (Bai, 2016; Elfgang et al., 1995; Hill et al., 2002; van Kempen and Jongsma, 1999). The coupling characteristics, $\mathrm{G}_{\mathrm{j}}$, and

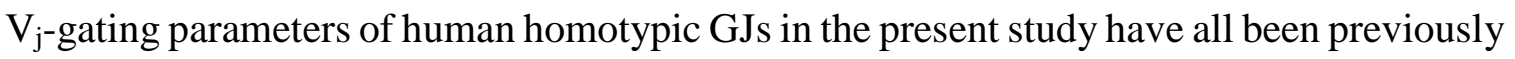
characterized (Barrio et al., 1997; Gonzalez et al., 2007; Jassim et al., 2016; Noureldin et al., 2018; Reed et al., 1993; Veenstra et al., 1994; Ye et al., 2017). Compared to the other vascular connexins, $\mathrm{Cx} 45$ GJs notably displayed the strongest and fastest $\mathrm{V}_{\mathrm{j}}$-dependent

deactivation as reported in the literature (Barrio et al., 1997; Ye et al., 2017). For Cx37, the 
present electrophysiological study showed approximately a little over $60 \%$ of the cell pairs were coupled as previously reported (Reed et al., 1993; Veenstra et al., 1994); although other parameters including average $\mathrm{G}_{\mathrm{j}}, \mathrm{G}_{\min }, \mathrm{V}_{0}$, and $A$ were slightly higher.

Reported in previous studies as heterotypic GJs are composed of different connexin hemichannels, the $\mathrm{G}_{\mathrm{jss}}-\mathrm{V}_{\mathrm{j}}$ relationship for both $\mathrm{V}_{\mathrm{j}}$ polarities will be asymmetric which was consistent with the asymmetric $\mathrm{V}_{\mathrm{j}}$-gating of heterotypic Cx37/Cx43 and $\mathrm{Cx} 37 / \mathrm{Cx} 45$ GJs (Barrio et al., 1991; Jassim et al., 2016; Ye et al., 2017). In the contingent gating model, it has been proposed that a GJ channel possesses two gates in series (one per hemichannel) and the gating state of one hemichannel can influence the voltage applied on the other hemichannel (Harris et al., 1981). In other words, a large $V_{j}$ could affect one of two gates driving the GJ channel to a reduced subconducting or closed state. For homotypic Cx45 GJs, the $\mathrm{V}_{\mathrm{j}}$-gating polarity is known to be negative meaning that $\mathrm{V}_{\mathrm{j}}$-gating closes the hemichannel at $-\mathrm{V}_{\mathrm{j}} \mathrm{s}$ (Chen-Izu et al., 2001). Furthermore as the unitary channel conductance $\left(\gamma_{\mathrm{j}}\right)$ of $\mathrm{Cx} 45 \mathrm{GJ}$ (32-38 pS) is much lower than the $\gamma_{\mathrm{j}}$ of $\mathrm{Cx} 37$ (300 pS) (Elenes et al., 2001; Veenstra et al., 1994), most of the administered $V_{j} s$ on a heterotypic Cx37/Cx45 GJ would be on the docked Cx45 hemichannel and make the GJ prone to close when $-\mathrm{V}_{\mathrm{j}}$ is on the $\mathrm{Cx} 45$ cell. This is consistent with data as heterotypic Cx37/Cx45 GJs displayed noticeable and fast $V_{j}$-dependent deactivation when $-V_{j}$ s were applied on the $\mathrm{Cx} 45$ cell (or $\mathrm{Cx} 37$ cell with $+\mathrm{V}_{\mathrm{j}} \mathrm{s}$ ) which indicated that $\mathrm{Cx} 37 / \mathrm{Cx} 45$ follows the contingent gating model. Detailed Boltzmann fitting of the $\mathrm{V}_{\mathrm{j}}$-gating properties of $\mathrm{Cx} 37 / \mathrm{Cx} 45 \mathrm{GJ}$ revealed no significant changes for the $\mathrm{G}_{\min }$, slope $A$ and $\mathrm{V}_{0}$, but the $\mathrm{G}_{\min }$ was about half of those observed for homotypic Cx45 GJs. On the other hand there was a significant decrease for $\mathrm{G}_{\min }$ and $\mathrm{V}_{0}$, but the slope $A$ was similar to those observed for homotypic Cx37. 
Heterotypic Cx37/Cx45 GJs was further investigated due to their distinct $\mathrm{V}_{\mathrm{j}}$-gating profile and potentially modelled EC-VSMC connections via the MEJ. Although studies have reported the membrane potentials $\left(\mathrm{V}_{\mathrm{m}}\right)$ of ECs and VSMCs to be identical (Emerson and Segal, 2000; Welsh and Segal, 1998), a noticeable change in $I_{j}$ occurred within a narrow $\mathrm{V}_{\mathrm{j}}$ range $(-5 \mathrm{mV}$ to $+10 \mathrm{mV})$ between the cell pair. This experiment suggested if ECVSMCs are coupled by heterotypic Cx37/Cx45 GJs, then the GJs would be modulated by small voltage differences between these two cell types. Although at small $\mathrm{V}_{\mathrm{j}} \mathrm{s}( \pm 2$ to \pm 20 ) the $\mathrm{I}_{\mathrm{j}}-\mathrm{V}_{\mathrm{j}}$ plot of $\mathrm{Cx} 37 / \mathrm{Cx} 45$ displayed similar features to the $\mathrm{I}_{\mathrm{j}}-\mathrm{V}_{\mathrm{j}}$ plot at $\operatorname{largr} \mathrm{V}_{\mathrm{j}} \mathrm{s}( \pm 20$ to $\pm 100)$, the ratio $G_{j}(-) / G_{j}(+)$ of $C x 37 / C x 45$ were found to be $V_{j}$ dependent at small $V_{j}$ s. It is difficult to make comparisons on the responses of $\mathrm{Cx} 37 / \mathrm{Cx} 45$ at different sets of $\mathrm{V}_{\mathrm{j}} \mathrm{s}$ as different experimental conditions were used during the administration of small or large $\mathrm{V}_{\mathrm{j}} \mathrm{s}$.Among the four human connexins studied, the $\mathrm{V}_{\mathrm{j}}$-gating polarity for $\mathrm{Cx} 45$ is known (Chen-Izu et al., 2001) however the $\mathrm{V}_{\mathrm{j}}$-gating polarities of $\mathrm{Cx} 37$, Cx 40, and $\mathrm{Cx} 43$ have not been clearly identified and have been based on their corresponding rodent connexins (e.g. mouse or rat) (Bruzzone et al., 1994; Hennemann et al., 1992; Valiunas et al., 2001; White et al., 1994). The $\mathrm{V}_{\mathrm{j}}$-gating polarity of $\mathrm{Cx} 37$ was difficult to determine with homotypic GJ channels because of the symmetry in its $V_{j}$-gating profile (Hennemann et al., 1992). In comparison to $\mathrm{Cx} 37 / \mathrm{Cx} 45$, the consistent characteristic of pronounced and fast $\mathrm{V}_{\mathrm{j}^{-}}$ dependent deactivation when $-\mathrm{V}_{\mathrm{j}} \mathrm{s}$ were applied on the $\mathrm{Cx} 45$ cell (or $+\mathrm{V}_{\mathrm{j}} \mathrm{s}$ on $\mathrm{Cx} 37$ cell) indicated that the $\mathrm{V}_{\mathrm{j}}$-gating polarity of $\mathrm{Cx} 37$ was positive. For $\mathrm{Cx} 43$, the $\mathrm{V}_{\mathrm{j}}$-dependent deactivation of heterotypic $\mathrm{Cx} 37 / \mathrm{Cx} 43$ GJs occurred when $+\mathrm{V}_{\mathrm{j}}$ s were applied on the $\mathrm{Cx} 43$ cell (or $-\mathrm{V}_{\mathrm{j}} \mathrm{s}$ on $\mathrm{Cx} 37$ cell) indicating that $\mathrm{V}_{\mathrm{j}}$-gating polarity of $\mathrm{Cx} 43$ was also positive. Further evidence is seen in another study with the asymmetric $\mathrm{V}_{\mathrm{j}}$-gating of heterotypic 
$\mathrm{Cx} 43 / \mathrm{Cx} 45$ as $\mathrm{V}_{\mathrm{j}}$-dependent deactivation was observed with $+\mathrm{V}_{\mathrm{j}} \mathrm{s}$ on $\mathrm{Cx} 43$ cell $\left(\right.$ or $-\mathrm{V}_{\mathrm{j}} \mathrm{s}$ on Cx45 cell) (Ye et al., 2017). In a previous mutational study of Cx26 and Cx32 hemichannels, Verselis and colleagues explained that the $\mathrm{V}_{\mathrm{j}}$-gating polarity of these connexins can be determined by the presence of a charged residue at the $2^{\text {nd }}$ or $3^{\text {th }}$ position of the NT domain (D2) (Verselis et al., 1994). In other words a connexin with a negatively charged residue at $2^{\text {nd }}$ or $3^{\text {th }}$ position (D2), would close the hemichannel at a $+\mathrm{V}_{\mathrm{j}}$ polarity whereas the absence of the negatively charged residue would close the hemichannel at a $\mathrm{V}_{\mathrm{j}}$ polarity (Verselis et al., 1994). Amino acid sequence alignment of $\mathrm{Cx} 37, \mathrm{Cx} 40, \mathrm{Cx} 43$, and $\mathrm{Cx} 45$ with $\mathrm{Cx} 26$ in the NT domain showed that these connexins except $\mathrm{Cx} 45$ contained an aspartic acid at $2^{\text {nd }}$ or $3^{\text {th }}$ position; which is consistent with our prediction. Although $\mathrm{V}_{\mathrm{j}^{-}}$ gating was not observed with $\mathrm{Cx} 37 / \mathrm{Cx} 40$, it is speculated that $\mathrm{Cx} 40$ hemichannel, too, possess a positive $\mathrm{V}_{\mathrm{j}}$-gating polarity based on the explanation above and from the $\mathrm{V}_{\mathrm{j}}$-gating of the designed $\mathrm{Cx} 40$ variants. Furthermore the $\gamma \mathrm{j}$ of $\mathrm{Cx} 43 \mathrm{GJ}(60-100 \mathrm{pS})$ is lower than the $\gamma \mathrm{j}$ of Cx37 (300 pS) (Fishman et al., 1991; Veenstra et al., 1994). Based on the $\mathrm{V}_{\mathrm{j}^{-}}$ gating polarity of $\mathrm{Cx} 43$, most of the applied $\mathrm{V}_{\mathrm{j}}$ on a heterotypic $\mathrm{Cx} 37 / \mathrm{Cx} 43 \mathrm{GJ}$ would be on the docked Cx43 hemichannel and making the GJ likely to close when $-\mathrm{V}_{\mathrm{j}}$ is on the Cx43 cell. This is consistent with data as heterotypic Cx37/Cx43 GJs displayed fast $\mathrm{V}_{\mathrm{j}}$ dependent deactivation when $-\mathrm{V}_{\mathrm{j}} \mathrm{s}$ were administered on the $\mathrm{Cx} 43$ cell which indicated that Cx37/Cx43 also follows the contingent gating model. Detailed Boltzmann fitting of the $\mathrm{V}_{\mathrm{j}^{-}}$ gating properties of $\mathrm{Cx} 37 / \mathrm{Cx} 43 \mathrm{GJ}$ revealed significant increase for $\mathrm{V}_{0}$ but the slope $A$ and $\mathrm{G}_{\min }$ were lower than those observed for homotypic Cx37 GJs. 


\subsubsection{Single Channel Analysis of Cx37/Cx43 GJ}

The single channel study of $\mathrm{Cx} 37 / \mathrm{Cx} 43$ GJ is the first for human $\mathrm{Cx} 37$. The preliminary data showed multiple (main open, one or more subconductance, and fully closed) states as well as different gating transitions over time between the Cx37 hemichannel and $\mathrm{Cx} 43$ hemichannel suggesting the two $\mathrm{V}_{\mathrm{j}}$-gating mechanisms (fast $\mathrm{V}_{\mathrm{j}^{-}}$ gating and slow $\mathrm{V}_{\mathrm{j}}$-gating). Fast $\mathrm{V}_{\mathrm{j}}$-gating is defined by the rapid transition time $(<1-2$ $\mathrm{mS}$ ) from a main open state to a subconductance state and slow $\mathrm{V}_{\mathrm{j}}$-gating is defined by the slow transition time (generally tens of milliseconds) from a main open or subconductance state to a fully closed state (Bukauskas and Verselis, 2004; Bukauskas and Weingart, 1994; Xin et al., 2010). With $-\mathrm{V}_{\mathrm{j}} \mathrm{s}$ on $\mathrm{Cx} 43$ hemichannel (or $\mathrm{Cx} 37$ with $+\mathrm{V}_{\mathrm{j}} \mathrm{s}$ ), the GJ channel displayed gating transitions between all three states indicating the presence of both fast and

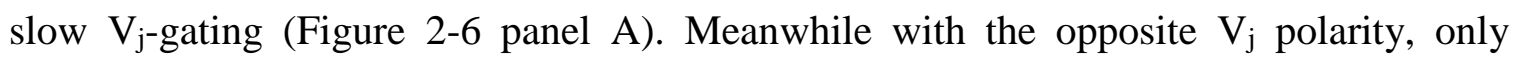
transitions between two (main open and closed) states were observed indicating slow $\mathrm{V}_{\mathrm{j}^{-}}$ gating (Figure 2-6 panel A). In a previous study, Elenes and colleagues investigated single channel studies on heterotypic $\mathrm{rCx} 43 / \mathrm{mCx} 45$ GJ channel. Despite the use of non-human connexins, a similar observation was made when $-\mathrm{V}_{\mathrm{j}} \mathrm{s}$ were applied to the $\mathrm{rCx} 43$ side in which all the gating transitions were between the main open state and the fully close state (Elenes et al., 2001). They explained that with the heterotypic docking of $\mathrm{rCx} 43$ and $\mathrm{mCx} 45$ hemichannels, the fast $\mathrm{V}_{\mathrm{j}}$-gating of $\mathrm{rCx} 43$ seemed to disappear; similar to what was observed in the present study.

\subsubsection{Cx40 hemichannel does not dock with Cx37 hemichannel}

To our surprise, most heterotypic $\mathrm{Cx} 37 / \mathrm{Cx} 40$ cell pairs were not coupled, and even the pairs that showed coupling exhibited very low level of $\mathrm{G}_{\mathrm{j}}$. As we used a transient 
expression system, the connexins under study tend to be overexpressed and therefore likely to be an over representation of the actual heterotypic interaction. It is speculated that under physiological conditions, the probability of these two connexins to form heterotypic GJs could be even lower. Jassim and colleagues aligned both the E1 and E2 amino acid sequences of $\mathrm{Cx} 40$ and $\mathrm{Cx} 43$ with $\mathrm{Cx} 26$ as a reference which later incorporated $\mathrm{Cx} 45$ (Jassim et al., 2016; Ye et al., 2017). Although the three cysteine residues in each domain were conserved, $\mathrm{Cx} 40$ possessed a few different amino acids at the docking interface; two of which were associated with hydrogen bonds (HBs). In the $55^{\text {th }}$ and $193^{\text {rd }}$ positions of Cx40 were aspartic acid and proline respectively. Based on Cx40 homology model, aspartic acid contained a negative side chain that contributed to electrostatic repulsion with two nearby Cx43 residues (Jassim et al., 2016). Meanwhile the cyclic side chain of proline restricted the E2 domain to an incompatible formation with Cx43 E2 (Jassim et al., 2016). By mutating the residue, D55N or P193Q, the electrostatic repulsion or steric interference were eliminated respectively and $\mathrm{HB}$ interactions improved, which might have played a role in rescuing the heterotypic coupling between $\mathrm{Cx} 40$ with other connexins as also noticed in the current study. In the literature, it has been well documented that mCx37 can form functional heterotypic GJs with $\mathrm{mCx} 40$ as they belong in the same group of dockingcompatible connexins (Bruzzone et al., 1993; Elfgang et al., 1995; White et al., 1995). However the present study is the first to demonstrate that this interaction is not the case through human connexins. With the collection of previous investigations including the present study, it is argued that amongst human connexins, $\mathrm{Cx} 40$ may not belong in the same group of docking compatible connexins (Jassim et al., 2016; Ye et al., 2017). 


\subsubsection{Conclusion}

The ability of human Cx37 to form heterotypic GJs with other human connexins such as $\mathrm{Cx} 40, \mathrm{Cx} 43$, and $\mathrm{Cx} 45$ have not been established in the past. The present study provided experimental evidence that $\mathrm{Cx} 37$ hemichannel can dock with $\mathrm{Cx} 43$ or $\mathrm{Cx} 45$ hemichannels to form functional heterotypic GJs but not with Cx40 hemichannels. The formation of heterotypic Cx37/Cx43 and Cx37/Cx45 GJs exhibited distinct characteristics including asymmetric $\mathrm{V}_{\mathrm{j}}$-gating and $\mathrm{I}_{\mathrm{j}}$ rectifications at different $\mathrm{V}_{\mathrm{j}}$ polarities. It has been previously established that both the E1 and E2 domains are crucial for the non-covalent interactions between two docked hemichannels. Mutating the residue, D55N or P193Q, in WT Cx40 rescued the heterotypic interaction with Cx37. Human Cx40 showed docking incompatibility with $\mathrm{Cx} 43, \mathrm{Cx} 45$, and $\mathrm{Cx} 37$ indicating that $\mathrm{Cx} 40$ is not docking compatible with many in this group of connexins and may be better removed from this docking compatible group. 


\subsection{Supplemental Material}
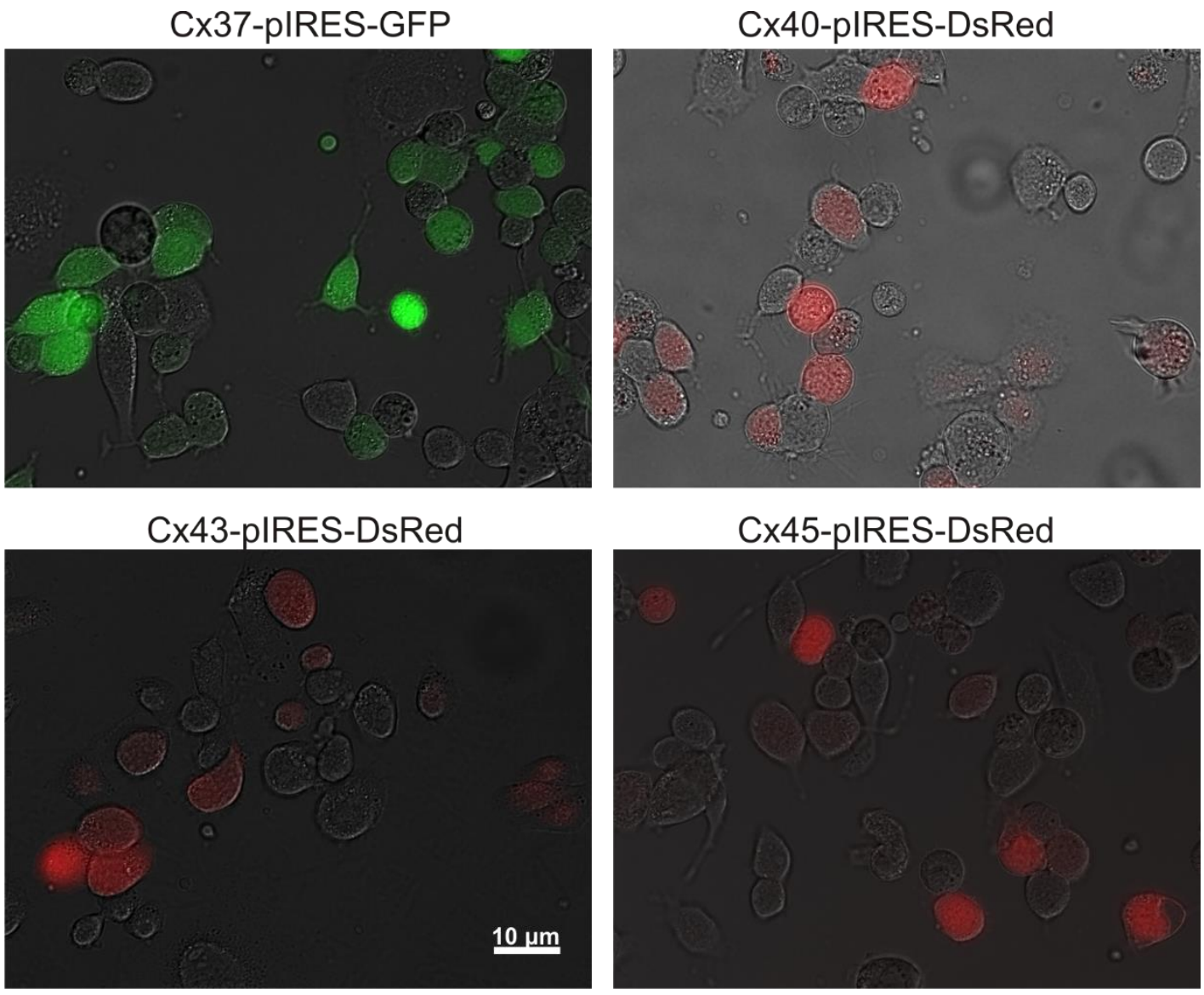

Supplemental Figure 2-1. Fluorescence microscopy images superimposed with DIC of transfected N2A cells.

N2A cells were transfected with Cx37-IRES-GFP (or Cx40, Cx43, Cx45, each of them in IRES-DsRed vector). Prior to performing dual whole cell patch clamp, the cell confluency on the glass coverslips were around $60-70 \%$ and majority of the cells fluoresced for each respective transfection. For heterotypic GJ studies, Cx37-IRES-GFP transfected cells were mixed with cells transfected with Cx40-IRES-DsRed, Cx43-IRES-DsRed, or Cx45-IRESDsRed to allow formation of heterotypic cell pairs. 


\subsection{References}

Bagher, P., and S.S. Segal. 2011. Regulation of blood flow in the microcirculation: role of conducted vasodilation. Acta Physiol (Oxf). 202:271-284.

Bai, D. 2016. Structural analysis of key gap junction domains_-Lessons from genome data and disease-linked mutants. Seminars in Cell \& Developmental Biology. 50:74-82.

Bai, D., and J. Cameron. 2016. Patch Clamp Analysis of Gap Junction Channel Properties. CRC Press Taylor \& Francis Group, London.

Bai, D., B. Yue, and H. Aoyama. 2018. Crucial motifs and residues in the extracellular loops influence the formation and specificity of connexin docking. Biochim Biophys Acta. 1860:9-21.

Barr, L., M.M. Dewey, and W. Berger. 1965. Propagation of Action Potentials and the Structure of the Nexus in Cardiac Muscle. J Gen Physiol. 48:797-823.

Barrio, L.C., J. Capel, J.A. Jarillo, C. Castro, and A. Revilla. 1997. Species-specific voltage-gating properties of connexin-45 junctions expressed in Xenopus oocytes. Biophys J. 73:757-769.

Barrio, L.C., T. Suchyna, T. Bargiello, L.X. Xu, R.S. Roginski, M.V. Bennett, and B.J. Nicholson. 1991. Gap junctions formed by connexins 26 and 32 alone and in combination are differently affected by applied voltage. Proc Natl Acad Sci U S A. $88: 8410-8414$

Begandt, D., M.E. Good, A.S. Keller, L.J. DeLalio, C. Rowley, B.E. Isakson, and X.F. Figueroa. 2017. Pannexin channel and connexin hemichannel expression in vascular function and inflammation. BMC Cell Biology. 18.

Bennett, M.V., and V.K. Verselis. 1992. Biophysics of gap junctions. Semin Cell Biol. $3: 29-47$.

Beny, J.L., and J.L. Connat. 1992. An electron-microscopic study of smooth muscle cell dye coupling in the pig coronary arteries. Role of gap junctions. Circ Res. 70:4955.

Bergoffen, J., S.S. Scherer, S. Wang, M.O. Scott, L.J. Bone, D.L. Paul, K. Chen, M.W. Lensch, P.F. Chance, and K.H. Fischbeck. 1993. Connexin mutations in X-linked Charcot-Marie-Tooth disease. Science. 262:2039-2042. 
Brink, P.R., K. Cronin, K. Banach, E. Peterson, E.M. Westphale, K.H. Seul, S.V. Ramanan, and E.C. Beyer. 1997. Evidence for heteromeric gap junction channels formed from rat connexin43 and human connexin37. Am J Physiol. 273:C1386-1396.

Bruzzone, R., J.A. Haefliger, R.L. Gimlich, and D.L. Paul. 1993. Connexin40, a component of gap junctions in vascular endothelium, is restricted in its ability to interact with other connexins. Mol. Biol. Cell. 4:7-20.

Bruzzone, R., T.W. White, and D.L. Paul. 1994. Expression of chimeric connexins reveals new properties of the formation and gating behavior of gap junction channels. $J$ Cell Sci. 107 ( Pt 4):955-967.

Bukauskas, F.F., and V.K. Verselis. 2004. Gap junction channel gating. Biochim Biophys Acta. 1662:42-60.

Bukauskas, F.F., and R. Weingart. 1994. Voltage-dependent gating of single gap junction channels in an insect cell line. Biophys J. 67:613-625.

Campbell, G.J., and M.R. Roach. 1981. Fenestrations in the internal elastic lamina at bifurcations of human cerebral arteries. Stroke. 12:489-496.

Chen-Izu, Y., A.P. Moreno, and R.A. Spangler. 2001. Opposing gates model for voltage gating of gap junction channels. Am J Physiol Cell Physiol. 281:C1604-1613.

Clauss, S.B., D.L. Walker, M.L. Kirby, D. Schimel, and C.W. Lo. 2006. Patterning of coronary arteries in wildtype and connexin43 knockout mice. Dev Dyn. 235:27862794.

Dahl, G., R. Werner, E. Levine, and C. Rabadan-Diehl. 1992. Mutational analysis of gap junction formation. Biophys J. 62:172-180.

Davis, L.M., M.E. Rodefeld, K. Green, E.C. Beyer, and J.E. Saffitz. 1995. Gap junction protein phenotypes of the human heart and conduction system. J Cardiovasc Electrophysiol. 6:813-822.

de Wit, C., M. Boettcher, and V.J. Schmidt. 2009. Signaling across myoendothelial gap junctions - fact or fiction? Cell Communication \& Adhesion. 15:231-245.

Elenes, S., A.D. Martinez, M. Delmar, E.C. Beyer, and A.P. Moreno. 2001. Heterotypic docking of $\mathrm{Cx} 43$ and $\mathrm{Cx} 45$ connexons blocks fast voltage gating of $\mathrm{Cx} 43$. Biophys J. 81:1406-1418. 
Elfgang, C., R. Eckert, H. Lichtenberg-Frate, A. Butterweck, O. Traub, R.A. Klein, D.F. Hulser, and K. Willecke. 1995. Specific permeability and selective formation of gap junction channels in connexin-transfected HeLa cells. J. Cell Biol. 129:805817.

Emerson, G.G., and S.S. Segal. 2000. Electrical coupling between endothelial cells and smooth muscle cells in hamster feed arteries: role in vasomotor control. Circ Res. 87:474-479.

Figueroa, X.F., and B.R. Duling. 2009. Gap junctions in the control of vascular function. Antioxid Redox Signal. 11:251-266.

Fishman, G.I., A.P. Moreno, D.C. Spray, and L.A. Leinwand. 1991. Functional analysis of human cardiac gap junction channel mutants. Proc Natl Acad Sci U S A. 88:35253529.

Gabriels, J.E., and D.L. Paul. 1998. Connexin43 is highly localized to sites of disturbed flow in rat aortic endothelium but connexin37 and connexin40 are more uniformly distributed. Circ Res. 83:636-643.

Goldberg, G.S., P.D. Lampe, and B.J. Nicholson. 1999. Selective transfer of endogenous metabolites through gap junctions composed of different connexins. Nat Cell Biol. 1:457-459.

Gonzalez, D., J.M. Gomez-Hernandez, and L.C. Barrio. 2007. Molecular basis of voltage dependence of connexin channels: an integrative appraisal. Prog Biophys Mol Biol. 94:66-106.

Good, M.E., J.F. Ek-Vitorin, and J.M. Burt. 2012. Extracellular loop cysteine mutant of cx37 fails to suppress proliferation of rat insulinoma cells. J Membr Biol. 245:369380.

Goodenough, D.A., and D.L. Paul. 2009. Gap Junctions. Cold Spring Harbor Perspectives in Biology. 1:a002576-a002576.

Haddock, R.E., and C.E. Hill. 2005. Rhythmicity in arterial smooth muscle. J Physiol. 566:645-656.

Harris, A.L., D.C. Spray, and M.V. Bennett. 1981. Kinetic properties of a voltagedependent junctional conductance. J Gen Physiol. 77:95-117. 
Hennemann, H., T. Suchyna, H. Lichtenberg-Frate, S. Jungbluth, E. Dahl, J. Schwarz, B.J. Nicholson, and K. Willecke. 1992. Molecular cloning and functional expression of mouse connexin40, a second gap junction gene preferentially expressed in lung. $J$ Cell Biol. 117:1299-1310.

Hill, C.E., N. Rummery, H. Hickey, and S.L. Sandow. 2002. Heterogeneity in the distribution of vascular gap junctions and connexins: implications for function. Clin Exp Pharmacol Physiol. 29:620-625.

Jassim, A., H. Aoyama, W.G. Ye, H. Chen, and D. Bai. 2016. Engineered Cx40 variants increased docking and function of heterotypic Cx40/Cx43 gap junction channels. $J$ Mol Cell Cardiol. 90:11-20.

Johnson, R., M. Hammer, J. Sheridan, and J.P. Revel. 1974. Gap junction formation between reaggregated Novikoff hepatoma cells. Proc Natl Acad Sci U SA. $71: 4536-4540$.

Kirchhoff, S., E. Nelles, A. Hagendorff, O. Kruger, O. Traub, and K. Willecke. 1998. Reduced cardiac conduction velocity and predisposition to arrhythmias in connexin40-deficient mice. Curr Biol. 8:299-302.

Ko, Y.S., H.I. Yeh, S. Rothery, E. Dupont, S.R. Coppen, and N.J. Severs. 1999. Connexin make-up of endothelial gap junctions in the rat pulmonary artery as revealed by immunoconfocal microscopy and triple-label immunogold electron microscopy. $J$ Histochem Cytochem. 47:683-692.

Kruger, O., A. Plum, J.S. Kim, E. Winterhager, S. Maxeiner, G. Hallas, S. Kirchhoff, O. Traub, W.H. Lamers, and K. Willecke. 2000. Defective vascular development in connexin 45-deficient mice. Development. 127:4179-4193.

Kumar, N.M., and N.B. Gilula. 1996. The gap junction communication channel. Cell. 84:381-388.

Laird, D.W. 1996. The life cycle of a connexin: gap junction formation, removal, and degradation. J Bioenerg Biomembr. 28:311-318.

Laird, D.W. 2006. Life cycle of connexins in health and disease. Biochem J. 394:527-543.

Little, T.L., E.C. Beyer, and B.R. Duling. 1995. Connexin 43 and connexin 40 gap junctional proteins are present in arteriolar smooth muscle and endothelium in vivo. Am J Physiol. 268:H729-739. 
Liu, X.Z., J. Walsh, P. Mburu, J. Kendrick-Jones, M.J. Cope, K.P. Steel, and S.D. Brown. 1997. Mutations in the myosin VIIA gene cause non-syndromic recessive deafness. Nat Genet. 16:188-190.

Maeda, S., S. Nakagawa, M. Suga, E. Yamashita, A. Oshima, Y. Fujiyoshi, and T. Tsukihara. 2009. Structure of the connexin 26 gap junction channel at $3.5 \mathrm{~A}$ resolution. Nature. 458:597-602.

Maza, J., M. Mateescu, J. Das Sarma, and M. Koval. 2003. Differential oligomerization of endoplasmic reticulum-retained connexin43/connexin32 chimeras. Cell Commun Adhes. 10:319-322.

Milks, L.C., N.M. Kumar, R. Houghten, N. Unwin, and N.B. Gilula. 1988. Topology of the 32-kd liver gap junction protein determined by site-directed antibody localizations. EMBO J. 7:2967-2975.

Noureldin, M., H. Chen, and D. Bai. 2018. Functional Characterization of Novel Atrial Fibrillation-Linked GJA5 (Cx40) Mutants. Int J Mol Sci. 19.

Pogoda, K., M. Füller, U. Pohl, and P. Kameritsch. 2014. NO, via its target Cx37, modulates calcium signal propagation selectively at myoendothelial gap junctions. Cell Communication and Signaling. 12:33.

Rackauskas, M., M.M. Kreuzberg, M. Pranevicius, K. Willecke, V.K. Verselis, and F.F. Bukauskas. 2007. Gating properties of heterotypic gap junction channels formed of connexins 40, 43, and 45. Biophys J. 92:1952-1965.

Reaume, A.G., P.A. de Sousa, S. Kulkarni, B.L. Langille, D. Zhu, T.C. Davies, S.C. Juneja, G.M. Kidder, and J. Rossant. 1995. Cardiac malformation in neonatal mice lacking connexin43. Science. 267:1831-1834.

Reed, K.E., E.M. Westphale, D.M. Larson, H.Z. Wang, R.D. Veenstra, and E.C. Beyer. 1993. Molecular cloning and functional expression of human connexin37, an endothelial cell gap junction protein. J Clin Invest. 91:997-1004.

Rummery, N.M., H. Hickey, G. McGurk, and C.E. Hill. 2002. Connexin37 is the major connexin expressed in the media of caudal artery. Arterioscler Thromb Vasc Biol. 22:1427-1432. 
Saez, J.C., V.M. Berthoud, M.C. Branes, A.D. Martinez, and E.C. Beyer. 2003. Plasma membrane channels formed by connexins: their regulation and functions. Physiol Rev. 83:1359-1400.

Sandow, S.L., and C.E. Hill. 2000. Incidence of myoendothelial gap junctions in the proximal and distal mesenteric arteries of the rat is suggestive of a role in endothelium-derived hyperpolarizing factor-mediated responses. Circ Res. 86:341346.

Sandow, S.L., R. Looft-Wilson, B. Doran, T.H. Grayson, S.S. Segal, and C.E. Hill. 2003. Expression of homocellular and heterocellular gap junctions in hamster arterioles and feed arteries. Cardiovasc Res. 60:643-653.

Severs, N.J., S. Rothery, E. Dupont, S.R. Coppen, H.I. Yeh, Y.S. Ko, T. Matsushita, R. Kaba, and D. Halliday. 2001. Immunocytochemical analysis of connexin expression in the healthy and diseased cardiovascular system. Microsc Res Tech. $52: 301-322$.

Shiels, A., D. Mackay, A. Ionides, V. Berry, A. Moore, and S. Bhattacharya. 1998. A missense mutation in the human connexin50 gene (GJA8) underlies autosomal dominant "zonular pulverulent" cataract, on chromosome 1q. Am J Hum Genet. 62:526-532.

Simon, A.M., D.A. Goodenough, E. Li, and D.L. Paul. 1997. Female infertility in mice lacking connexin 37. Nature. 385:525-529.

Simon, A.M., and A.R. McWhorter. 2003. Decreased intercellular dye-transfer and downregulation of non-ablated connexins in aortic endothelium deficient in connexin37 or connexin40. J Cell Sci. 116:2223-2236.

Sohl, G. 2004. Gap junctions and the connexin protein family. Cardiovascular Research. 62:228-232.

Spray, D.C., A.L. Harris, and M.V. Bennett. 1981. Equilibrium properties of a voltagedependent junctional conductance. J Gen Physiol. 77:77-93.

Sun, Y., Y.-Q. Yang, X.-Q. Gong, X.-H. Wang, R.-G. Li, H.-W. Tan, X. Liu, W.-Y. Fang, and D. Bai. 2013. Novel GermlineGJA5/Connexin40 Mutations Associated with Lone Atrial Fibrillation Impair Gap Junctional Intercellular Communication. Human Mutation:n/a-n/a. 
Valiunas, V., J. Gemel, P.R. Brink, and E.C. Beyer. 2001. Gap junction channels formed by coexpressed connexin40 and connexin43. Am J Physiol Heart Circ Physiol. 281:H1675-1689.

van Kempen, M.J., and H.J. Jongsma. 1999. Distribution of connexin37, connexin40 and connexin43 in the aorta and coronary artery of several mammals. Histochem Cell Biol. 112:479-486.

van Kempen, M.J., I. ten Velde, A. Wessels, P.W. Oosthoek, D. Gros, H.J. Jongsma, A.F. Moorman, and W.H. Lamers. 1995. Differential connexin distribution accommodates cardiac function in different species. Microsc Res Tech. 31:420-436.

Veenstra, R.D., H.Z. Wang, E.C. Beyer, S.V. Ramanan, and P.R. Brink. 1994. Connexin37 forms high conductance gap junction channels with subconductance state activity and selective dye and ionic permeabilities. Biophys J. 66:1915-1928.

Verselis, V.K., C.S. Ginter, and T.A. Bargiello. 1994. Opposite voltage gating polarities of two closely related connexins. Nature. $368: 348-351$.

Walker, D.L., S.J. Vacha, M.L. Kirby, and C.W. Lo. 2005. Connexin43 deficiency causes dysregulation of coronary vasculogenesis. Dev Biol. 284:479-498.

Welsh, D.G., and S.S. Segal. 1998. Endothelial and smooth muscle cell conduction in arterioles controlling blood flow. Am J Physiol. 274:H178-186.

White, T.W., R. Bruzzone, S. Wolfram, D.L. Paul, and D.A. Goodenough. 1994. Selective interactions among the multiple connexin proteins expressed in the vertebrate lens: the second extracellular domain is a determinant of compatibility between connexins. J Cell Biol. 125:879-892.

White, T.W., D.L. Paul, D.A. Goodenough, and R. Bruzzone. 1995. Functional analysis of selective interactions among rodent connexins. Mol Biol Cell. 6:459-470.

Willecke, K., J. Eiberger, J. Degen, D. Eckardt, A. Romualdi, M. Guldenagel, U. Deutsch, and G. Sohl. 2002. Structural and functional diversity of connexin genes in the mouse and human genome. Biol Chem. 383:725-737.

Xin, L., X.Q. Gong, and D. Bai. 2010. The role of amino terminus of mouse Cx50 in determining transjunctional voltage-dependent gating and unitary conductance. Biophys J. 99:2077-2086. 
Yamamoto, Y., M.F. Klemm, F.R. Edwards, and H. Suzuki. 2001. Intercellular electrical communication among smooth muscle and endothelial cells in guinea-pig mesenteric arterioles. J Physiol. 535:181-195.

Ye, W.G., B. Yue, H. Aoyama, N.K. Kim, J.A. Cameron, H. Chen, and D. Bai. 2017. Junctional delay, frequency, and direction-dependent uncoupling of human heterotypic Cx45/Cx43 gap junction channels. J Mol Cell Cardiol. 111:17-26.

Yeh, H.I., S. Rothery, E. Dupont, S.R. Coppen, and N.J. Severs. 1998. Individual gap junction plaques contain multiple connexins in arterial endothelium. Circ Res. 83:1248-1263. 


\section{Discussion}

\subsection{Overall Study}

The present study aimed to address the gap in knowledge on the functional status of heterotypic GJs and their channel properties of human vascular connexins specifically the heterotypic docking compatibility of human Cx37 with Cx40, Cx43 and Cx45. Accumulated experimental evidence in the heterotypic docking compatibility of mouse connexins is mostly true for human connexins but with a few exceptions especially on Cx40 (Brink et al., 1997; Elfgang et al., 1995; Jassim et al., 2016; Ye et al., 2017). Electrophysiological recordings showed that heterotypic Cx37/Cx43 and Cx37/Cx45 displayed comparable coupling status and $\mathrm{G}_{\mathrm{j}}$ to their respective homotypic GJ controls. Interestingly, heterotypic $\mathrm{Cx} 37 / \mathrm{Cx} 40$ cell pairs exhibited low coupling status and $\mathrm{G}_{\mathrm{j}}$. From heterotypic Cx37/Cx43 and Cx37/Cx45 GJs recordings, asymmetric $\mathrm{V}_{\mathrm{j}}$-gating and $\mathrm{I}_{\mathrm{j}}$ rectifications were characteristics commonly observed. Cx37/Cx43 GJs displayed $\mathrm{V}_{\mathrm{j}}$ dependent deactivation with both $\mathrm{V}_{\mathrm{j}}$ polarities. On the other hand, Cx37/Cx45 GJs exhibited strong channel deactivation with $-\mathrm{V}_{\mathrm{j}} \mathrm{s}$ administered to the $\mathrm{Cx} 45$ cell and reverse gating in the opposite $V_{j}$ polarity. A possible explanation for this observation could be attributed by the negative $\mathrm{V}_{\mathrm{j}}$-gating polarity of $\mathrm{Cx} 45$ hemichannels. The $\mathrm{I}_{\mathrm{j}}$ rectification of $\mathrm{Cx} 37 / \mathrm{Cx} 43$ appeared to be voltage dependent and was continuously observed within the preliminary single channel analysis of $\mathrm{Cx} 37 / \mathrm{Cx} 43$ as the ratio of $\gamma_{\mathrm{j}}(-) / \gamma_{\mathrm{j}}(+)$ appeared to increase with $\mathrm{V}_{\mathrm{j}}$ values in a linear fashion. However $\mathrm{I}_{\mathrm{j}}$ rectification of $\mathrm{Cx} 37 / \mathrm{Cx} 45$ did not appear to be voltage dependent. After the application of a different $V_{j}$ pulse protocol, it was revealed that heterotypic $\mathrm{Cx} 37 / \mathrm{Cx} 45$ GJs can be modulated by few millivolt differences in the membrane potentials. Finally designed docking variants in Cx40 E1 or 
E2 domains (D55N or P193Q respectively) successfully established heterotypic docking between $\mathrm{Cx} 37$ and $\mathrm{Cx} 40$. Overall, $\mathrm{Cx} 37$ was able to form heterotypic GJ channels with Cx43 and Cx45 but not with Cx40.

\subsection{Limitations and future studies}

To address the heterotypic formation of Cx37 with $\mathrm{Cx} 40, \mathrm{Cx} 43$ or Cx45, transfection of the respective cDNAs took place in N2A cells. This cell line is an excellent model system to study different connexins as these cell lines are GJ deficient, easily transfected with connexin cDNA, and easily used for functional characterization of GJs (Bai and Cameron, 2016). As mentioned before, several $\mathrm{Cx} 43$ expressing cell pairs exhibited very high $\mathrm{G}_{\mathrm{j}}$ levels limiting the maintenance of proper voltage clamp and proper

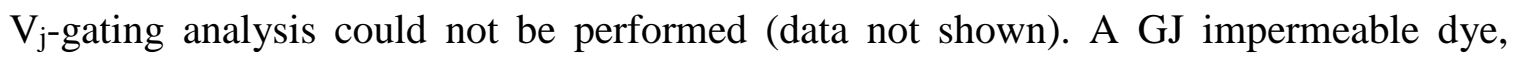
Dextran Green (molecular weight 10,000 Da, $0.25 \mathrm{mg} / \mathrm{mL}$ in pipette solution), was occasionally implemented to ensure some of the highly coupled cell pairs were not caused by cytoplasmic bridges (Sun et al., 2013). If green dye was not seen in both cells, the high $\mathrm{G}_{\mathrm{j}}$ was not attributed by cytoplasmic bridges (Sun et al., 2013). The $\mathrm{V}_{\mathrm{j}}$-gating analysis for $\mathrm{Cx} 43$ could be resolved with different experimental conditions by decreasing the amount of transfected DNA, reducing transfection time, or even shortening the replate time of the cells (Bai and Cameron, 2016). Due to stringent experimental conditions, it is speculated that the collected data is an over-representation of the homotypic and heterotypic coupling status. Physiologically, the probability of these two connexins to form heterotypic GJs could be even lower. Importantly these model cells are not native in the human body nor do they express all the native connexins concurrently. Although interconnected cell pairs can be coupled via homotypic and heterotypic GJs, there is added complexity of including 
the possible formation of heteromeric heterotypic GJ channels (Valiunas et al., 2001). Studies have reported heteromeric GJ channels to be inconsistent with large variability in the $\mathrm{G}_{\mathrm{j}} / \mathrm{V}_{\mathrm{j}}$ relationship and different from homotypic or heterotypic GJs (Brink et al., 1997; Valiunas et al., 2001). In respect to heterotypic GJs, it was mentioned that more experiments are required for the $\mathrm{Cx} 37 / \mathrm{Cx} 43$ single channel study. It would be interesting to study if the gating transitions at different $\mathrm{V}_{\mathrm{j}}$ polarities is consistent in different cell pairs. Likewise it would be intriguing to observe $\mathrm{Cx} 37 / \mathrm{Cx} 45$ single channels on its gating transitions at different $\mathrm{V}_{\mathrm{j}}$ polarities and if the voltage independent $\mathrm{i}_{\mathrm{j}}$ rectification holds true as observed with macroscopic $\mathrm{I}_{\mathrm{j}}$ recordings.

Furthermore a different $\mathrm{V}_{\mathrm{j}}$ pulsing protocol was used in the present study containing a long pulsing duration (15 seconds) and long inter pulse intervals (15 seconds) for two reasons. First, Ye and colleagues fitted the $\mathrm{V}_{\mathrm{j}}$-gating process of homotypic $\mathrm{Cx} 45$ with a single exponential equation for the $\mathrm{I}_{\mathrm{j}} \mathrm{s}$ in response to $\mathrm{V}_{\mathrm{j}}$-pulses. The time constant $(\tau)$ of homotypic Cx45 GJs decreased with increasing $\mathrm{V}_{\mathrm{j}} \mathrm{s}$ and the $\tau-\mathrm{V}_{\mathrm{j}}$ relationship appeared to be linear on a semi-logarithmic plot (Ye et al., 2017). As a result, the pulsing duration of 7 seconds did not give the channel enough time to fully deactivate at low $\mathrm{V}_{\mathrm{j}} \mathrm{s}$. Second, a pulsing interval of 15 seconds would ensure ample amount of time for the channels to fully recover from the previous $\mathrm{V}_{\mathrm{j}}$ pulse (Ye et al., 2017). However after the application of the different protocol, a definitive steady state was not observed at $-20 \mathrm{mV}$ despite the lower $\mathrm{G}_{\mathrm{j}, \mathrm{ss}}$ at this $\mathrm{V}_{\mathrm{j}}$. This indicated that a longer pulsing period may be required. With $+\mathrm{V}_{\mathrm{j}} \mathrm{s}$ on the $\mathrm{Cx} 45$ cell, reverse gating was observed as shown by the increasing $\mathrm{G}_{\mathrm{j}, \mathrm{ss}}$. But it is not clear if the rising $\mathrm{I}_{\mathrm{j}} \mathrm{s}$ are influenced from the recovery of prior deactivated channels. To 
address this concern, a $V_{j}$ protocol (with the same inter pulse interval) that administers a set of $\mathrm{V}_{\mathrm{j}}$ pulses (with identical polarity) at a time would be ideal.

\subsection{Physiological role of vascular connexins from mice KOs}

GJs have been found at cell junctions between endothelial cells (ECs), between vascular smooth muscle cells, and also at the myoendothelial junctions connecting the two cell types (de Wit et al., 2009; Figueroa and Duling, 2009). Vascular connexins (Cx37, $\mathrm{Cx} 40, \mathrm{Cx} 43$, and $\mathrm{Cx} 45)$ can form various types of GJ channels to transfer electrical signals through interconnected cells and synchronize spontaneous diameter changes during vasodilation/constriction (Haddock and Hill, 2005). Most of our knowledge comes from studies on rodent connexin but the same vascular connexins also exist in humans. Collectively many studies directed the abundant expression of Cx37 and Cx40 in the ECs (Gabriels and Paul, 1998; van Kempen and Jongsma, 1999) while Cx43 and Cx45 in the VSMCs (Bruzzone et al., 1993; Little et al., 1995; Pogoda et al., 2014; Severs et al., 2001). However, expression of Cx43 and Cx37 have been reported in ECs and VSMCs to a lesser degree (Gabriels and Paul, 1998; Little et al., 1995; Rummery et al., 2002; Severs et al., 2001; van Kempen and Jongsma, 1999).

A considerable amount of studies have performed vascular connexin gene knockouts (KOs) in mice to highlight the importance of these genes physiologically. Cx45 $\mathrm{KO}$ mice demonstrated various impairment in blood vessel development and maturation resulting in death during the early embryonic stages (E9.5 to E10.5) (Kruger et al., 2000). Cx43 KO mice died due to the elimination of this connexin as the expression of genes regulating vascular cell differentiation and function were altered; affecting vasculogenesis and angiogenesis (Clauss et al., 2006; Reaume et al., 1995; Walker et al., 2005). Individual 
Cx40 and Cx37 KOs were considered non-lethal. Cx40 KO mice were susceptible towards arrhythmias and displayed little defects during heart development whereas Cx37 KO mice females suffered infertility (Figueroa and Duling, 2009; Kirchhoff et al., 1998; Simon et al., 1997). However for $\mathrm{Cx} 37$ and $\mathrm{Cx} 40$ double KO, mice died around birth because of several vascular abnormalities with susceptibility to vasodilatations (Simon and McWhorter, 2003).

\subsection{Characterization of heterotypic GJs with Cx37}

The majority of experimental evidence on the heterotypic docking compatibility of vascular connexins were on rodent connexins. Collectively this revealed that $\mathrm{Cx} 37, \mathrm{Cx} 40$, $\mathrm{Cx} 43$, and $\mathrm{Cx} 45$ belong to the same group of docking-compatible connexins and each were fully capable of forming heterotypic GJs with each other (Bai, 2016; Brink et al., 1997; Elenes et al., 2001; Elfgang et al., 1995; Hennemann et al., 1992; Rackauskas et al., 2007). However, studies on human vascular connexins revealed otherwise prompting the characterization of $\mathrm{Cx} 37$ and its heterotypic docking capabilities with $\mathrm{Cx} 40, \mathrm{Cx} 43$, or $\mathrm{Cx} 45$ (Jassim et al., 2016; Ye et al., 2017). All characteristics of homotypic GJs in the present study have been previously reported including the coupling status, $\mathrm{G}_{\mathrm{j}}$, and $\mathrm{V}_{\mathrm{j}}$-gating parameters (Barrio et al., 1997; Gonzalez et al., 2007; Jassim et al., 2016; Noureldin et al., 2018; Reed et al., 1993; Veenstra et al., 1994; Ye et al., 2017). The asymmetric macroscopic $I_{j}$ recordings and $G_{j s s}-V_{j}$ relationship at both $V_{j}$ polarities observed in $\mathrm{Cx} 37 / \mathrm{Cx} 43$ or $\mathrm{Cx} 37 / \mathrm{Cx} 45$ cell pairs are common characteristics for heterotypic GJs (Barrio et al., 1991; Elenes et al., 2001; Jassim et al., 2016; Ye et al., 2017). Although the $\mathrm{V}_{\mathrm{j} \text {-gating }}$ polarity for homotypic $\mathrm{Cx} 45$ GJs has been determined to be negative, the $\mathrm{V}_{\mathrm{j}}$-gating polarities of $\mathrm{Cx} 37, \mathrm{Cx} 40$, and $\mathrm{Cx} 43$ have not been clearly identified and been based on 
rodent variants (Bruzzone et al., 1994; Chen-Izu et al., 2001; Hennemann et al., 1992; Valiunas et al., 2001; White et al., 1994). Heterotypic Cx37/Cx45 GJs consistently displayed pronounced $\mathrm{V}_{\mathrm{j}}$-dependent deactivation at $-\mathrm{V}_{\mathrm{j}} \mathrm{s}$ applied on the $\mathrm{Cx} 45$ cell $\left(\right.$ or $+\mathrm{V}_{\mathrm{j}} \mathrm{S}$ on $\mathrm{Cx} 37$ cell) indicating the $\mathrm{V}_{\mathrm{j}}$-gating polarity of $\mathrm{Cx} 37$ was positive. In heterotypic Cx37/Cx43 cell pairs, $\mathrm{V}_{\mathrm{j}}$-dependent deactivation occurred at $+\mathrm{V}_{\mathrm{j}} \mathrm{s}$ on the $\mathrm{Cx} 43$ cell as this was also observed in previous study which indicates that $\mathrm{V}_{\mathrm{j}}$-gating polarity of $\mathrm{Cx} 43$ was positive (Ye et al., 2017). Sequence alignment of Cx37, Cx40, Cx43, and Cx45 with Cx26 in the NT domain showed that these connexins except $\mathrm{Cx} 45$ contained a negatively charged residue at the $3^{\text {th }}$ position (D3). As explained by Verselis and colleagues, the presence of a negatively charged residue at the $2^{\text {nd }}$ or $3^{\text {rd }}$ position can dictate the $\mathrm{V}_{\mathrm{j}}$-gating polarity (Verselis et al., 1994). Based on this explanation and $\mathrm{V}_{\mathrm{j}}$-gating from the designed $\mathrm{Cx} 40$ variants, it is speculated that $\mathrm{Cx} 40$, too, possess a positive $\mathrm{V}_{\mathrm{j}}$-gating polarity.

The unitary channel conductance $\left(\gamma_{\mathrm{j}}\right)$ of homotypic Cx37 GJ (300 pS) is higher than the $\gamma_{\mathrm{j}}$ of both Cx43 (60-100 pS) and Cx45 GJ (32-38 pS) (Elenes et al., 2001; Fishman et al., 1991; Veenstra et al., 1994). Most of the applied $\mathrm{V}_{\mathrm{j}} \mathrm{s}$ on a heterotypic Cx37/Cx45 GJ would be on the docked $\mathrm{Cx} 45$ hemichannel making the GJ susceptible to close when $-\mathrm{V}_{\mathrm{j}}$ is on the $\mathrm{Cx} 45$ cell. Whereas for heterotypic $\mathrm{Cx} 37 / \mathrm{Cx} 43 \mathrm{GJ}$, most of the applied $\mathrm{V}_{\mathrm{j}} \mathrm{s}$ would be on the docked Cx43 hemichannel and making the GJ likely to close when $-\mathrm{V}_{\mathrm{j}}$ is on the Cx43 cell. This is consistent with the data as heterotypic Cx37/Cx45 and Cx37/Cx43 GJs displayed $\mathrm{V}_{\mathrm{j}}$-dependent deactivation when $-\mathrm{V}_{\mathrm{j}} \mathrm{s}$ were applied on the $\mathrm{Cx} 45$ cell (or $\mathrm{Cx} 43$ cell) indicating that both $\mathrm{Cx} 37 / \mathrm{Cx} 45$ and $\mathrm{Cx} 37 / \mathrm{Cx} 43$ follow the contingent gating model. The model describes a GJ channel possessing two gates aligned in series (one in each hemichannel). A large $\mathrm{V}_{\mathrm{j}}$ could affect one of the two gates, driving the channel to a reduced 
subconducting or close state and influencing the voltage applied on the other hemichannel (Harris et al., 1981). The membrane potential $\left(\mathrm{V}_{\mathrm{m}}\right)$ of ECs and VSMCs in the human body have not be clearly stated but studies on animal models reported the $\mathrm{V}_{\mathrm{m}}$ of ECs and VSMCs to be identical (Emerson and Segal, 2000; Welsh and Segal, 1998). In hamster feed arteries, Emerson and Segal observed that a small negative current injection into an EC resulted in $\mathrm{V}_{\mathrm{j}}$ of $-5 \mathrm{mV}$ causing hyperpolarization and relaxation of VSMCs. Whereas a positive current injection of the same magnitude, resulted in $\mathrm{V}_{\mathrm{j}}$ of $+2 \mathrm{mV}$ causing depolarization and constrictions of VSMCs (Emerson and Segal, 2000). This observation is complemented in the present study as $\mathrm{V}_{\mathrm{j}}$-gating of heterotypic $\mathrm{Cx} 37 / \mathrm{Cx} 45$ cell pairs were modulated with just a few millivolts in the event of a hyperpolarization or depolarization. The preliminary single channel study is the first to characterize the channel properties of heterotypic Cx37/Cx43 GJs; specifically human connexins. With $-\mathrm{V}_{\mathrm{j}} \mathrm{s}$ on the $\mathrm{Cx} 43$ hemichannel (or $+\mathrm{V}_{\mathrm{j}} \mathrm{s}$ on $\mathrm{Cx} 37$ cell), the GJ channel displayed gating transitions between all three states suggesting that both fast and slow $\mathrm{V}_{\mathrm{j}}$-gating were present. On the other hand with $+\mathrm{V}_{\mathrm{j}} \mathrm{s}$, the channel displayed gating transitions only between two (main open and closed) states suggesting slow $\mathrm{V}_{\mathrm{j}}$-gating. As previously explained, fast $\mathrm{V}_{\mathrm{j}}$-gating is the rapid transition time $(<1-2 \mathrm{mS})$ from a main open state to a subconductance state and slow $\mathrm{V}_{\mathrm{j}}$-gating is the slow transition time (generally tens of milliseconds) from a main open or subconductance state to a fully closed state (Bukauskas and Verselis, 2004; Bukauskas and Weingart, 1994; Xin et al., 2010). Similarly when investigating single channels of heterotypic $\mathrm{rCx} 43 / \mathrm{mCx} 45 \mathrm{GJs}$, although non-human connexins were examined, all the gating transitions were between the main open and the fully close states when $-\mathrm{V}_{\mathrm{j}} \mathrm{s}$ were applied to the rCx43 hemichannel (Elenes et al., 2001). They interpreted that the fast $\mathrm{V}_{\mathrm{j}^{-}}$ 
gating of $\mathrm{rCx} 43$ seemed to disappear with the heterotypic docking of $\mathrm{rCx} 43$ and $\mathrm{mCx} 45$ hemichannels (Elenes et al., 2001).

\subsection{Cx40 hemichannel does not dock with Cx37 hemichannel}

Despite the several heterotypic studies on rodent connexins, the present study is the first to report docking incompatibility from cell pairs forming human heterotypic Cx37/Cx40 GJs due to low coupling\% and $\mathrm{G}_{\mathrm{j}}$ (Bruzzone et al., 1993; Elfgang et al., 1995; Hennemann et al., 1992). Previous studies also reported low coupling\% and $\mathrm{G}_{\mathrm{j}}$ between the docking of $\mathrm{Cx} 40$ hemichannels with $\mathrm{Cx} 43$ hemichannels or $\mathrm{Cx} 45$ hemichannels (Jassim et al., 2016; Ye et al., 2017). Sequence alignment in both the E1 and E2 domains of Cx40, Cx43 and Cx45 with Cx26 revealed Cx40 to have a few different residues at the docking interface; two of which were associated with hydrogen bonds (HBs), D55 and P193 (Jassim et al., 2016; Ye et al., 2017). Cx40 homology model revealed that the negative side chain of D55 contributed to electrostatic repulsion with two nearby $\mathrm{Cx} 43$ residues and the cyclic side chain of P193 restricted the E2 domain to an incompatible formation with Cx43 E2 (Jassim et al., 2016). The heterotypic coupling between Cx40 with other connexins was rescued as also seen in the present study by mutating these residues to either D55N or P193Q which eliminated the electrostatic repulsion or steric interference respectively. With the difference between human and rodent connexins, it is suggested that human $\mathrm{Cx} 40$ may not belong in the same group of docking compatible connexins.

\subsection{Summary}

The goal of the present study was to address the functional status of heterotypic GJs and their channel properties of human vascular connexins specifically Cx37, Cx40, Cx43 
and $\mathrm{Cx} 45$. From the literature, $\mathrm{KO}$ studies in mice have revealed the importance of vascular connexins in proper blood vessel development and function. Previous reports from the Bai lab indicated differences between mouse and human connexins in terms of their heterotypic docking compatibility (Jassim et al., 2016; Ye et al., 2017). Electrophysiological recordings revealed that $\mathrm{Cx} 37$ can form heterotypic GJs channel with $\mathrm{Cx} 43$ and $\mathrm{Cx} 45$ but not with $\mathrm{Cx} 40 . \mathrm{Cx} 37 / \mathrm{Cx} 43$ and $\mathrm{Cx} 37 / \mathrm{Cx} 45$ GJs were further characterized for their asymmetric $\mathrm{V}_{\mathrm{j}}$-gating, $\mathrm{I}_{\mathrm{j}}$ rectifications, and Boltzmann fitting parameters. Based on the

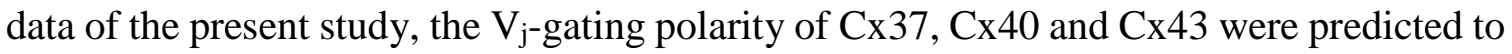
be positive and it was suggested that $\mathrm{Cx} 37 / \mathrm{Cx} 43$ and $\mathrm{Cx} 37 / \mathrm{Cx} 45$ GJs both follow the contingent gating model. Upon evaluating heterotypic $\mathrm{Cx} 37 / \mathrm{Cx} 45 \mathrm{GJ}$ s, it was revealed that the channels can be modulated by few millivolt differences in the membrane potentials; complementing the observations in another study (Emerson and Segal, 2000). Preliminary single channel analysis of $\mathrm{Cx} 37 / \mathrm{Cx} 43$ revealed that the voltage dependent $\mathrm{i}_{\mathrm{j}}$ rectifications were continuously observed at the single channel level and the presence of the different $\mathrm{V}_{\mathrm{j}^{-}}$ gating mechanisms. However more experiments will be needed for proper statistical analysis. Finally designed docking variants in Cx40 E1 or E2 domains (D55N or P193Q respectively) successfully rescued the coupling status and $\mathrm{G}_{\mathrm{j}}$ for heterotypic $\mathrm{Cx} 37 / \mathrm{Cx} 40$ GJs. Data from the present study with previous investigations on human vascular connexins suggest that human $\mathrm{Cx} 40$ may not belong in the same group of docking compatible connexins as $\mathrm{Cx} 37, \mathrm{Cx} 43$ and $\mathrm{Cx} 45$. 


\subsection{References}

Bai, D. 2016. Structural analysis of key gap junction domains-Lessons from genome data and disease-linked mutants. Seminars in Cell \& Developmental Biology. 50:74-82.

Bai, D., and J. Cameron. 2016. Patch Clamp Analysis of Gap Junction Channel Properties. CRC Press Taylor \& Francis Group, London.

Barrio, L.C., J. Capel, J.A. Jarillo, C. Castro, and A. Revilla. 1997. Species-specific voltage-gating properties of connexin-45 junctions expressed in Xenopus oocytes. Biophys J. 73:757-769.

Barrio, L.C., T. Suchyna, T. Bargiello, L.X. Xu, R.S. Roginski, M.V. Bennett, and B.J. Nicholson. 1991. Gap junctions formed by connexins 26 and 32 alone and in combination are differently affected by applied voltage. Proc Natl Acad Sci U S A. 88:8410-8414.

Brink, P.R., K. Cronin, K. Banach, E. Peterson, E.M. Westphale, K.H. Seul, S.V. Ramanan, and E.C. Beyer. 1997. Evidence for heteromeric gap junction channels formed from rat connexin43 and human connexin37. Am J Physiol. 273:C1386-1396.

Bruzzone, R., J.A. Haefliger, R.L. Gimlich, and D.L. Paul. 1993. Connexin40, a component of gap junctions in vascular endothelium, is restricted in its ability to interact with other connexins. Mol Biol Cell. 4:7-20.

Bruzzone, R., T.W. White, and D.L. Paul. 1994. Expression of chimeric connexins reveals new properties of the formation and gating behavior of gap junction channels. $J$ Cell Sci. 107 ( Pt 4):955-967.

Bukauskas, F.F., and V.K. Verselis. 2004. Gap junction channel gating. Biochim Biophys Acta. 1662:42-60.

Bukauskas, F.F., and R. Weingart. 1994. Voltage-dependent gating of single gap junction channels in an insect cell line. Biophys J. 67:613-625.

Chen-Izu, Y., A.P. Moreno, and R.A. Spangler. 2001. Opposing gates model for voltage gating of gap junction channels. Am J Physiol Cell Physiol. 281:C1604-1613.

Clauss, S.B., D.L. Walker, M.L. Kirby, D. Schimel, and C.W. Lo. 2006. Patterning of coronary arteries in wildtype and connexin43 knockout mice. Dev Dyn. 235:27862794. 
de Wit, C., M. Boettcher, and V.J. Schmidt. 2009. Signaling across myoendothelial gap junctions - fact or fiction? Cell Communication \& Adhesion. 15:231-245.

Elenes, S., A.D. Martinez, M. Delmar, E.C. Beyer, and A.P. Moreno. 2001. Heterotypic docking of $\mathrm{Cx} 43$ and $\mathrm{Cx} 45$ connexons blocks fast voltage gating of $\mathrm{Cx} 43$. Biophys J. 81:1406-1418.

Elfgang, C., R. Eckert, H. Lichtenberg-Frate, A. Butterweck, O. Traub, R.A. Klein, D.F. Hulser, and K. Willecke. 1995. Specific permeability and selective formation of gap junction channels in connexin-transfected HeLa cells. J Cell Biol. 129:805-817.

Emerson, G.G., and S.S. Segal. 2000. Electrical coupling between endothelial cells and smooth muscle cells in hamster feed arteries: role in vasomotor control. Circ Res. 87:474-479.

Figueroa, X.F., and B.R. Duling. 2009. Gap junctions in the control of vascular function. Antioxid Redox Signal. 11:251-266.

Fishman, G.I., A.P. Moreno, D.C. Spray, and L.A. Leinwand. 1991. Functional analysis of human cardiac gap junction channel mutants. Proc Natl Acad Sci U S A. 88:35253529.

Gabriels, J.E., and D.L. Paul. 1998. Connexin43 is highly localized to sites of disturbed flow in rat aortic endothelium but connexin37 and connexin40 are more uniformly distributed. Circ Res. 83:636-643.

Gonzalez, D., J.M. Gomez-Hernandez, and L.C. Barrio. 2007. Molecular basis of voltage dependence of connexin channels: an integrative appraisal. Prog Biophys Mol Biol. 94:66-106.

Haddock, R.E., and C.E. Hill. 2005. Rhythmicity in arterial smooth muscle. J Physiol. 566:645-656.

Harris, A.L., D.C. Spray, and M.V. Bennett. 1981. Kinetic properties of a voltagedependent junctional conductance. J Gen Physiol. 77:95-117.

Hennemann, H., T. Suchyna, H. Lichtenberg-Frate, S. Jungbluth, E. Dahl, J. Schwarz, B.J. Nicholson, and K. Willecke. 1992. Molecular cloning and functional expression of mouse connexin40, a second gap junction gene preferentially expressed in lung. $J$ Cell Biol. 117:1299-1310. 
Jassim, A., H. Aoyama, W.G. Ye, H. Chen, and D. Bai. 2016. Engineered Cx40 variants increased docking and function of heterotypic $\mathrm{Cx} 40 / \mathrm{Cx} 43$ gap junction channels. $J$ Mol Cell Cardiol. 90:11-20.

Kirchhoff, S., E. Nelles, A. Hagendorff, O. Kruger, O. Traub, and K. Willecke. 1998. Reduced cardiac conduction velocity and predisposition to arrhythmias in connexin40-deficient mice. Curr Biol. 8:299-302.

Kruger, O., A. Plum, J.S. Kim, E. Winterhager, S. Maxeiner, G. Hallas, S. Kirchhoff, O. Traub, W.H. Lamers, and K. Willecke. 2000. Defective vascular development in connexin 45-deficient mice. Development. 127:4179-4193.

Little, T.L., E.C. Beyer, and B.R. Duling. 1995. Connexin 43 and connexin 40 gap junctional proteins are present in arteriolar smooth muscle and endothelium in vivo. Am J Physiol. 268:H729-739.

Maeda, S., S. Nakagawa, M. Suga, E. Yamashita, A. Oshima, Y. Fujiyoshi, and T. Tsukihara. 2009. Structure of the connexin 26 gap junction channel at $3.5 \mathrm{~A}$ resolution. Nature. 458:597-602.

Noureldin, M., H. Chen, and D. Bai. 2018. Functional Characterization of Novel Atrial Fibrillation-Linked GJA5 (Cx40) Mutants. Int J Mol Sci. 19.

Pogoda, K., M. Füller, U. Pohl, and P. Kameritsch. 2014. NO, via its target Cx37, modulates calcium signal propagation selectively at myoendothelial gap junctions. Cell Communication and Signaling. 12:33.

Rackauskas, M., M.M. Kreuzberg, M. Pranevicius, K. Willecke, V.K. Verselis, and F.F. Bukauskas. 2007. Gating properties of heterotypic gap junction channels formed of connexins 40, 43, and 45. Biophys J. 92:1952-1965.

Reaume, A.G., P.A. de Sousa, S. Kulkarni, B.L. Langille, D. Zhu, T.C. Davies, S.C. Juneja, G.M. Kidder, and J. Rossant. 1995. Cardiac malformation in neonatal mice lacking connexin43. Science. 267:1831-1834.

Reed, K.E., E.M. Westphale, D.M. Larson, H.Z. Wang, R.D. Veenstra, and E.C. Beyer. 1993. Molecular cloning and functional expression of human connexin37, an endothelial cell gap junction protein. J Clin Invest. 91:997-1004. 
Rummery, N.M., H. Hickey, G. McGurk, and C.E. Hill. 2002. Connexin37 is the major connexin expressed in the media of caudal artery. Arterioscler Thromb Vasc Biol. 22:1427-1432.

Severs, N.J., S. Rothery, E. Dupont, S.R. Coppen, H.I. Yeh, Y.S. Ko, T. Matsushita, R. Kaba, and D. Halliday. 2001. Immunocytochemical analysis of connexin expression in the healthy and diseased cardiovascular system. Microsc Res Tech. 52:301-322.

Simon, A.M., D.A. Goodenough, E. Li, and D.L. Paul. 1997. Female infertility in mice lacking connexin 37. Nature. 385:525-529.

Simon, A.M., and A.R. McWhorter. 2003. Decreased intercellular dye-transfer and downregulation of non-ablated connexins in aortic endothelium deficient in connexin37 or connexin40. J Cell Sci. 116:2223-2236.

Sun, Y., Y.-Q. Yang, X.-Q. Gong, X.-H. Wang, R.-G. Li, H.-W. Tan, X. Liu, W.-Y. Fang, and D. Bai. 2013. Novel GermlineGJA5/Connexin40 Mutations Associated with Lone Atrial Fibrillation Impair Gap Junctional Intercellular Communication. Human Mutation:n/a-n/a.

Valiunas, V., J. Gemel, P.R. Brink, and E.C. Beyer. 2001. Gap junction channels formed by coexpressed connexin40 and connexin43. Am J Physiol Heart Circ Physiol. 281:H1675-1689.

van Kempen, M.J., and H.J. Jongsma. 1999. Distribution of connexin37, connexin40 and connexin 43 in the aorta and coronary artery of several mammals. Histochem Cell Biol. 112:479-486.

Veenstra, R.D., H.Z. Wang, E.C. Beyer, S.V. Ramanan, and P.R. Brink. 1994. Connexin37 forms high conductance gap junction channels with subconductance state activity and selective dye and ionic permeabilities. Biophys J. 66:1915-1928.

Verselis, V.K., C.S. Ginter, and T.A. Bargiello. 1994. Opposite voltage gating polarities of two closely related connexins. Nature. 368:348-351.

Walker, D.L., S.J. Vacha, M.L. Kirby, and C.W. Lo. 2005. Connexin43 deficiency causes dysregulation of coronary vasculogenesis. Dev Biol. 284:479-498.

Welsh, D.G., and S.S. Segal. 1998. Endothelial and smooth muscle cell conduction in arterioles controlling blood flow. Am J Physiol. 274:H178-186. 
White, T.W., R. Bruzzone, S. Wolfram, D.L. Paul, and D.A. Goodenough. 1994. Selective interactions among the multiple connexin proteins expressed in the vertebrate lens: the second extracellular domain is a determinant of compatibility between connexins. J Cell Biol. 125:879-892.

Xin, L., X.Q. Gong, and D. Bai. 2010. The role of amino terminus of mouse Cx50 in determining transjunctional voltage-dependent gating and unitary conductance. Biophys J. 99:2077-2086.

Ye, W.G., B. Yue, H. Aoyama, N.K. Kim, J.A. Cameron, H. Chen, and D. Bai. 2017. Junctional delay, frequency, and direction-dependent uncoupling of human heterotypic Cx45/Cx43 gap junction channels. J Mol Cell Cardiol. 111:17-26. 


\section{Curriculum Vitae}

Name:

Post-secondary

Education and

Degrees:

Honors and

Awards:

Related Work

Experience:
Nicholas Kiwon Kim

University of Western Ontario

London, Ontario, Canada

2012-2016 BMSc

University of Western Ontario

London, Ontario, Canada

2016-2018 MSc (Expected October 2018)

Entrance Scholarship (\$2000)

University of Western Ontario

Dean's Honor List

2013-2016

Teaching Assistant

University of Western Ontario

2016-2018

\section{Publications:}

Ye WG, Yue B, Aoyama H, Kim NK, Cameron JA, Chen HH, Bai D. (2017). Human Cx40 does not form functional heterotypic gap junction channels with $\mathrm{Cx} 45$. JMCC, (111), 17-26.

Tejada MG, Sudhakar S, Kim NK, Aoyama H, Shilton BH, Bai D. (Under revision). Putative pore lining residues and $[\mathrm{Mg} 2+] \mathrm{i}$ influence $\mathrm{Cx} 50$ unitary gap junction channel conductance. BJ, (n/a),

\section{Presentations:}

London Health Research Day Poster Presentation

March 2017

Physiology Pharmacology Research Day Poster

Presentation

November 2017

Nexin (Connexin \& Pannexin) Forum

April 2018

London Health Research Day Poster Presentation

May 2018 